\title{
Essential oils in broiler nutrition
}

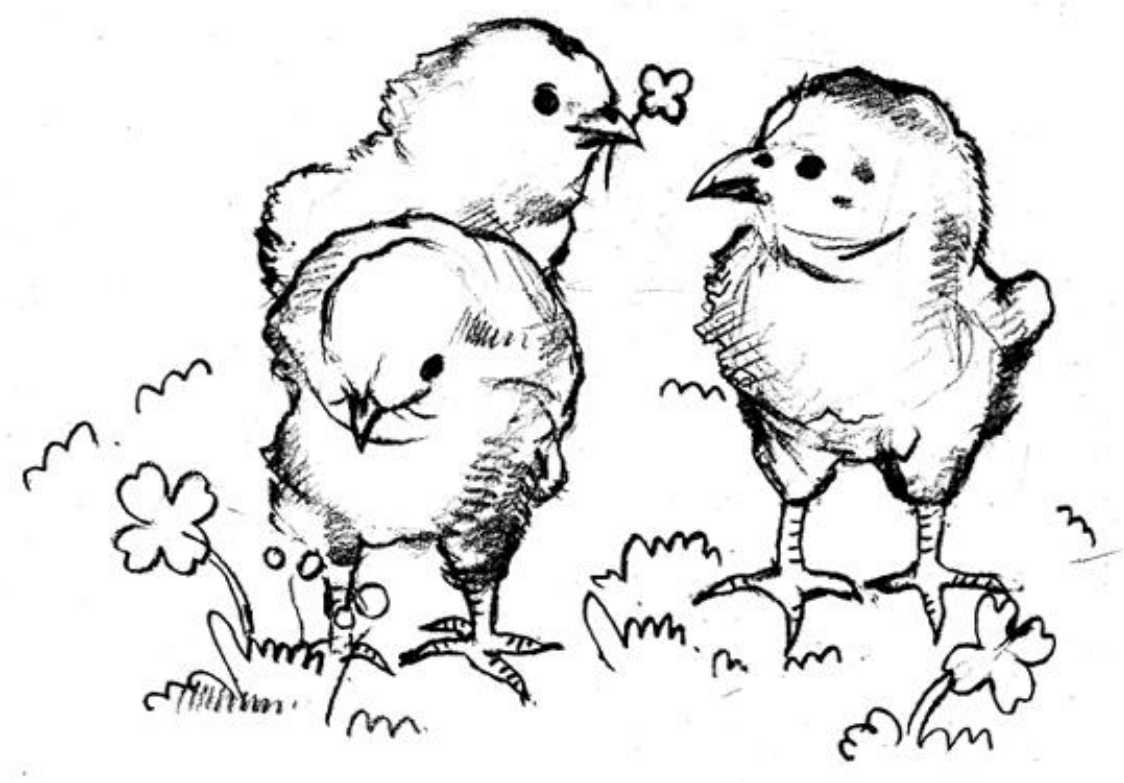

Kyung-Woo Lee 


\section{Essential oils in broiler nutrition}

Utrecht

2002 
ISBN Number: 90-393-3222-3

Cover drawing: Sam-Soon Yeom 


\section{Essential oils in broiler nutrition}

Etherische oliën in de voeding van vleeskuikens

(met een samenvatting in het Nederlands)

\section{Proefschrift}

ter verkrijging van de graad van doctor, aan de Universiteit Utrecht, op gezag van de Rector Magnificus,

Prof. Dr. W.H. Gispen, ingevolge het besluit van het College voor Promoties in het openbaar te verdedigen op donderdag 28 november 2002 des namiddags te 4.15 uur

door

$$
\text { Kyung-Woo Lee }
$$

geboren op 25 september 1970 te Dangjin, Chungnam, Zuid Korea 
Promotor:

Prof. dr. ir. A.C. Beynen

Department of Nutrition, Faculty of Veterinary Medicine, Utrecht University, The Netherlands

Co-promotor: $\quad$ Dr. H. Everts

Department of Nutrition, Faculty of Veterinary Medicine, Utrecht University, The Netherlands 
To Keum-hee and In-kyu (Koen) who taught me the nature of love 


\section{CONTENTS}

Scope of thesis

Chapter 1. Essential oils in broiler nutrition: a review (submitted)

Chapter 2. Effects of dietary essential oil components on growth performance, digestive enzymes and lipid metabolism in female broiler chickens (Brit. Poult. Sci., in press)

Chapter 3. Dietary carvacrol lowers body-weight gain, but improves feed conversion in female broiler chickens (J. Appl. Poult. Res., in press)

Chapter 4. Addition of $\beta$-ionone to the diet fails to affect growth performance in female broiler chickens (Anim. Feed Sci. Technol., in press)

Chapter 5. Cinnamaldehyde, but not thymol, counteracts the carboxymethylcellulose-induced growth depression in female broiler chickens (submitted)

Chapter 6. Effects of dietary essential oil components on growth performance, fat digestibility, intestinal viscosity and plasma cholesterol in female broiler chickens fed a diet rich in rye (submitted)

Chapter 7. Effect of a mixture of carvacrol and cinnamaldehyde on growth performance in female broiler chickens fed a diet containing carboxymethylcellulose

(submitted)

General conclusions

Summary

Summary (in Dutch)

Acknowledgements

Curriculum vitae 


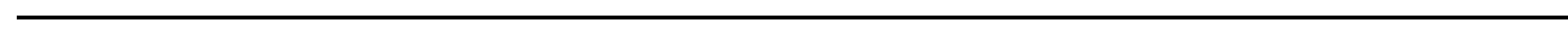




\section{Scope of thesis}


Broiler chickens (Gallus domesticus) may obtain $5-10 \%$ of their energy requirement in the form of volatile fatty acids produced by cecal fermentation of feedstuffs that are not digested in the upper gut (Gasaway, 1976; cited by Ferket, 1991). Muramatsu et al. (1991) reported that when chickens are fed a low-energy diet with high fiber content, the intestinal microflora supplies even more energy to sustain growth. Besides the positive effect of the microflora in providing resistance against colonisation of pathogens, it is also believed (Visek, 1978) that it can inhibit growth of chickens. Indeed, dietary antibiotics stimulate growth when birds are raised conventionally (Roura et al., 1992), but not when raised under germ-free conditions or in a clean environment (Jukes, 1955). Thus, bacteria normally present in the intestinal tract may inhibit growth, this inhibition being related with the microbial pressure of the chicken's environment (Thomke and Elwinger, 1998).

It is common practice to add antibiotics to poultry diets to improve chicken health, productivity and meat quality. However, it is generally accepted that the use of antibiotics may potentially affect human health due to their ubiquitous presence (Levy, 1987; Bach Knudsen, 2001; Schwarz et al., 2001). This may result in proliferation of antibiotics-insensitive bacteria and thus a decrease in the therapeutic effectiveness of antibiotics used to treat a variety of bacterial infections in humans. This threat to human health has urged European countries to ban antibiotics, and alternatives to antibiotics are currently being encouraged (World Health Organization; cited by Humphrey et al., 2002).

Many authors have searched for alternatives to antibiotics (Langhout, 2000; Mellor, 2000a,b; Wenk, 2000; Kamel, 2001; Talyor, 2001; Humphrey et al., 2002). For example, Humphrey et al. (2002) emphasized the antibiotic property of lactoferrin and lysozyme as alternatives to antibiotics in chickens, these compounds improving growth performance without inducing bacterial resistance to the additives. Various alternatives (Taylor, 2001), as indicated by Humphrey et al. (2002), are known to possess antibiotic property or will at least indirectly modulate the intestinal microflora when fed to chickens.

Essential oils have recently emerged as alternatives to antibiotics in animal production. There are commercially available products. Essential oils derived mainly from spices and herbs and their pure compounds have been shown to have antimicrobial effects in vitro (Cowan, 1999). In addition to their antimicrobial activity, essential oils possess various biological activities such as acting as antioxidants (Krause and Ternes, 1999; Botsoglou et al., 2002), being hypocholesterolemic (Yu et al., 1994; Case et al., 1995; Craig, 1999), affecting flavor (Anonymous, 1998) and 
stimulating the digestion process (Langhout, 2000; Williams and Losa, 2001, 2002). They are classified as "generally recognized as safe (GRAS)" as endorsed by the Flavor and Extract Manufacturers' Association (FEMA) and the Food and Drug Administration (FDA) from the U.S.A., and they are widely used in the food industry. Introduction of essential oils into animal production may have promising potentials as growth and health promoter without adverse effects. However, the effects of essential oils have not yet been well studied in chickens.

This thesis describes the effect of essential oil components on growth performance in relation to digestive enzymes, macronutrient digestion and lipid metabolism in female broiler chickens. In addition, the question addressed was whether dietary essential oil components would counteract growth depression induced by diets either containing carboxymethylcellulose (CMC) or being rich in rye. A literature review describes the general biological activities of essential oils and attempts to apply the information obtained to animal nutrition (Chapter 1). Essential oil components, i.e. thymol, cinnamaldehyde, and a commercial essential oil product (CRINA $^{\circledR}$ Poultry) were tested for any effect on digestive enzyme activities (Chapter 2). Carvacrol (Chapter 3 ) and beta-ionone (Chapter 4) as dietary supplements were investigated to see whether they affect growth performance and lipid metabolism. Further studies with dietary essential oil components were done to find out whether they would counteract the anti-nutritional effect of soluble fiber. CMC was used as non-fermentable soluble fiber (Chapter 5) and rye was used as source of fermentable soluble fiber (Chapter 6). The possible synergistic effects of individual essential oil components were tested (Chapter 7) in relation to growth performance when chickens were fed on a diet containing CMC. Finally, the main conclusions are listed.

\section{References}

Anonymous, 1998. Feed additives: the added value to feed. NEFATO Vereniging van Netherlandse Fabrikanten van Voedertoevoegingen. Aalsmeer.

Bach Knudsen, K. E., 2001. Development of antibiotic resistance and options to replace antimicrobials in animal diets. Proceedings of the Nutrition Society 60: 291-299.

Bedford, M. R., 1996. Interaction between ingested feed and the digestive system in poultry. Journal of Applied Poultry Research 5: 86-95. 
Botsoglou, N. A., P. Florou-Paner, E. Christaki, D. J. Fletouris, and A. B. Spais, 2002. Effect of dietary oregano essential oil on performance of chickens and on iron-induced lipid oxidation of breast, thigh and abdominal fat tissues. British Poultry Science 43: 223-230.

Case, G. L., L. He, H. Mo, and C. E. Elson, 1995. Induction of geranyl pyrophosphate pyrophophatase activity by cholesterol-suppressive isoprenoids. Lipids 30: 357-359.

Cowan, M. M., 1999. Plant products as antimicrobial agents. Clinical Microbiology Reviews 12: 564582.

Craig, W. J., 1999. Health-promoting properties of common herbs. American Journal of Clinical Nutrition 70 (suppl): 491S-499S.

Ferket, P. R., 1991. Effect of diet on gut microflora of poultry. Zootecnica International (July/August): 44-49.

Gasaway, W. C., 1976. Volatile fatty acids and metabolizable energy derived from cecal fermentation in the willow ptarmigan. Comp. Biochem. Physiol. 53A: 115.

Humphrey, B. D., N. Huang, and K. C. Klasing, 2002. Rice expressing lactoferrin and lysozyme has antibiotic-like properties when fed to chicks. Journal of Nutrition 132: 1214-1218.

Jukes, T. H., 1955. Antibiotics in nutrition. Medical Encyclopedia, Inc., New York.

Kamel, C., 2001. Tracing modes of action and the roles of plant extracts in non-ruminants. Pages 135-150 in: Recent advances in animal nutrition. Garnsworthy, P. C., and J. Wiseman, eds. Nottingham University Press, Nottingham.

Krause, E. L., and W. Ternes, 1999. Bioavailability of the antioxidative thyme compounds thymol and $\rho$-cymene-2,3-diol in eggs. European Food Research and Technology 209: 140-144.

Langhout, P., 2000. New additives for broiler chickens. World Poultry 16 (No 3): 22-27.

Levy, S. T., 1987. Antibiotic use for growth promotion in animals: Ecologic and public health consequences. Journal of Food Protection 50: 616-620.

Mellor, S., 2000a. Antibiotics are not the only growth promoters. World Poultry 16 (No 1): 14-15.

Mellor, S., 2000b. Nutraceuticals - alternatives to antibiotics. World Poultry 16 (No 2): 30-33.

Muramatsu, T., H. Kodama, T. Morishita, M. Furus, and J. Okumura. 1991. Effect of intestinal microflora on digestible energy and fiber digestion in chickens fed a high-fiber diet. American Journal of Veterinary Research 52: 1178-1181.

Roura, E., J. Homedes, and K. C. Klasing, 1992. Prevention of immunologic stress contributes to the growth-permitting ability of dietary antibiotics in chicks. Journal of Nutrition 122: 2383-2390.

Schwarz, S., C. Kehrenberg, and T. R. Walsh, 2001. Use of antimicrobial agents in veterinary medicine and food animal production. International Journal of Antimicrobial Agents 17: 431437.

Taylor, D. J., 2001. Effects of antimicrobials and their alternatives. British Poultry Science 42: S67S68. 
Thomke, S., and K. Elwinger, 1998. Growth promotants in feeding pigs and poultry. III. Alternatives to antibiotic growth promotants. Annales de Zootechnie 47: 245-271.

Visek, W. J., 1978. The mode of growth promotion by antibiotics. Journal of Animal Science 46: 14471469.

Wenk, C., 2000. Recent advances in animal feed additives such as metabolic modifiers, antimicrobial agents, probiotics, enzymes and highly available minerals. Review. Asian-Australasian Journal of Animal Sciences 13: 86-95.

Williams, P., and R. Losa, 2001. The use of essential oils and their compounds in poultry nutrition. World Poultry 17 (No 4): 14-15.

Wiliams, P., and R. Losa, 2002. Blending essential oils for poultry. Feed Mix 10 (No 3): 8-9.

Yu, S. G., N. M. Abuirmeileh, A. A. Qureshi, and C. E. Elson, 1994. Dietary $\beta$-ionone suppresses hepatic 3-hydroxy-3-methylglutaryl coenzyme A reductase activity. Journal of Agricultural and Food Chemistry 42: 1493-1496 


\title{
Chapter 1
}

\section{Essential oils in broiler nutrition}

\author{
K.-W. Lee, H. Everts, A. C. Beynen
}

Department of Nutrition, Faculty of Veterinary Medicine, Utrecht University, 3508 TD, Utrecht, The Netherlands 


\section{Introduction}

There are no doubts that dietary antibiotics have played a fundamental role in animal production as growth and health promoter. However, it is the current trend to look for alternatives to antibiotics due to public concerns as to their in-feed use and the resulting residues, and subsequent occurrence of antibiotic-resistant bacteria. Dietary antibiotics presumably act on intestinal microflora, leading to improved animal performance. Most supplements claimed to be alternatives to antibiotics have effects on the microflora either directly or indirectly (Taylor, 2001). Thus, the microflora in chickens should not be ignored in relation to birds' performance. However, unlike ruminant and non-ruminant herbivores, chickens have little nutritional benefit from the microflora (Moran, 1982). Microflora, on the other hand, can adversely affect the host if it is not properly controlled. It is well-known that nonstarch polysaccharides present in cereals stimulate growth of microflora (Smits and Annison, 1997), leading to lower growth performance. Gut microflora can hydrolyze conjugated bile salts (Feighner and Dashkevicz, 1987) which limits fat digestion (Krogdahl, 1985). It is thus clear that controlling the microflora could positively influence birds' performance and that feed supplements with antimicrobial activity are potential alternatives to antibiotics.

Various authors have extensively reviewed and compared various compounds regarded as alternatives to antibiotics in animal production (Langhout, 2000; Mellor, 2000a,b; Wenk, 2000; Taylor, 2001). Essential oils are already marketed for use in animal production and are claimed to be "digestive enhancers" (Williams and Losa, 2002). This urged us to collect published information on essential oils and assess the possible application in poultry nutrition.

\section{Definition of essential oils and general introduction}

An essential oil is a mixture of fragrant, volatile compounds, named after the aromatic characteristics of plant materials from which they can be isolated (Oyen 
and Dung, 1999). The term 'essential' was adapted from the theory of 'quinta essentia' proposed by Paracelsus who believed that this quintessence was the effective element in a medical preparation (Oyen and Dung, 1999). Because the term, 'essential oil' is a poorly defined concept from medieval pharmacy, the term 'volatile oil' is proposed (Hay and Waterman, 1993). However, the name of 'essential oil' will be preferentially used in this review.

Essential oils are very complex mixtures of compounds and their chemical compositions and concentrations are variable. For example, the concentrations of two predominant components of thyme essential oils, i.e. thymol and carvacrol have been reported to range from as low as $3 \%$ to as high as $60 \%$ of total essential oils (Lawrence and Reynolds, 1984). Cinnamaldehyde, a main principle of cinnamon essential oil amounts to approximately 60 to $75 \%$ of the total oil (Duke, 1986). Because of the large variation in composition, the biological effects (Schilcher, 1985; Jassen et al., 1987; Deans and Waterman, 1993), if any, of essential oils may differ. This diversity of essential oils urged us to select four pure principles, i.e. thymol, cinnamaldehyde, beta-ionone and carvacrol, for evaluating their possible role as alternatives to antibiotics in poultry production. The chemical properties and biological activities are summarized in Table 1.

\section{Classification of essential oils}

Essential oils are basically composed of two classes of compound, terpenes and phenylpropenes. Terpenes, depending on 5-carbon building block (isoprene unit), can be sub-divided into mono-, sesqui-, and di-terpenes in which the number of isoprene units are 2, 3 and 4, respectively. Further derivatives of terpenes occur due to the presence or absence of a ring structure, double bond, addition of oxygen or stereochemistry. It is estimated that there are more than 1000 monoterpenes and 3000 sesquiterpenes. On the other hand, phenylpropenes consist of a 6-carbon aromatic ring with a 3 -carbon side chain attached $\left(\mathrm{C}_{6}-\mathrm{C}_{3}\right.$ compounds). Unlike terpenes, only approximately 50 phenylpropenes are described. 
Table 1 Chemical properties of the essential oil constituents thymol, carvacrol, cinnamaldehyde and $\beta$-ionone

\begin{tabular}{|c|c|c|c|c|}
\hline & Thymol & Carvacrol & Cinnamaldehyde & $\beta$-ionone \\
\hline Molecular weight & $150 \mathrm{C}_{10} \mathrm{H}_{14} \mathrm{O}$ & $150 \mathrm{C}_{10} \mathrm{H}_{14} \mathrm{O}$ & $132 \mathrm{C}_{9} \mathrm{H}_{8} \mathrm{O}$ & $192 \mathrm{C}_{13} \mathrm{H}_{20} \mathrm{O}$ \\
\hline Synonym & $\begin{array}{l}\text { 5-methyl-2-(1- } \\
\text { methylethyl)phenol }\end{array}$ & $\begin{array}{l}\text { 2-methyl-5-(1- } \\
\text { methylethyl)phenol }\end{array}$ & 3-phenyl-2-propenal & $\begin{array}{l}\text { 4-(2,3,3-trimethyl-1- } \\
\text { cyclohexen-1-yl)-3-buten-2- } \\
\text { one }\end{array}$ \\
\hline FEMA-GRAS 1 & 3066 & 2245 & 2286 & 2595 \\
\hline FDA 1 & 21CFR 172.515 & 21CFR 172.515 & 21CFR 182.60 GRAS & 21CFR 172.515 \\
\hline Found in & Thyme (Lamiaceae) & Oregano (Lamiaceae) & Cinnamon (Lauraceae) & Boronia (Rutaceae) \\
\hline Odor & Pungent, caustic taste & Thymol-odor like & Cinnamon & Violet \\
\hline Boiling point & 233 & 237 & 246 & 266 \\
\hline Density, g/Ml & 0.969 & 0.976 & 1.048 & 0.945 \\
\hline $\begin{array}{l}\mathrm{LD}_{50}{ }^{2} \\
\text { Stability }{ }^{1}\end{array}$ & $\begin{array}{l}980 \mathrm{mg} / \mathrm{kg} \text {, orally rat } \\
\text { Good }\end{array}$ & $\begin{array}{l}810 \text { mg/kg, orally rat } \\
\text { Good }\end{array}$ & $\begin{array}{l}2,220 \mathrm{mg} / \mathrm{kg} \text {, orally rat } \\
\text { Fair to poor }\end{array}$ & $\begin{array}{l}4,590 \mathrm{mg} / \mathrm{kg} \text {, orally rat } \\
\text { Good }\end{array}$ \\
\hline \multicolumn{5}{|l|}{ Structure } \\
\hline \multirow{7}{*}{ Biological activity ${ }^{3}$} & Antimicrobial & Antimicrobial & Antimicrobial & Antimicrobial \\
\hline & Antiinflammatory & Antiinflammatory & Antiinflammatory & Antimelanomic \\
\hline & Antimelanomic & Antimelanomic & Antispasmodic & Antitumor \\
\hline & Antioxidant & Antioxidant & Antiurease & Cytochrome-P450-inducer \\
\hline & Antiseptic & Antispasmodic & Cancer-preventive & Hypocholesterolemic \\
\hline & Caminative & Carminative & Flavor & \\
\hline & Flavor & Flavor & Hypoglycemic & \\
\hline
\end{tabular}

${ }^{1}$ Furia and Bellanca, 1975; ${ }^{2}$ Jenner et al., 1964; ${ }^{3}$ Agricultural Research Service (ARS). 


\section{Synthesis of essential oils}

Terpenes and phenylpropenes are mostly synthesized by the mevalonic and shikimic pathway, respectively. Six-carbon mevalonic acid, formed by condensation of three acetate units and by HMG-CoA reductase, is converted to 5-carbon isopentenyl pyrophosphate (IPP) and then to dimethylallyl pyrophosphate (DMAPP), which are the activated 5-carbon units of isoprene. IPP and DMAPP are then combined in a 1:1 molar ratio to generate 10-carbon geranyl pyrophosphate (GPP) which is the precursor of monoterpenes. The addition of IPP to GPP produces the 15-carbon sesquiterpene compound, farnesyl pyrophosphate (FPP). Thymol and carvacrol are derived from GPP and classified as monoterpenoids or isoprenoids. On the other hand, $\beta$-ionone is derived from FPP and thus classified as either sesquiterpene or isoprenoid.

The shikimic acid pathway produces the aromatic amino acid phenylalanine, the products of which are cinnamic acid and p-coumaric acid, occurring in trans configuration (Seigler, 1998). Among the important phenylpropene compounds are eugenol, trans-cinnamaldehyde, safrole and also the pungent principles, capsaicin and piperine. These are classified as phenylpropenoids. The synthetic pathways and the related compounds are reviewed in more detail elsewhere (Friedrich, 1976; Waterman, 1993; Seigler, 1998; Loza-Tavera, 1999).

\section{Biological effects of essential oils}

\section{In-vitro antimicrobial activities of essential oil}

Essential oils have long been recognized because of their antimicrobial activity (Deans and Ritchie, 1987; Paster et al., 1990; Reddy et al., 1991; Lis-Blachin et al., 1998; Smith-Palmer et al., 1998; Hammer et al., 1999). Due to this property, essential oils have gained much attention in investigations on their potential as alternatives to antibiotics for therapeutic purposes and applications in the cosmetics and food industry. For example, Lee and Ahn (1998) found that cinnamaldehyde, derived from the cinnamon essential oil strongly inhibits Clostridium perfringens and Bacteroides fragilis and moderately inhibits Bifidobacterium longum and Lactobacillus acidophilus isolated from human feces. The selective inhibition by 
cinnamaldehyde of pathogenic, intestinal bacteria may have a pharmacological role in balancing the intestinal microbiota. The wide range of in-vitro antimicrobial activities of essential oils derived from cinnamon, thyme and oregano have been published (Deans and Ritchie, 1987; Paster et al., 1990; Biondi et al., 1993; Stiles et al., 1995; Sivropoulou et al., 1996; Nelson, 1997; Adam et al., 1998; Farag et al., 1989b; Manou et al., 1998; Smith-Palmer et al., 1998; Cosentino et al., 1999; Hammer et al., 1999; Ferhout et al., 1999; Dorman and Deans, 2000) which supports their possible use as antimicrobial agents. It is reasonable to expect that the main components of essential oils displaying in vitro antimicrobial activity are responsible for this activity. The essential oils and their pure components displaying antimicrobial activities are shown in Table 2. Antimicrobial activity of individual compounds against selected microorganisms is presented also (Table 3). The minimum inhibitory concentrations (MIC) of the pure compounds differ and vary between experiments.

It is considered beneficial to keep the effective antimicrobial concentration of essential oils as low as possible due to their characteristic flavors. This problem can be overcome, as suggested by Moleyar and Narasimham (1992), by using synergistic properties of different oils, thus improving the antimicrobial activity in spite of low dosages. This synergism was highlighted in studies of Didry et al. (1994) and Montes-Belmont and Carvajal (1998).

\section{Antimicrobial mode of action of essential oils}

The exact antimicrobial mechanism of essential oils is poorly understood. However, it has been suggested that their lipophilic property (Conner, 1993) and chemical structure (Farag et al., 1989b,c) could play a role. Helander et al. (1998) investigated how two isomeric phenols, carvacrol and thymol, and the phenylpropanoid, cinnamaldehyde, exerts their antibacterial effects on Escherichia coli $\mathrm{O} 157$ and Salmonella typhimurium. Carvacrol and thymol both, in a similar fashion, disintegrated the membrane of bacteria, leading to the release of membrane-associated material from the cells to the external medium. On the other hand, cinnamaldehyde failed to affect the membrane but did exhibit antibacterial activity, indicating that two molecules have different mechanisms underlying antibacterial activity. The authors, however, suggested that terpenoids and phenylpropanoids can penetrate the membrane of the bacteria and reach the inner part of the cell because of their lipophilicity, but it has also been ascribed to structural 
properties such as the presence of the functional groups (Farag et al., 1989b,c) and aromaticity (Bowles and Miller, 1993). It is thought that membrane perforation or binding is the principle mode of action (Shapiro and Guggenheim, 1995; Stiles et al., 1995), leading to an increase of permeability and leakage of vital intracellular constituents (Juven et al., 1994), resulting in impairment of bacterial enzyme systems (Farag et al., 1989b,c). The mechanism of antifungal action of cinnamaldehyde has been investigated (Kurita et al., 1979) and it was proposed that it takes place through the reaction with sulfhydryl groups, which are indispensable for the fungal growth, and that the formation of charge transfer complexes with electron donors in the fungus cell could lead to inhibition of cell division and thus interferes with cell metabolism. It was also reported that cinnamaldehyde inhibits fungal cell wall synthesizing enzymes (Bang et al., 2000).

Table 2 Essential oils and their main components exhibiting antimicrobial activities

\begin{tabular}{|c|c|c|c|c|}
\hline Scientific name & $\begin{array}{l}\text { Common } \\
\text { name }\end{array}$ & Part & $\begin{array}{l}\text { Antimicrobial } \\
\text { components }\end{array}$ & References \\
\hline $\begin{array}{l}\text { Boronia megastima Nees } \\
\text { ex Bartl. }\end{array}$ & Boronia & Flower & ß-ionone & Gueldner et al 1985 \\
\hline Zea mays L. & Corn & Leaf & & \\
\hline $\begin{array}{l}\text { Cinnamomum verum J. } \\
\text { Presl }\end{array}$ & Cinnamon & Bark & Cinnamaldehyde & Ouattara et al., 1997 \\
\hline $\begin{array}{l}\text { Origanum vulgare spp. } \\
\text { hirtum (Link) (letsw.) }\end{array}$ & Oregano & Shoot & Carvacrol & $\begin{array}{l}\text { Sivropoulou et al., } \\
1996\end{array}$ \\
\hline $\begin{array}{l}\text { Syzygium aromaticum (L.) } \\
\text { Merr. \& Perry }\end{array}$ & Cloves & Flower & Eugenol & Hammer et al., 1999 \\
\hline Thymus vulgaris L. & Thyme & Plant & Thymol & $\begin{array}{l}\text { Dorman and deans, } \\
2000\end{array}$ \\
\hline
\end{tabular}

\section{In-vivo study}

On the basis of their in vitro antimicrobial activity, it is logical to consider for essential oils applications as prophylactic and therapeutic agents in animal 
production. As would be expected, the intake of essential oils might affect the gastrointestinal microflora composition and population. Allen et al. (1997) investigated Artemisia annua as a potential anticoccidial drug in poultry. Pure components of $A$. annua, i.e., artemisinin, 1,8-cineole and camphor at the levels of 17, 119 and $119 \mathrm{ppm}$, respectively, were fed to chicks from 1-d-old to 3 weeks of age. At 2 wk of age, half of the chicks were inoculated with Eimeria acervulina and Eimeria tenella. Some prophylactic action against the coccidia challenge was shown in treated chicks, especially in those fed artemisinin. Evans et al. (2001) investigated whether a mixture of essential oils from clove $(1.0 \%)$, thyme $(0.1 \%)$, peppermint $(0.1 \%)$ and lemon $(0.1 \%)$ could have effects on coccidia oocyte output and the number of Clostridium perfringens in broiler chicks when artificially inoculated. There was no positive control included. Chicks fed the diets containing an essential oil blend showed a reduced oocyte excretion when compared to those fed the nonsupplemented diet. However, the number of Clostridium perfringens in the intestine did not differ between treatments. A field study conducted by Köhler (1997) with a commercial preparation of essential oils showed a reduction of colony forming units of Clostridium perfringens as compared to the positive control diet containing zinc bacitracin at the level of $20 \mathrm{ppm}$. The commercial preparation was supplied in a powdered form and added to the diet at the level of $50 \mathrm{ppm}$. This preparation was also reported to slightly lower ileal ATP concentration (Veldman and Enting, 1996) which is an indicator of microbial activity in broilers (Smits et al., 1997). Similarly, a blend of capsicum, cinnamaldehyde and carvacrol lowered the number of Escherichia coli and Clostridium perfringens in ceca (Jamroz and Kamel, 2002).

Essential oils have been reported to affect rumen microbial activity, the effects being either positive (Mclntosh et al., 2000) or negative (Oh et al., 1967 and 1968). Oh et al. (1967 and 1968) observed an inhibitory effect of essential oils against rumen microorganisms in terms of total gas and volatile fatty acid production. It was hypothesized that the characteristic odor and antibacterial action of essential oils from unpalatable plant species may reduce voluntary feed intake by ruminants. Scholl et al. (1977) studied the utilization of sagebrush by mule deer and found that the presence of essential oils was a negative factor for the utilization of sagebrush. McIntosh et al. (2000) reported that a commercial preparation of essential oils did not affect the protozoal numbers in the rumen but did increase the bacterial population, possibly leading to increased nitrogen availability to the host. 
Essential oils in broiler nutrition

Table 3 Minimum inhibitory concentration (MIC, ppm) of carvacrol, cinnamaldehyde and thymol

\begin{tabular}{lcccl}
\hline Microorganisms & Carvacrol & $\begin{array}{c}\text { Cinnama- } \\
\text { ldehyde }\end{array}$ & Thymol & References \\
\hline Escherichia coli & 450 & 396 & 450 & Helander et al., 1998 \\
Escherichia coli & 225 & NT & 225 & Cosentino et al., 1999 \\
Staphylococcus aureus & 450 & NT & 225 & Cosentino et al., 1999 \\
Candida albicans & 150 & NT & 150 & Ali-shtayeh et al., 1997 \\
Candida albicans & 113 & NT & 113 & Cosentino et al., 1999 \\
Candida albicans & 200 & 200 & NT & Ferhout et al., 1999 \\
Pseudomonas aeruginosa & 500 & NT & 500 & Ali-shtayeh et al., 1997 \\
Pseudomonas aeruginosa & $>900$ & NT & $>900$ & Cosentino et al., 1999 \\
Salmonella typhimurium & 150 & 396 & 150 & Helander et al., 1998 \\
Salmonella typhimurium & 225 & NT & 56 & Cosentino et al., 1999 \\
Streptococcus mutans & 125 & 250 & 250 & Didry et al., 1994 \\
Streptococcus mitis & 125 & 125 & 125 & Didry et al., 1994 \\
\hline
\end{tabular}

NT: not tested.

\section{In vitro antioxidant effects of essential oils}

The antioxidative properties of the extracts of oregano, dittany, thyme, marjoram, spearmint, lavender and basil have been evaluated when added to lard kept at $75{ }^{\circ} \mathrm{C}$ (Economou et al., 1991). Oregano extract was found to be most effective in stabilizing lard, followed by thyme, dittany, marjoram and lavender. It was reported that $\rho$-cymene-2,3-diol (Schwarz et al., 1996) and thymol and carvacrol (Aeschbach et al., 1994; Aruoma, 1997; Baratta et al., 1998) which are found in thyme showed strong antioxidant properties. Farag et al. (1989a) discussed the relationship between the antioxidant property and the chemical composition of the essential oils. It was suggested that the high antioxidant activity of thymol is due to the presence of phenolic $\mathrm{OH}$ groups which act as hydrogen donors to the peroxy radicals produced during the first step in lipid oxidation, thus retarding the hydroxyperoxide formation. Teissedre and Waterhouse (2000) reported a high correlation $(r=0.75)$ between the total phenol content of essential oils and human low-density-lipoprotein oxidation in vitro. 


\section{Antioxidant property of essential oils as based on animal studies}

Youdim and Deans (1999a,b and 2000) investigated the effect of thyme oil and its major compound, thymol, as dietary antioxidant supplements on age-related changes in polyunsaturated fatty acids in various organs. Thyme oil and thymol were fed to rats on a basis of $42.5 \mathrm{mg} / \mathrm{kg}$ of body weight daily until 28 months of age. Rats fed the supplements maintained higher levels of polyunsaturated fatty acids, especially C20:4n-6 and C22:6n-3 in the phospholipid fractions of liver, brain, kidney and heart, than did those fed the control diet. It would appear that the supplements act as effective free radicals scavengers and influence the in vivo antioxidant defence systems such as superoxide dismutase, glutathione peroxidase and vitamin E. There is evidences that the antioxidant components in thyme can be transferred to egg yolk as based on a lower concentration of malonaldehyde in it (Botsoglou et al., 1997). Thymol and $\rho$-cymene-2,3-diol, which are responsible for the antioxidant properties of thyme, have been determined in eggs collected during 24-day-feeding periods (Krause and Ternes, 1999). 1.12 and 1.68\% thyme extracts, which correspond with $50 \mathrm{mg} \rho$-cymene-2,3-diol and $224 \mathrm{mg}$ thymol, and $75 \mathrm{mg} \rho$-cymene2,3-diol and $336 \mathrm{mg}$ thymol per $100 \mathrm{~g}$ of diet, respectively, were included in the layers' diet. Approximately, 0.004 and $0.006 \%$ of the ingested $\rho$-cymene-2,3-diol and thymol were transferred to egg yolk after 12 days of feeding. The compounds disappeared from egg yolk soon after supplementation was ceased. An antioxidant effect of essential oils in broiler chickens has been reported as well (Lopez-Bote et al., 1998; Botsoglou et al., 2002). The latter study (Botsoglou et al., 2002) reported that oregano essential oils exerted antioxidant property in meats and abdominal fat, pointing at the incorporation of the protective antioxidant components of the essential oil into the membrane. The authors further found that the antioxidant effect was dose dependent. It is thus concluded that thymol and carvacrol can act as antioxidant in egg and meat of chickens when introduced into the diets. However, as discussed by Botsoglou et al. (2002), a reliable laboratory method to determine essential oils in biological systems is necessary to support the view.

\section{Role of essential oil as flavor}

Besides as antimicrobials and antioxidants, essential oils and their pure components are also used as flavor in human foods. Carvacrol can be used in non- 
alcoholic beverages up to the level of $26 \mathrm{ppm}$ and in baked goods up to $120 \mathrm{ppm}$ (Furia and Bellanca, 1975). Cinnamaldehyde can be used at low as 8 ppm in ice cream products and as high as 4900 ppm in chewing gum (Furia and Bellanca, 1975). Thymol and beta-ionone are also used as flavoring agents in foods.

The characteristic flavors of essential oils can be advantageous in standardizing tastes and smells of the diet if the diet ingredients are changed such as during the weaning transition of piglets (Anonymous, 1998). Specific effects of flavors on chickens' performance has not received much attention because poultry may not acutely respond to flavor when compared to pigs (Moran, 1982). With the limited literature there is evidence (Deyoe et al., 1962) that flavors could affect feed intake. On the other hand, the effects of flavors on poultry performance are regarded as negligible (Moran, 1982). The aspect of essential oil as flavor in poultry nutrition needs to be assessed.

\section{Can essential oils affect the digestion process?}

There are suggestions that dietary essential oils can improve digestion (Anonymous, 1997; Mellor, 2000a,b). It might be reasoned that spices and herbs, from which essential oils are derived, have been shown to positively affect food digestion (Pradeep et al., 1991; Pradeep and Geervani, 1994). A number of studies have reported the effect of spices or their active components on bile salt secretion (Bhat et al., 1984, 1985; Bhat and Chandrasekhara, 1987; Sambaiah and Srinivasan, 1991). In addition, the dietary pungent principles, i.e. curcumin, capsaicin, and piperine, have been shown to stimulate digestive enzyme activities of intestinal mucosa and of pancreas (Platel and Srinivasan, 1996 and 2000). It was reported earlier (Harada and Yano, 1975) that cinnamaldehyde increased bile secretion in the rat. It is interesting to note that the pungent principles, capsaicin and piperine and cinnamaldehyde share their synthetic pathways (shikimic pathway). Whether or not dietary thymol and cinnamaldehyde, at the level of $100 \mathrm{ppm}$, stimulate secretion of pancreatic digestive enzymes, i.e. amylase, lipase, trypsin, and chymotrypsin has been tested in our laboratory in female broiler chickens (Chapter 2). As shown in Table 4, there are no clear effects of thymol and cinnamaldehyde on the enzyme activities at either 21 or 40 days of age of the chickens. On the other hand, cinnamaldehyde, and eugenol, a main component of clove essential oils, when fed at the dietary concentrations of 1000 and $850 \mathrm{ppm}$, 
significantly impaired the absorption of alanine by rat jejunum (Kreydiyyeh et al., 2000). The authors postulated that the two principles inhibit the activity of $\mathrm{Na+-} \mathrm{K}_{+-}$ ATPase located in enterocyte, and consequently impair transport processes in the intestine. In addition, in vitro results showed that $\mathrm{IC}_{50}$ values, i.e. the concentration of the principles that inhibit the activity of intestinal $\mathrm{Na}+-\mathrm{K}_{+}-\mathrm{ATPase}$ by $50 \%$, were 1.1 and $1.4 \mathrm{mg} / \mathrm{mg}$ of protein for cinnamaldehyde and eugenol, respectively. It can be expected that high doses of the two principles, when introduced into the chickens' diet, could inhibit the digestion process. However, the inhibitory concentration in diet has not been established yet. In any event, dietary cinnamaldehyde as compared to thymol seems to participate in the digestion process as based on the literature published so far.

Table 4 Effects of dietary essential oils on digestive enzyme activities in pancreatic extracts prepared from female broiler chickens that were fed diets without or with additives ${ }^{1}$

\begin{tabular}{|c|c|c|c|}
\hline & Control & Thymol & Cinnamaldehyde \\
\hline \multicolumn{4}{|l|}{21 days of age } \\
\hline Amylase $^{2}$ & $22 \pm 1.7$ & $23 \pm 4.3$ & $21 \pm 2.9$ \\
\hline Lipase 3 & $8.7 \pm 1.0$ & $11.2 \pm 1.4$ & $9.1 \pm 2.0$ \\
\hline Trypsin $^{4}$ & $1.07 \pm 0.28$ & $1.26 \pm 0.31$ & $1.10 \pm 0.10$ \\
\hline Chymotrypsin ${ }^{5}$ & $1.00 \pm 0.23$ & $1.14 \pm 0.25$ & $1.01 \pm 0.17$ \\
\hline \multicolumn{4}{|l|}{40 days of age } \\
\hline Amylase $^{2}$ & $39 \pm 1.9$ & $38 \pm 3.1$ & $37 \pm 1.9$ \\
\hline Lipase $^{3}$ & $33 \pm 6.5$ & $36 \pm 7.5$ & $32 \pm 9.2$ \\
\hline Trypsin ${ }^{4}$ & $0.96 \pm 0.14$ & $1.00 \pm 0.23$ & $1.02 \pm 0.15$ \\
\hline Chymotrypsin ${ }^{5}$ & $0.97 \pm 0.14$ & $1.13 \pm 0.11$ & $1.02 \pm 0.09$ \\
\hline
\end{tabular}

${ }_{1}^{1}$ Means (SD, $\left.n=4\right)$ are expressed as unit/mg of protein.

2 One unit was defined as hydrolysis of $1 \mathrm{mg}$ of maltose per minute at $\mathrm{pH} 6.9$ and $37 \stackrel{\circ}{\mathrm{C}}$.

$31 \mu \mathrm{mol}$ of free fatty acid released per minute at $\mathrm{pH} 8.5$.

${ }^{4} 1 \mu \mathrm{mol}$ of $\mathrm{p}$-toluenesulfonyl-L-arginine methyl ester hydrolyzed per minute at $\mathrm{pH} 8.1$ and $37^{\circ} \mathrm{C}$.

${ }^{5} 1 \mu \mathrm{mol}$ of benzoyl-L-tyrosine ethyl ester hydrolyzed per minute at $\mathrm{pH} 7.8$ and $37{ }^{\circ} \mathrm{C}$.

\section{Effects of essential oils on lipid metabolism}

Craig (1999) reviewed the role of herbs and their essential oils as to their cholesterol lowering properties and in the protection against cancer. Elson et al. 
(1989) reported the hypocholesterolemic effect of lemongrass oil, which rich in geraniol and cital, in human subjects. On the contrary, hardly any effects on plasma lipids other than cholesterol were observed (Cooke et al., 1998).

The pure components of essential oils inhibit hepatic 3-hydroxy-3methylglutaryl coenzyme A (HMG-CoA) reductase activity (Crowell, 1999) which is a key regulatory enzyme in cholesterol synthesis. As a result, a hypocholesterolemic effect of essential oils can be expected. According to Case et al. (1995), a 5\% inhibition of HMC-COA reductase lowered serum cholesterol by $2 \%$ in poultry. Qureshi et al. (1983) reported a correlation between HMG-CoA reductase activity and either total or LDL cholesterol in chicken, but not with HDL cholesterol. It has been reported (Qureshi et al., 1988) that when cockerels are fed dietary limonene at levels of $25-100$ ppm for 26 days, hepatic HMG-CoA reductase activity and serum cholesterol show a dose-dependent decrease whereas hepatic fatty acid synthetase activity was unaffected. A variety of essential oil compounds, such as borneol, cineole, citral, geraniol, menthone, menthol, fenchone, fenchyl alcohol, and $\beta$-ionone have been shown to suppress hepatic HMG-CoA reductase activity (Middleton et al., 1979; Clegg et al., 1980; Middleton and Hui, 1982; Fitch et al., 1989; Yu et al., 1994). $\beta$-lonone is a precursor of vitamin A (Naves, 1971), but the relation with its hypocholesterolemic effect is not clear. Hood et al. (1978) tested the hypothesis that dietary essential oils may inhibit biosynthesis of FPP, a precursor of cholesterol synthesis. Layers were force-fed individually with a capsule containing an essential oil daily for 5 weeks and cholesterol levels in plasma were monitored. Essential oils studied and their levels were $\alpha$-terpineol (10, 50, 100, and $200 \mathrm{mg} /$ day), citronellol (100mg/day), linalool (100 mg/day) and geraniol (100mg/day). Contrary to the hypothesis, no significant differences among treatments were observed as to cholesterol levels in plasma. The authors ascribed the non-significant effect of the selected essential oil components to either ineffective inhibition of HMC-CoA reductase or to their fast degradation in liver.

\section{Mode of action}

The hypocholesterolemic effects of essential oils are mediated by downregulating the regulatory enzyme, HMG-CoA reductase, post-transcriptionally without changing the enzyme mRNA levels (Elson and Qureshi, 1995; Qureshi et al., 1996). Middleton and Hui (1982) proposed that the inhibitory action of essential oils on 
hepatic HMG-CoA reductase is independent of the diurnal cycle of the enzyme, and of hormones such as insulin, glucocorticoids, triiodothyronine, and glucagon. The complete inhibition of cholesterol synthesis, as proposed by Goldstein and Brown (1990), requires two regulators, i.e. cholesterol derived from LDL and a non-sterol product(s) derived from mevalonate, both of which modulate HMG-CoA reductase activity. It has been reported that thymol, carvacrol and $\beta$-ionone might induce a putative regulatory non-sterol product(s) (Case et al., 1995; Elson, 1996).

\section{Effect of essential oils on growth performance in chickens}

The observed effects of essential oils on growth performance in chickens are either positive (Anonymous, 1997; Bassett, 2000; Langhout, 2000; Kamel, 2001) or non-significant (Vogt and Rauch, 1991; Case et al., 1995; Veldman and Enting, 1996; Botsoglou et al., 2002). The inclusion levels varied from 20 to $200 \mathrm{ppm}$. When the effect was positive, weight gain and feed intake were increased whereas the feed:gain ratio was lowered when compared to control. On the other hand, Botsoglou et al. (2002) reported that when dietary oregano essential oils, at the concentrations of 50 and $100 \mathrm{ppm}$, were fed to broiler chickens for a period of 38 days hardly any effects on body weight and feed conversion ratio could be demonstrated. The authors explained the lack of effect by pointing out that the birds' performance was already superior, leaving no room for growth enhancing effects of the additives. This statement could be in line with studies of Coates et al. (1951) and Hill et al. (1952), who demonstrated that well-nourished healthy chicks responded less to antibiotic supplements when they were housed in a carefully cleaned and disinfected place. Caution is required when interpreting the results of Botsoglou et al. (2002) because the experimental diet used contained $75 \mathrm{ppm}$ lasalocid and $0.01 \%$ exogenous enzymes which might either mask or diminish an effect of the essential oils. Vogt and Rauch (1991) also failed to observe any effects on growth performance when thyme essential oils were supplemented at one of four levels, 0, 20, 40 and $80 \mathrm{ppm}$. On the other hand, positive effects of essential oils have been obtained from the numerous field studies (Anonymous, 1997; Bassett, 2000; Langhout, 2000; Kamel, 2001). This may indicate that when experimental conditions and diets are marginal for the birds, a growth-enhancing effects of essential oils will be seen. Indeed, Allen et al. (1997) reported that two essential oil components, camphor and 1,8-cineole at the dietary level of $119 \mathrm{ppm}$, showed no clear effects on weight gain when birds were reared 
without coccidia challenge, but led to significant weight gains when the birds were infected with coccidia. This result, and the outcome of field studies (Anonymous, 1997; Bassett, 2000; Langhout, 2000; Kamel, 2001), indicates that the effects of dietary essential oils on growth performance become apparent when chickens are subjected to suboptimal conditions such as a less digestible diet and/or a less clean environment.

Our own results (Chapters 3 and 4) show that dietary carvacrol versus thymol at the concentration of $200 \mathrm{ppm}$ lowered weight gain and feed intake, but improved the feed:gain ratio when birds were fed the respective diet for 4 weeks. We proposed that the effect of dietary carvacrol on feed:gain ratio could relate to increased efficiency of feed utilization and/or altered carcass composition. According to Yu et al. (1994), chicks fed on a diet containing $\beta$-ionone at the level of 100 or $250 \mathrm{ppm}$ were heavier by on average 10.6 and $22.3 \%$, respectively, when compared to the controls. The $\beta$-ionone-induced increase in body-weight-gain did not reach statistical significance, but the statistical power was low due to large inter-individual variation. It might be suggested that dietary essential oils may act not only on intestinal microflora, but also on nutrient utilization. Moreover, it seems that isomers can have different effects on growth performance.

\section{Metabolic pathway of components of essential oils}

Kohlert et al. (2000) reviewed the various pure components of essential oils that are used in herbal medicine and summarized their absorption, metabolism and excretion. The authors concluded that essential oil constituents are quickly absorbed after oral, pulmonary, or dermal administration and that most are metabolized and either eliminated by the kidneys in the form of glucuronides or exhaled as $\mathrm{CO}_{2}$. Their accumulation in the body is unlikely due to rapid clearance and short half lives. Igimi et al. (1974) studied the metabolic fate of ${ }^{14} \mathrm{C}$-labelled d-limonene in rats. The authors reported that $d$-limonene absorbed from the intestine was rapidly excreted without significant deposition in the body. Two hours after administration, the adrenals, liver and kidney showed the highest concentrations of d-limonene and then declined to negligible concentrations at 24 hours after administration. Most radioactivity was recovered in the urine. The metabolites of d-limonene in rabbits also were excreted with urine (Kodama et al., 1974). 


\section{Metabolic pathway of thymol and carvacrol}

The metabolic pathways of thymol and carvacrol are well studied in rats. Rats have been given thymol and carvacrol at $1 \mathrm{mmol} / \mathrm{kg}$ of body weight and the excretory patterns of the compounds in urinary samples have been measured (Austgulen et al., 1987). Urinary excretion of metabolites was rapid, and negligible amounts were excreted after 24-hrs. No metabolites were found in urine samples after 48 hours. Large quantities of carvacrol, and especially of thymol, were excreted in unchanged form. Extensive oxidation of the methyl and isopropyl groups of both compounds occurred which resulted in the formation of derivatives of benzyl alcohol and 2phenylpropanol and their corresponding carboxylic acids. On the other hand, the hydroxyl group of the two compounds was not affected. Tanaka et al. (1979) reported that the major portions of thymol (when orally given to rabbits) were excreted within 24 hours and that thymol glucuronide was the main metabolite in urine. However, intact thymol was not excreted in appreciable amounts.

\section{Metabolic fate of cinnamaldehyde and $\beta$-ionone}

Urinary metabolites of cinnamaldehyde have been studied in rats and mice (Peters and Caldwell, 1994). Trans-[ $\left[3-{ }^{14} \mathrm{C}\right]$ cinnamaldehyde was given to laboratory rodents by different routes of administration (ip injection and oral gavage) and with various dosages (2 to $250 \mathrm{mg} / \mathrm{kg}$ of body weight). Generally, cinnamaldehyde was rapidly excreted via urine in the first $24 \mathrm{hrs}$ and less than $2 \%$ of the administered doses remained in the carcass after 72 hrs. The major metabolite was hippuric acid, which was supposed to arise from oxidation of the aldehyde to cinnamic acid and further metabolism by way of $\beta$-oxidation of the side-chain followed by glycine conjugation to yield hippuric acid. In addition, another metabolic pathway of the compound was conjugation with reduced glutathione, leading to mercapturic acids as end products in the urine. Hoskins (1984) extensively reviewed the metabolic pathways of cinnamaldehyde via oxidation and glutathione conjugation.

Yuan et al. (1993) studied the bioavailability of cinnamaldehyde when rats were gavaged at doses of 50,250 and $500 \mathrm{mg} / \mathrm{kg}$ of body weight. A low bioavailability of less than $20 \%$ was shown when gavaged at 250 and $500 \mathrm{mg} / \mathrm{kg}$ of body weight. No blood cinnamaldehyde was detected at the lowest levels while 1.3 
and $2.4 \mu \mathrm{g} / \mathrm{mL}$ for the doses of 250 and $500 \mathrm{mg} / \mathrm{kg}$, respectively, were observed. The authors suggested that systemic exposure by low concentrations of absorbed cinnamaldehyde would be negligible due to rapid oxidation in the liver and that at higher concentrations of cinnamaldehyde, some escaped oxidation and was conjugated with protein.

The metabolic pathway of $\beta$-ionone was studied by Ide and Toki (1970). $\beta$ ionone was gavaged to rabbits for 7 days at the level of $1 \mathrm{~g}$ per $\mathrm{kg}$ body weight and urine was collected during the administration and for 4 days after the last administration. Five metabolites were found to be excreted in the urine: unchanged $\beta$-ionone, 3-oxo- $\beta$-ionone, 3-hyroxy- $\beta$-ionol, 3-oxo- $\beta$-ionol, and dihydro-3-oxo- $\beta$-ionol. The last two compounds were detected as major metabolites. The glucuronides of $3-$ oxo- $\beta$-ionol and dihydro-3-oxo- $\beta$-ionol were also detected. The authors suggested that $\beta$-ionone is metabolized by hydroxylation of the ring system at the carbon atom $\alpha$ to the ring double bond and then oxidation of the hydroxyl group to 3-oxo derivatives occurs.

Besides the metabolism by the host, it seems unlikely that the intestinal microflora could metabolize the essential oils. Varel (2002) reported that thymol and carvacrol were not metabolized by microorganisms residing in swine feces.

\section{Toxicological studies}

The toxicity studies consist of determination of the acute oral effects, subacute studies in which the flavoring agents are mixed in the diet or administered by stomach tube, and chronic feeding studies. Acute oral toxicity studies with carvacrol, cinnamaldehyde, beta-ionone and thymol have been conducted (Jenner et al., 1964). The acute oral $L_{50}$ ( $\mathrm{mg} / \mathrm{kg}$ of body weight) of carvacrol, cinnamaldehyde, beta-ionone, and thymol in the rat are 810, 2220, 4590 and 980, respectively.

Hébert et al. (1994) studied the toxicological effects of cinnamaldehyde in rodents. Rats were fed 188 to $3000 \mathrm{mg} / \mathrm{kg}$ of body weight/day and mice 474 to 7500 $\mathrm{mg} / \mathrm{kg}$ of body weight/day. Cinnamaldehyde was added to the rodent's diet. Rats and mice receiving cinnamaldehyde with their feed showed a dose-related decrease in body weight gain, which resulted from a decreased food consumption (food aversion) at the beginning. Rodents typically show an aversion to food with strong odors. Relative weights of liver, kidney and spleen ( $\mathrm{g}$ of organ/100 $\mathrm{g}$ of body weight) were not affected by the various doses in the feed. Toxicological studies with 
cinnamaldehyde have been extensively reviewed and reported elsewhere in relation to its carcinogenicity, mutagenicity, its characterisitc being a potent teratogen in chickens, and being a skin sensitizer (Abramovici and Rachmuth-Roizman, 1983; Hoskins, 1984; National Toxicology Program, 1989; Stammati et al., 1999; Smith et al., 2000). When rats were fed diets containing thymol at the level of 1000 and 10000 ppm for 19 weeks, no clear signs of toxicity were observed (Hagan et al., 1967). On the other hand, ionone (a mixture of $\alpha$ - and $\beta$-ionone) administered at the level of 2500 and 10000 ppm for 17 weeks caused slight to moderate swelling of parenchymal cells.

\section{Tissue residue of essential oils}

Accumulation of essential oils in the body is unlikely due to their fast metabolic conversion and excretion. However, when continuously feeding diets containing essential oils to chickens without withdrawal periods, essential oil constituents can be deposited in various tissues. Botsoglou et al. (2002) showed that essential oils can be deposited in a dose-dependent fashion. On the other hand, their impact on sensory quality of poultry meat is regarded as minor (Vogt and Rauch, 1991). Essential oils deposited in poultry tissue can be consumed by humans. Whether this consumption of essential oils with poultry meat will evoke negative effects needs to be assessed. It should however be emphasized that the compounds, thymol, carvacrol, cinnamaldehyde, and $\beta$-ionone, are given 'GRAS' status by the Flavor and Extract Manufacturers' Association (FEMA) and the Food and Drug Administration (FDA) (Furia and Bellanca, 1975), implying their use safe.

\section{Microflora, fat digestibility and essential oils}

Schaedler (1973) stated that an 'ideal flora' would allow optimum growth performance. Any alteration of the indigenous flora by diet or environment can be deleterious to the host. Extensive reviews (Jukes, 1955; Visek, 1978; March, 1979; Fuller, 1989; Vanbelle et al., 1990; Ewing and Cole, 1994; Stavric and Kornegay, $1995)$ on the role of microflora on animal performance support the view of Schaedler (1973). It was thus assumed that dietary essential oils could have growth-enhancing 
effects due to their actions on the intestinal microflora. This implies that the efficacy of essential oils on animal performance could be affected by the microbial status. In other words, their effects on germ-free chicks are expected to be negligible at best. This statement is backed up by as study of Coates et al. (1963) who demonstrated that dietary penicillin had no apparent effect on growth performance by germ-free chicks. There are also indications showing that dietary antibiotics may not play a significant role in growth performance when birds are kept in a clean environment and fed well-balanced diets. On the other hand, when birds are challenged by gut microbial loads, then dietary essential oils can positively affect growth performance. This concept has been tested as to the efficacy of dietary antibiotics in counteracting the negative effects of rye in chickens (MacAuliffe and McGinnis, 1971; Wagner and Thomas, 1978; Patel et al., 1980; Antonoiu and Marquardt, 1982; Honeyfield et al., 1983). It is well known that feeding rye to chickens increases number of bacteria in the intestine (Wagner and Thomas, 1978; Feighner and_Dashkevicz, 1987) so that growth-enhancing property of dietary antibiotics can be seen. The microbial overpopulation by rye feeding is attributed to its pentosan contents which raise intestinal viscosity. It is suggested that intestinal viscosity, caused by ingestion of soluble fiber, impairs the normal digestion process so that more undigested materials travel to distal parts where they can be used as substrates by the microflora. Increased microbial populations are also apparent in the upper part of the small intestine (Smits et al., 1998) where digestion occurs.

There is evidence (Kussaibati et al., 1982; Smits et al., 1998) that the intestinal microflora has a pronounced impact on fat digestion in chickens because of a lowered bile acid availability. Bile salts are known to be a limiting factor for efficient fat digestion (Krogdahl, 1985). Redinger et al. (1973) found that $87 \%$ of total bile acid pool is present in the intestine. Birds are well equipped with the efficient reabsorption of bile acids, the absorption be as high as $93 \%$ (Hurwitz et al., 1973). This reduces the need of hepatic synthesis of bile acids in order to maintain the bile salts pool in the chicken (Freeman, 1984), and can be an important factor especially in young chicks with limited secretion of bile acids (Kussaibati et al., 1982). Ketels (1994) reported that when the bile concentration is lower than 50 to $60 \mu \mathrm{mol} / \mathrm{g}$ of fatfree matter, the digestibility of tallow will be impaired.

It has been reported that the intestinal microflora can hydrolyse bile salts (Freigher and Dashkevicz, 1987). This flora includes Clostridium, Lactobacillus, Peptostreptococcus, Bifidobacterium, Fusobacterium, Eubacterium, Streptococcus, and Bacterioids (Feighner and Dashkevicz, 1987). Freigher and Dashkevicz (1988) 
reported that chickens fed on a diet rich in rye exhibited an 18-fold increase in bacterial cholytaurin hydrolase activity in ileal homogenates when compared their counterparts fed on corn diet. Unconjugated bile acids are less effective in forming micelles (Smits et al., 1998). It is thus expected that feeding soluble fiber to chicken can severely affect fat digestion. Smits et al. (1998) suggested that carboxymethylcellulose (CMC), which is a non-fermentable soluble fiber, can impair re-absorption of bile acids, leading to a lower bile acid availability. The extra fecal loss of bile acids can occur by either direct binding to the soluble fiber (Smits et al., 1998) or by less efficient utilization of unconjugated bile acids (Angelin et al., 1982) as only $40-50 \%$ of the deconjugated bile acids are recycled. In this regard, with antimicrobial agents fat digestion may be improved. Antoniou and Marquardt (1982) proposed that fat digestibility can be a good index of the nutritive value of cereals such as barley and rye. Consequently, fat digestion can reflect the efficacy of dietary essential oils under this circumstance.

Table 5. Effect of dietary essential oils on ileal viscosity and fat digestibility in female broiler chickens fed on diets containing CMC

\begin{tabular}{|c|c|c|c|c|c|c|}
\hline & Base & $\mathrm{CMC}$ & $\begin{array}{l}\mathrm{CMC}+ \\
\text { thymol }\end{array}$ & $\begin{array}{l}\mathrm{CMC}+ \\
\text { cinnam- } \\
\text { aldehyde }\end{array}$ & $\begin{array}{c}\mathrm{CMC}+ \\
\text { Commercial } \\
\text { preparation }{ }^{1}\end{array}$ & SEM $^{2}$ \\
\hline Viscosity, mPa.s & $1.56^{3}$ & 8.20 & 8.83 & 9.17 & 10.30 & 2.076 \\
\hline $\begin{array}{l}\text { Fat digestion, } \\
\% \text { of intake }\end{array}$ & $88.9 a$ & $86.8 b$ & $86.7 b$ & 87.2ab & $87.5 \mathrm{ab}$ & 0.432 \\
\hline $\begin{array}{l}{ }^{1} \text { CRINA }^{\circledR} \text { Poultry } \\
{ }^{2} \text { SEM }=\text { standard } \\
{ }^{3} \text { Values are mean }\end{array}$ & $\begin{array}{l}\text { NA S. A. } \\
\text { of mea } \\
3 \text { replic }\end{array}$ & Nobel, & and, Swi & land). & & \\
\hline
\end{tabular}

Besides the putative, positive antimicrobial effect of essential oils affecting fat digestibility in chickens fed on diets containing soluble fiber, there might be a direct effect of essential oils on either secreting or synthesizing bile acids. The latter holds true for essential oils classified as phenylpropanoids and is highlighted by the effects of capsaicin and piperine on either bile secretion or cholesterol $7 \alpha$-hydroxylase 
activity (Bhat and Chandrasekhara 1987; Srinivasan and Sambaiah, 1991). Cinnamaldehyde, a phenylpropanoid and a major essential oil component of cinnamon essential oils, shares a common synthetic pathway with capsaicin and piperine and thus affect bile acid metabolism. Indeed, Harada and Yano (1975) reported that cinnamaldehyde increased bile secretion in rats. Whether this effect extends to carvacrol, thymol and $\beta$-ionone awaits further study.

We have recently investigated whether dietary essential oils could counteract the CMC-suppressive effect on fat digestibility in female broiler chickens (Chapter 5). We supplemented either thymol, cinnamaldehyde or a commercial preparation at the level of $100 \mathrm{ppm}$ to a CMC-containing diet and found that cinnamaldehyde and the commercial preparation overcame the CMC effect (Table 5). Unexpectedly, thymol did not show any effect on fat digestibility. The improvement of fat digestibility as induced by cinnamaldehyde was not mediated by a lowering of ileal viscosity as shown in Table 5. At present, a clear explanation for the result is not readily available, but it is certain at this point that two principles, thymol and cinnamaldehyde, have different biological effects in female broiler chickens.

\section{Summary}

It can be summarized that the antimicrobial activities of essential oils originating from plants have been well documented while their toxicological effects are seen only at very high doses. Antioxidant and hypocholesterolemic effects have been reported in chickens. The characteristic flavor of essential oils might play role in poultry performance, but various studies need to be confirmed. Essential oils may stimulate the digestion process. It appears that individual compounds of an essential oil have a wide range of activities. They may also act in an additive, synergistic and antagonistic way. "The activity" may not only confine to the microflora, but also extend to animal metabolism. Knowing the activity of individual compounds is useful to formulate mixtures of compounds so as to enhance efficacy.

In conclusion, dietary essential oils may be used as alternatives to antibiotics, but whether their effects on growth performance are a consequence of antimicrobial activity needs to be studied further. 


\section{References}

Abramovici, A., and P. Rachmuth-Roizman, 1983. Molecular structure-teratogenicity relationships of some fragrance additives. Toxicology 29: 143-156.

Adam, K., A. Sivropoulou, S. Kokkini, T. Lanara, and M. Arsenakis, 1998. Antifungal activities of Origanum vulgare subsp. hirtum, Mentha spicata, Lavandula angustifolia, and Salvia fruticosa essential oils against human pathogenic fungi. Journal of Agricultural and Food Chemistry 46: 1739-1745.

Aeschbach, R., J. Löliger, B. C. Scott, A. Murcia, J. Butler, B. Halliwell, and O. I. Aruoma, 1994. Antioxidant actions of thymol, carvacrol, 6-gingerol, zingerone and hyroxytyrosol. Food and Chemical Toxicology 32: 31-36.

Ali-Shtayeh, M. S., M. A. Al-Nuri, R. M.-R. Yaghmour, and Y. R. Faidi, 1997. Antimicrobial activity of Micromeria nervosa from the Palestinian area. Journal of Ethnopharmacology 58: 143-147.

Allen, P. C., J. Lydon, and H. D. Danforth, 1997. Effects of components of Artemisia annua on coccidia infections in chickens. Poultry Science 76: 1156-1163.

Angelin, B., I. Bjorkhem, K. Einarsson, and S. Ewerth, 1982. Hepatic uptake of bile acids in man. Fasting and postprandial concentrations of individual bile acids in portal venous and systemic blood serum. Journal of Clinical Investigation 70: 724-731.

Anonymous, 1997. CRINA ${ }^{\circledR}$ HC for poultry based on essential oils. Akzo Nobel.

Anonymous, 1998. Feed additives: the added value to feed. NEFATO Vereniging van Netherlandse Fabrikanten van Voedertoevoegingen. Aalsmeer.

Antoniou, T., and R. Marquardt, 1982. Utilization of rye diets by chicks as affected by lipid type and level of penicillin supplementation. Poultry Science 61: 107-116.

Aruoma, O. I., 1997. Extracts as antioxidant prophylactic agents. International News on Fats, Oils and Related Materials 8: 1236-1242.

Agricultural Research Service (ARS), Dr. Duke's phytochemical and ethnobotanical databases. http://www.ars-grin.gov/duke/ Assessed at June, 2002.

Austgulen, L.-T., E. Solheim, and R. R. Scheline, 1987. Metabolism in rats of $\rho$-cymene derivatives: carvacrol and thymol. Pharmacology and Toxicology 61: 98-102.

Bang, K.-H., D.-W. Lee, H.-M. Park, and Y.-H. Rhee, 2000. Inhibition of fungal cell wall synthesizing enzymes by trans-cinnamaldehyde. Bioscience, Biotechnology, and Biochemistry 64: 10611063.

Baratta M. T., H. J. D. Dorman, S. G. Deans, D. M. Biondi, and G. Ruberto, 1998. Chemical composition, antimicrobial and antioxidant activity of laurel, sage, rosemary, oregano and coriander essential oils. Journal of Essential Oil Research 10: 618-627. 
Bassett, R., 2000. Oregano's positive impact on poultry production. World Poultry 16 (9): 31-34.

Bhat, B. G., and N. Chandrasekhara, 1987. Effect of black pepper and piperine on bile secretion and composition in rats. Nahrung 31: 913-916.

Bhat, B. G., K. Sambaiah, and N. Chandrasekhara, 1985. The effect of feeding fenugreek and ginger on bile composition in the albino rat. Nutritional Reports International 32: 1145-1151.

Bhat, B. G., M. R. Srinivasan, and N. Chandrasekhara, 1984. Influence of curcumin and capsaicin on the composition and secretion of bile in rats. Journal of Food Science and Technology 21: 225-227.

Biondi, D., P. Cianci, C. Geraci, G. Ruberto, and M. Piattelli, 1993. Antimicrobial activity and chemical composition of essential oils from Sicilian aromatic plants. Flavour and Fragrance Journal 8: 331-337.

Botsoglou, N. A., A. L. Yannakopoulos, D. J. Fletouris, A. S. Tserveni-Goussi, and P. D. Fortomaris, 1997. Effect of dietary thyme on the oxidative stability of egg yolk. Journal of Agricultural and Food Chemistry 45: 3711-3716.

Botsoglou, N. A., P. Florou-Paner, E. Christaki, D. J. Fletouris, and A. B. Spais, 2002. Effect of dietary oregano essential oil on performance of chickens and on iron-induced lipid oxidation of breast, thigh and abdominal fat tissues. British Poultry Science 43: 223-230.

Bowles, B. L., and A. J. Miller, 1993. Antibotulinal properties of selected aromatic and aliphatic aldehydes. Journal of Food Protection 56: 788-794.

Case, G. L., L. He, H. Mo, and C. E. Elson, 1995. Induction of geranyl pyrophosphate pyrophosphatase activity by cholesterol-suppressive isoprenoids. Lipids 30: 357-359.

Clegg, R. J., B. Middleton, G. D. Bell, and D. A. White, 1980. Inhibition of hepatic cholesterol synthesis and S-3-hydroxy-3-methylglutaryl-CoA reductase by mono and bicyclic monoterpenes administered in vivo. Biochemical Pharmacology 29: 2125-2127.

Coates, M. E., C. D. Dickinson, G. F. Harrison, S. K. Kon, S. H. Cummins, and W. F. J. Cuthbertson, 1951. Mode of action of antibiotics in stimulating growth of chicks. Nature 168: 332.

Coates, M. E., R. Fuller, G. F. Harrison, M. Lev, and S. F. Suffolk, 1963. A comparison of the growth of chicks in the Gustafsson germ-free apparatus and in a conventional environment, with and without dietary supplements of penicillin. British Journal of Nutrition 17: 141-150.

Conner, D. E., 1993. Naturally occurring compounds. Pages 441-468 in: Antimicrobials in Foods, Davidson, P. M., and A. L. Branen, eds. Dekker, New York.

Cooke, C. J., M. N. Nanjee, P. Dewey, J. A. Cooper, G. J. Miller, and N. E. Miller, 1998. Plant monoterpenes do not raise plasma high-density-lipoprotein concentrations in humans. American Journal of Clinical Nutrition 68: 1042-1045. 
Cosentino, S., C. I. G. Tuberoso, B. Pisano, M. Satta, V. Mascia, E. Arzedi, and F. Plamas, 1999. Invitro antimicrobial activity and chemical composition of Sardinian Thymus essential oils. Letters in Applied Microbiology 29: 130-135.

Craig, W. J., 1999. Health-promoting properties of common herbs. American Journal of Clinical Nutrition 70 (suppl): 491S-499S.

Crowell, P. L., 1999. Prevention and therapy of cancer by dietary monoterpenes. Journal of Nutrition 129: 775S-778S.

Deans, S. G., and G. Ritchie, 1987. Antibacterial properties of plant essential oils. International Journal of Food Microbiology 5: 165-180.

Deans, S. G., and P. G. Waterman, 1993. Biological activity of volatile oils. Pages 97-111 In: Volatile oil crops, Hay, R. K. M., and P. G. Waterman, Eds. Longman Scientific \& Technical, Essex.

Deyoe, C. W., R. E. Davies, R. Krishnan, R. Khaund, and J. R. Couch, 1962. Studies on the taste preference of the chick. Poultry Science 41: 781-784.

Didry, N., L. Dubreuil, and M. Pinkas, 1994. Activity of thymol, carvacrol, cinnamaldehyde and eugenol on oral bacteria. Pharmaceutica Acta Helvetiae 69: 25-28.

Dorman, H. J. D., and S. G. Deans, 2000. Antimicrobial agents from plants: antibacterial activity of plant volatile oils. Journal of Applied Microbiology 83: 308-316.

Duke, J.A., 1986. CRC handbook of medicinal herbs. CRC press, Florida.

Economou, K. D., V. Oreopoulou, and C. D. Thomopoulos, 1991. Antioxidant activity of some plant extracts of the family Labiatae. Journal of the American Oil Chemists' Society 66: 792-799.

Elson, C. E., and A. A. Qureshi, 1995. Coupling the cholesterol- and tumor-suppressive actions of palm oil to the impact of its minor constituents on 3-hydroxy-3-methylglutaryl coenzyme A reductase activity. Prostaglandings Leukotrienes and Essential fatty acids 52: 205-208.

Elson, C. E., 1996. Novel lipids and cancer. Isoprenoids and other phytochemicals. Advances in experimental medicine and biology 399: 71-86.

Elson, C. E., G. L. Underbakke, P. Hanson, E. Shrago, R. H. Wainberg, and A. A. Qureshi, 1989. Impact of lemongrass oil, an essential oil, on serum cholesterol. Lipids 24: 677-679.

Evans, J. W., M. S. Plunkett, and M. J. Banfield, 2001. Effect of an essential oil blend on coccidiosis in broiler chicks. Poultry Science 80 (suppl. 1): 258 (Abstract).

Ewing, W. N., and D. J. A. Cole, 1994. Lactic acid bacteria. Pages 91-112 in: The living gut: an introduction to microorganisms in nutrition. Ewing, W. N., and D. J. A. Cole, eds. Context, Dungannon.

Farag, R. S., A Z. M. A. Badei, F. M. Hewedi, and G. S. A. El-Baroty, 1989a. Antioxidant activity of some spice essential oils on linoleic acid oxidation in aqueous media. Journal of the American Oil Chemists Society 66: 792-799. 
Farag, R. S., Z. Y. Daw, and S. H. Abo-Raya, 1989b. Influence of some spice essential oils on Aspergillus parasiticus growth and production of aflatoxins in a synthetic medium. Journal of Food Science 54: 74-76.

Farag, R. S., Z. Y. Daw, F. M. Hewed, and G. S. A. El-Baroty, 1989c. Antimicrobial activity of some Egyptian spice essential oils. Journal of Food Protection 52: 665-667.

Feighner, S. D., and M. P. Dashkevicz, 1987. Subtherapeutic levels of antibiotics in poultry feeds and their effects on weight gain, feed efficiency, and bacterial cholytaurine hydrolase activity. Applied and Environmental Microbiology 53: 331-336.

Feighner, S. D., and M. P. Dashkevicz, 1988. Effect of dietary carbohydrates on bacterial cholytaurin hydrolase in poultry intestinal homogenates. Applied and Environmental Microbiology 54: 337-342.

Ferhout, H., J. Bohatier, J. Guillot, and J. C. Chalchat, 1999. Antifungal activity of selected essential oils, cinnamaldehyde and carvacrol against Malassezia furfur and Candida albicans. Journal of Essential Oil Research 11: 119-129.

Fitch, M. E., A. R. Mangels, W. A. Altmann, M. E. Hawary, A. A. Qureshi, and C. E. Elson, 1989. Microbiological screening of mevalonate-suppressive minor plant constituents. Journal of Agricultural and Food Chemistry 37: 687-691.

Freeman, C. P., 1984. The digestion, absorption and transport of fats - Non-ruminants. Pages 105122 in: Fats in animal nutrition, Wiseman, J., ed. Butterworths, London.

Friedrich, H., 1976. Phenylpropanoid constituents of essential oils. Lloydia 39: 1-7.

Fuller, R., 1989. Probiotics in man and animals. Journal of Applied Bacteriology 66: 365-378.

Furia, T. E., and N. Bellanca, 1975. Fenaroli's handbook of flavor ingredients. Vol 2. Adapted from the Italian language works of Prof. Dr. Giovanni Fenaroli. 2nd edn. CRC Press, Ohio.

Goldstein, J. L., and M. S. Brown, 1990. Regulation of the mevalonate pathway. Nature 343: 425-430.

Gueldner, R., D. M. Wilson, and A. R. Heidt, 1985. Volatile compounds inhibiting Aspergillus flavus. Journal of Agricultural and Food Chemistry 33: 411-413.

Hagan, E. C., W. H. Hansen, O. G. Fitzhugh, P. M. Jenner, W. I. Jones, J. M. Taylor, E. L. Long, A. A. Nelson, and J. B. Brouwer, 1967. Food flavourings and compounds of related structure. II. Subacute and chronic toxicity. Food and Cosmetics Toxicology 5: 141-157.

Hammer, K. A., C. F. Carson, and T. V. Riley, 1999. Antimicrobial activity of essential oils and other plants extracts. Journal of Applied Microbiology 86: 985-990.

Harada, M., and S. Yano, 1975. Pharmacological studies on Chinese cinnamon. II. Effects of cinnamaldehyde on the cardiovascular and digestive system. Chemical and Pharmaceutical Bulletin 23: 941-947.

Hay, R. K. M., and P. G. Waterman, 1993. Volatile oil crops: their biology, biochemistry and production. Longman Scientific \& Technical, Essex. 
Hébert C. D., J. Yuan, and M. P. Dieter, 1994. Comparison of the toxicity of cinnamaldehyde when administered by microencapsulation in feed or by corn oil gavage. Food and Chemical Toxicology 32: 1107-1115.

Helander, I. M., H.-L. Alakomi, K. Latva-Kala, T, Mattila-Sandholm, I. Pol, E. J. Smid, L. G. M. Gorris, and A. Von Wright, 1998. Characterization of the action of selected essential oil components on Gram-negative bacteria. Journal of Agricultural and Food Chemistry 46: 3590-3595.

Hill, D. C., H. D. Branison, and S. J. Slinger, 1952. Influence of environment on the growth response of chicks to penicillin. Poultry Science 31: 920 (Abstract).

Honeyfield, D. C., J. A. Froseth, and J. McGinnis, 1983. Comparative feeding value of rye for poultry and swine. Nutritional Reports International 28: 1253-1260.

Hood, R. L., W. M. Bailey, and D. Svoronos, 1978. The effect of dietary monoterpenes on the cholesterol level of eggs. Poultry Science 57: 304-306.

Hoskins, J. A., 1984. The occurrence, metabolism and toxicity of cinnamic acid and related compounds. Journal of Applied Toxicology 4: 283-292.

Hurwitz, S., A. Bar, M. Katz, D. Sklan, and P. Budowski, 1973. Absorption and secretion of fatty acids and bile acids in the intestine of the laying fowl. Journal of Nutrition 103: 543-547.

Ide, H., and S. Toki, 1970. Metabolism of $\beta$-ionone. Isolation, characterization and identification of the metabolites in the urine of rabbits. Biochemical Journal 119: 281-287.

Igimi, H., M. Nishimura, R. Kodama, and H. Ide, 1974. Studies on the metabolism of $d$-limonene ( $p$ mentha-1,8-diene) I. The absorption, distribution and excretion of $d$-limonene in rats. Xenobiotica 4: 77-84.

Jamroz, D., and C. Kamel, 2002. Plant extracts enhance broiler performance. Journal of Animal Science 80 (Suppl. 1): 41 (Abstract).

Janssen, A. M., J. J. C. Scheffer, and A. B. Svendsen, 1987. Antimicrobial activities of essential oils. Pharmaceutisch Weekblad (Sci) 9: 193-197.

Jenner, P. M., E. C. Hagan, J. M. Taylor, E. L. Cook, and O. G. Fitzhugh, 1964. Food flavorings and compounds of related structure. I. Acute oral toxicity. Food and Cosmetics Toxicology 2: 327343.

Jukes, T. H., 1955. Antibiotics in Nutrition. Medical Encyclopedia. New York.

Juven, B. J., J. Kanner, F. Schved, and H. Weisslowicz, 1994. Factors that interact with the antibacterial action of thyme essential oil and its active constituents. Journal of Applied Bacteriology 76: 626-631.

Kamel, C., 2001. Tracing modes of action and the roles of plant extracts in non-ruminants. Pages 135-150 in: Recent advances in animal nutrition. Garnsworthy, P. C., and J. Wiseman, eds. Nottingham University Press, Nottingham. 
Ketels, E., 1994. The metabolizable energy values of fats in poultry diets. Ph.D. thesis. University of Gent, Belgium.

Kodama, R., K. Noda, and H. Ide, 1974. Studies on the metabolism of $d$-limonene ( $p$-mentha-1,8diene) II. The metabolic fate of $d$-limonene in rabbits. Xenobiotica 4: 85-95.

Köhler, B., 1997. Effects on gut microflora. Akzo Nobel.

Kohlert, C., I. Van Rensen, R. März, G. Schindler, E. U. Graefe, and M. Veit, 2000. Bioavailability and pharmacokinetics of natural volatile terpenes in animals and humans. Planta Medica 66: 495505.

Krause, E. L., and W. Ternes, 1999. Bioavailability of the antioxidative thyme compounds thymol and $\rho$-cymene-2,3-diol in eggs. European Food Research and Technology 209: 140-144.

Kreydiyyeh, S. I., J. Usta, and R. Copti, 2000. Effect of cinnamon, clove and some of their constituents on the Na+-K+-ATPase activity and alanine absorption in the rat jejunum. Food and Chemical Toxicology 38: 755-762

Krogdahl, A., 1985. Digestion and absorption of lipids in poultry. Journal of Nutrition 115: 675-685.

Kurita, N., M. Miyaji, R. Kurane, Y. Takahara, and K. Ichimura, 1979. Antifungal activity and molecular orbital energies of aldehyde compounds from oils of higher plants. Agricultural and Biological Chemistry 43: 2365-2371.

Kussaibati, R., J. Guillaume, B. Leclercq, and J. P. Lafont, 1982. Effects of the intestinal microflora and added bile salts on the metabolisable energy and digestibility of saturated fats in the chicken. Archiv für Geflügelkunde 46: 42-46.

Langhout, P., 2000. New additives for broiler chickens. World poultry 16 (No 3): 22-27.

Lawrence, B.M., and R. J. Reynolds, 1984. Progress in essential oils. Perfumer and Flavorist 9: 2331.

Lee, H.-S., and Y.-J. Ahn, 1998. Growth-inhibiting effects of Cinnamomum cassia bark-derived materials on human intestinal bacteria. Journal of Agricultural and Food Chemistry 46: 8-12.

Lis-Blachin, M., G. Buchbauer, T. Hirtenlehner, and M. Resch, 1998. Antimicrobial activity of Pelargonium essential oils added to a quiche filling as a model food system. Letters in Applied Microbiology 27: 207-210.

Lopez-Bote, C. J., J. I. Gray, E. A. Gomaa, and C. J. Flegal, 1998. Effect of dietary administration of oil extracts from rosemary and sage on lipid oxidation in broiler meat. British Poultry Science 39: 235-240.

Loza-Tavera, H., 1999. Monoterpenes in essential oils: Biosynthesis and properties. Advances in Experimental Medicine and Biology 464: 49-62.

MacAulliffe, T., and J. McGinnis, 1971. Effect of antibiotic supplements to diets containing rye on chick growth. Poultry Science 50: 1130-1134. 
Manou, I., L. Bouillard, M. J. Devleeschouwer, and A. O. Barel, 1998. Evaluation of the preservative properties of Thymus vulgaris essential oil in topically applied formulations under a challenge test. Journal of Applied Microbiology 84: 368-376.

March, B. E., 1979. The host and its microflora: An ecological unit. Journal of Animal Science 49: 857867.

McIntosh, F. M., C. J. Newbold, R. Losa, P. Williams, and R. J. Wallace, 2000. Effects of essential oils on rumen fermentation. Reproduction, Nutrition and Development 40: 221 (Abstract).

Mellor, S., 2000a. Antibiotics are not the only growth promoters. World Poultry 16 (No 1): 14-15.

Mellor, S., 2000b. Nutraceuticals - alternatives to antibiotics. World Poultry 16 (No 2): 30-33.

Middleton, A., B. Middleton, D. A. White, and G. D. Bell, 1979. The effects of monocyclic terpenes on hepatic S-3-hydroxy-3-methylglutaryl-Coenzyme A reductase in vivo. Biochemical Society Transactions 7: 407-408.

Middleton, B., and K.-P. Hui, 1982. Inhibition of hepatic S-3-hydroxy-3-methylglutaryl-CoA reductase and in vivo rates of lipogenesis by a mixture of pure cyclic monoterpenes. Biochemical Pharmacology 31: 2897-2901.

Moleyar, V., and P. Narasimham, 1992. Antibacterial activity of essential oil components. International Journal of Food Microbiology 16: 337-342.

Montes-Belmont, R., and M. Carvajal, 1998. Control of Aspergillus flavus in maize with plant essential oils and their components. Journal of Food Protection 61: 616-619.

Moran, E. T. Jr., 1982. Comparative nutrition of fowl and swine. The gastrointestinal systems. University of Guelph.

National Toxicology Program (NTP), 1989. Draft report. Support for chemical nomination and selection process of the national toxicology program. Summary of data Cinnamaldehyde. http://ntp-server.niehs.nih.gov/htdocs/chem_background/ExecSumm/Cinnamaldehyde.htm/ Accessed at May, 2002.

Naves, Y. R., 1971. Some developments in the chemistry of ionones and their derivatives - a subject review. Journal of the Society of Cosmetics Chemistry 22: 439-459.

Nelson, R. R. S., 1997. In-vitro activities of five plant essential oils against methicillin-resistant Staphylococcus aureus and vancomycin-resistant Enterococcus faecium. Journal of Antimicrobial and Chemotherapy 40: 305-306.

Oh, H. K., T. Sakai, M. B. Jones, and W. M. Longhurst, 1967. Effect of various essential oils isolated from Douglas fir needles upon sheep and deer rumen microbial activity. Applied Microbiology 15: 777-784.

Oh, H. K., M. B. Jones, and W. M. Longhurst, 1968. Comparison of rumen microbial inhibition resulting from various essential oils isolated from relatively unpalatable plant species. Applied Microbiology 16: 39-44. 
Ouattara, B., R. E. Simard, R. A. Holley, G. J.-P. Piette, and A. Begin, 1997. Antibacterial activity of selected fatty acids and essential oils against six meat spoilage organisms. International Journal of Food Microbiology 37: 155-162.

Oyen, L. P. A., and N. X. Dung, 1999. Essential-oil plants. Oyen, L. P. A., and N. X. Dung (Eds). Backhuys Publishers, Leiden.

Paster, N., B. J. Juven, E. Shaaya, M. Menasherov, R. Nitzan, H. Weisslowicz, and U. Ravid, 1990. Inhibitory effect of oregano and thyme essential oils on moulds and foodborne bacteria. Letters in Applied Microbiology 11: 33-37.

Patel, M. B., M. S. Jami, and J. McGinnis, 1980. Effect of gamma irradiation, penicillin, and/or pectic enzyme on chick growth depression and fecal stickiness caused by rye, citrus pectin, and guar gum. Poultry Science 59: 2105-2110.

Peters, M. M. C. G., and J. Caldwell, 1994. Studies on trans-cinnamaldehyde. 1. The influence of dose size and sex on its disposition in the rat and mouse. Food and Chemical Toxicology 32: 869-876.

Platel, K., and K. Srinivasan, 1996. Influence of dietary spices or their active principles on digestive enzymes of small intestinal mucosa in rats. International Journal of Food Sciences and Nutrition 47: 55-59.

Platel, K., and K. Srinivasan, 2000. Influence of dietary spices and their active principles on pancreatic digestive enzymes in albino rats. Nahrung 44: 42-46.

Pradeep, K. U., and P. Geervani, 1994. Influence of spices on protein utilization of winged bean (Psophocarpus tetragonolobus) and horsegram (Dolichos biflorus). Plant Foods for Human Nutrition 46: 187-193.

Pradeep, K. U., P. Geervani, and B. O. Eggum, 1991. Influence of spices on utilization of sorghum and chickpea protein. Plant Foods for Human Nutrition 41: 269-276.

Qureshi, A. A., J. W. Lehmann, and D. M. Peterson, 1996. Amaranth and its oil inhibit cholesterol biosynthesis in 6-week-old female chickens. Journal of Nutrition 126: 1972-1978.

Qureshi, A. A., W. R. Mangels, Z. Z. Din, and C. E. Elson, 1988. Inhibition of hepatic mevalonate biosynthesis by the monoterpene, d-limonene. Journal of Agricultural and Food Chemistry 36: 1220-1224.

Qureshi, A. A., Z. Z. Din, N. Abuirmeileh, W. C. Burger, Y. Ahmad, and C. E. Elson, 1983. Suppression of avian hepatic lipid metabolism by solvent extracts of garlic: Impact on serum lipids. Journal of Nutrition 113: 1746-1755.

Reddy, G. B. S., A. B. Melkhani, G. A. Kalyani, J. V. Rao, A. Shirwaikar, M. Kotian, R. Ramani, K. S. Aithal, A. L. Udupa, G. Bhat, and K. K. Srinivasan, 1991. Chemical and pharmacological investigations of Limnophila conferta and Limnophila heterophylla. International Journal of Pharmacognosy 29: 145-153. 
Redinger, R. N., A. H. Hermann, and D. M. Small, 1973. Primate biliary physiology. X. Effects of diet and fasting on biliary lipid secretion and relative composition and bile salt metabolism in the rhesus monkey. Gastroenterology 64: 610-621.

Sambaiah, K., and K. Srinivasan, 1991. Secretion and composition of bile in rats fed diets containing spices. Journal of Food Science and Technology 28: 35-38.

Schaedler, R. W., 1973. The relationship between the host and its intestinal microflora. Proceedings of the Nutrition Society 32: 41-47.

Schilcher, H., 1985. Effects and side-effects of essential oils. Pages 217-231 in: Proceedings of the 15th international symposium on essential oils. Noordwijkerhout. The Netherlands.

Scholl, J. P., R. G. Kelsey, and F. Shafizadeh, 1977. Involvement of volatile compounds of Artemisia in browse preference by mule deer. Biochemical Systematics and Ecology 5: 291-295.

Schwarz, K., H. Ernst, and W. Ternes, 1996. Evaluation of antioxidative constituents from thyme. Journal of the Science of Food and Agriculture 70: 217-223.

Seigler, D. S., 1998. Phenylpropanoids. Pages 106-129 in: Plant secondary metabolism D. S. Seigler ed. Kluwer Academic Publishers, Boston.

Shapiro, S., and B. Guggenheim, 1995. The action of thymol on oral bacteria. Oral Microbiology and Immunology 10: 241-246.

Sivropoulou, A., E. Papanikolaou, C. Nikolaou, S. Kokkini, T. Lanaras, and M. Arsenakis, 1996. Antimicrobial and cytotoxic activities of Origanum essential oils. Journal of Agricultural and Food Chemistry 44: 1202-1205.

Smith, C. K., C. A. Moore, E. N. Elahi, A. T. S. Smart, and S. A. M. Hotchkiss, 2000. Human skin absorption and metabolism of the contact allergens, cinnamic aldehyde, and cinnamic alcohol. Toxicology and Applied Pharmacology 168: 189-199.

Smith-Palmer, A., J. Stewart, and L. Fyfe, 1998. Antimicrobial properties of plant essential oils and essences against five important food-borne pathogens. Letters in Applied Microbiology 26: 118-122.

Smits, C. H. M., and G. Annison, 1997. Non-starch plant polysaccharides in broiler nutrition-towards a physiologically valid approach to their determination. World's Poultry Science Journal 52: 203221.

Smits, C. H. M., A. Veldman, M. W. A. Verstegen, and A. C. Beynen, 1997. Dietary carboxymethylcellulose with high instead of low viscosity reduces macronutrient digestion in broiler chickens. Journal of Nutrition 127: 483-487.

Smits, C. H. M., A. Veldman, H. J. Verkade, and A. C. Beynen, 1998. The inhibitory effect of carboxymethylcellulose with high viscosity on lipid absorption in broiler chickens coincides with reduced bile salt concentration and raised microbial numbers in the small intestine. Poultry Science 77: 1534-1539. 
Srinivasan, K., and K., Sambaiah, 1991. The effect of spices on cholesterol $7 \alpha$-hydroxylase activity and on serum and hepatic cholesterol levels in the rat. International Journal for Vitamin and Nutrition Research 61: 364-369.

Stammati, A., P. Bonsi, F. Zucco, R. Moezelaar, H.-L. Alakomi, and A. Von Wright, 1999. Toxicity of selected plant volatiles in microbial and mammalian short-term assays. Food and Chemical Toxicology 37: 813-823.

Starvric, S., and E. T. Kornegay, 1995. Microbial probiotics for pigs and poultry. Pages 205-231 in: Biotechnology in animal feeds and animal feeding. Wallace, R. J., and A. Chesson. eds. VCH, Weinheim.

Stiles, J. C., W. Sparks, and R. A. Ronzio, 1995. The inhibition of Candida albicans by oregano. Journal of Applied Nutrition 47: 96-102.

Takada, M., I. Agata, M. Sakamoto, N. Yagi, and N. Hayashi, 1979. On the metabolic detoxication of thymol in rabbit and man. Journal of Toxicological Sciences 4: 341-350.

Taylor, D. J., 2001. Effects of antimicrobials and their alternatives. British Poultry Science 42 (suppl): 67-68.

Teissedre, P. L., and A. L. Waterhouse, 2000. Inhibition of oxidation of human low-density lipoproteins by phenolic substances in different essential oils varieties. Journal of Agricultural and Food Chemistry 48: 3801-3805.

Vanbelle, M., E. Teller, and M. Focant, 1990. Probiotics in animal nutrition: a review. Archives of Animal Nutrition 40: 543-567.

Varel, V. H., 2002. Carvacrol and thymol reduce swine waste odor and pathogens: Stability of oils. Current Microbiology 44: 38-43.

Veldman, A., and H. Enting, 1996. Effects of crina HC 737 in feed on broiler performance and digestive physiology and microbiology. CLO-institute for Animal Nutrition "De schothost".

Visek, W. J., 1978. The mode of growth promotion by antibiotics. Journal of Animal Science 46: 14471469.

Vogt, H., and H.-W. Rauch, 1991. Der einsatz einzelner ätherischer öle im geflügelmastfutter. Lanbauforschung Völkenrode 41: 94-97.

Wagner, D. D., and O. P. Thomas, 1978. Influence of diets containing rye or pectin on the intestinal flora of chicks. Poultry Science 57: 971-975.

Waterman, P. G., 1993. The chemistry of volatile oils. Pages 47-61 in: Volatile oils: their biology, biochemistry and production. Hay, R. K. M., and P. G. Waterman, eds. Longman Scientific and Technical, Essex.

Wenk, C., 2000. Recent advances in animal feed additives such as metabolic modifiers, antimicrobial agents, probiotics, enzymes and highly available minerals. Review. Asian-Australasian Journal of Animal Sciences 13: 86-95. 
Youdim, K. A., and S. G. Deans, 1999a. Beneficial effects of thyme oil on age-related changes in the phospholipid $\mathrm{C}_{20}$ and $\mathrm{C}_{22}$ polyunsaturated fatty acid composition of various rat tissues. Biochimica et Biophysica Acta 1438: 140-146.

Youdim, K. A., and S. G. Deans, 1999b. Dietary supplementation of thyme (Thymus vulgaris L.) essential oil during the lifetime of the rat: its effects on the antioxidant status in liver, kidney and heart tissues. Mechanisms of Ageing and Development 109: 163-175.

Youdim, K. A., and S. G. Deans, 2000. Effect of thyme oil and thymol dietary supplementation on the antioxidant status and fatty acid composition of the ageing rat brain. British Journal of Nutrition 83: 87-93.

Yu, S. G., N. M. Abuirmeileh, A. A. Qureshi, and C. E. Elson, 1994. Dietary $\beta$-ionone suppresses hepatic 3-hydroxy-3-methylglutaryl coenzyme A reductase activity. Journal of Agricultural and Food Chemistry 42: 1493-1496.

Yuan, J., M. P. Dieter, J. R. Bucher, and C. W. Jameson, 1993. Application of microencapsulation for toxicology studies. III. Bioavailability of microcapsulated cinnamaldehyde. Fundamental and Applied Toxicology 20: 83-87. 
Chapter 2

Effects of dietary essential oil components on growth performance, digestive enzymes and lipid metabolism in female broiler chickens

K.-W. Lee, H. Everts, H.J. Kappert, M. Frehner ${ }^{1}$, R. Losa ${ }^{1}$, A.C. Beynen

Department of Nutrition, Faculty of Veterinary Medicine, Utrecht University, Utrecht, 3508 TD, The Netherlands ${ }^{1}$ CRINA S.A., Akzo Nobel, Gland, Switzerland 


\section{Summary}

The present experiment was conducted to describe the effects of thymol, cinnamaldehyde and a commercial preparation of essential oil components (CRINA ${ }^{\circledR}$ Poultry), in female broilers. Feed and water were provided for ad libitum consumption. Feed intake, weight gain and feed:gain ratio were not different among the treatments. Water intake was significantly lowered by cinnamaldehyde. Relative liver weight ( $\mathrm{g} / 100 \mathrm{~g}$ of body weight) was highest in birds fed thymol, but this was seen only at the age of 21 days and not at 40 days. Patterns of digestive enzymes in pancreatic tissue were similar for the four treatments. Amylase activity in intestinal digesta was highest in chickens fed CRINA ${ }^{\circledR}$ Poultry for 21 days, but the effect had disappeared after 40 days. Ileal digestibility coefficients of starch and protein were high and identical for all treatments. Fatty acid composition of diet was reflected in that of adipose tissue. Plasma lipid concentrations were not changed by any dietary treatment. Thus, the present results show no effect of essential oil constituents on growth performance in female broiler chickens, but it cannot be excluded that positive effects would have been observed under less hygienic environmental conditions or when using a less digestible diet. 


\section{Introduction}

The ban on the use of antibiotics as growth promoters has stimulated the search for alternative feed supplements in animal production. Products containing essential oils are among the alternative growth promoters that are already used in practice. Thymol (5-methyl-2-(1-methylethyl)phenol), a main component of the essential oil from thyme, has antimicrobial properties (Dorman and Deans, 2000). Cinnamaldehyde (3-phenyl-2-propenal) is the main principle of cinnamon essential oil and also has antimicrobial activity (Lee and Ahn, 1998). The two principles have the status of generally recognized as safe (GRAS) which is endorsed by the Flavor and Extract Manufacturers' Association (FEMA) and Food and Drug Administration (FDA) from the U.S.A.

There is a very limited number of controlled studies on the effects of essential oil components on growth performance and digestive enzymes in broiler chickens. However, there is evidence that a blend of essential oil components stimulate secretion of digestive enzymes in chickens (Williams and Losa, 2001). The present study was thus conducted to describe the effects of dietary essential oil components in female broiler chickens on growth performance, digestive enzyme activities and macronutrient digestibilities. In addition, there is evidence that dietary essential oils lower serum cholesterol in chickens (Yu et al., 1994; Case et al., 1995) which prompted us to also determine the concentration of plasma lipids and the fatty acid composition of adipose tissue. It was anticipated that the information obtained would be useful in assessing the value of essential oils in the feed of broiler chickens and could lead to the formulation of hypotheses to be tested in further studies.

\section{Materials and methods}

The experimental protocol was approved by the animal experiments committee of the Utrecht Faculty of Veterinary Medicine.

\section{Animals and diets}

Ninety six, one-day old feather-sexed female broilers (Cobbs) were purchased from a local hatchery. On arrival, they were wing-banded, weighed and randomly 
housed in wire-floored, suspended cages. Continuous lighting was provided throughout the experiment. Ambient temperature was gradually decreased from $32^{\circ} \mathrm{C}$ on Day 0 to $25^{\circ} \mathrm{C}$ on Day 21 and was then kept constant. There were four dietary treatments, each consisting of four replicates. A replicate was identical to a cage with 6 birds so that each treatment had 24 animals. The base diet was in powdered form (Table 1). The corn oil component was added when preparing the four experimental diets. Thymol (99\% purity, Acros Organics, Geel, Belgium) and cinnamaldehyde (99\% purity, Acros Organics) were mixed with corn oil and then added to the base diet so that the final diet contained $5 \%$ of corn oil and $100 \mathrm{ppm}$ of the supplements. One of the experimental diets contained a commercial preparation of essential oil components (CRINA ${ }^{\circledR}$ Poultry, Akzo Nobel, Crina S.A., Gland, Switzerland). According to the manufacturer, CRINA $^{\circledR}$ Poultry contains $29 \%$ of active components, including thymol, but not cinnamaldehyde. Apparently, the preparation acts as digestibility enhancer, stimulating the secretion of endogenous digestive enzymes and balancing the gut microbial ecosystem and thus improving growth performance in poultry (Williams and Losa, 2001). The manufacturer recommended a minimal inclusion level of $50 \mathrm{ppm}$. The commercial preparation was mixed with corn oil and then added to the base diet to attain a dietary concentration of $100 \mathrm{ppm}$, i.e. $29 \mathrm{ppm}$ of active components. The control diet was blended with corn oil only.

Feed and water were provided for ad libitum consumption. Fresh diets were prepared and supplied each day. Prior to feeding, feed leftovers were removed and weighed. Feed and water intake per cage were calculated for periods of one week and were used to calculate feed:gain and water:feed ratios. Individual body weights were recorded each week.

\section{Sampling}

From 14-21 and 33-40 days, birds were fed their diets with chromic oxide added to the level of $0.04 \%$. Total excreta were collected daily during the last three days of the chromic oxide feeding periods. Excreta samples were dried at $60^{\circ} \mathrm{C}$ for three days, weighed and pooled per pen. At the end of the chromic oxide feeding periods, three birds from each pen (12 chicks per treatment) were sampled. After the first 
Table 1 Ingredients and composition of the basal diet

\begin{tabular}{lc}
\hline Ingredients, & $\mathrm{g} / \mathrm{kg}$ \\
\hline Corn, yellow & 300 \\
Corn starch & 222 \\
Soybean meal, 48\% CP & 375 \\
Corn oil & 50 \\
Sodium chloride & 5 \\
Calcium carbonate & 15 \\
Monocalcium phosphate & 19 \\
DL-methionine & 4 \\
Premix ${ }^{1}$ & 10 \\
Total & 1000 \\
& \\
Chemical composition ${ }^{2}$ & \\
AME ${ }_{\mathrm{N}}$ (MJ/kg) & 13.27 \\
Crude protein & 208.3 \\
Lysine & 11.9 \\
Methionine+cystine & 10.0 \\
Calcium & 9.8 \\
Available phosphorus & 5.1 \\
Fatty acid composition ${ }^{3}$ & \\
C16:0, palmitic acid & \\
C18:0, stearic acid & 11.8 \\
C18:1n-9, oleic acid & 2.0 \\
C18:2n-6, linoleic acid & 25.7 \\
C18:3n-3, $\alpha$-linolenic acid & 56.7 \\
\hline
\end{tabular}

1 The $10 \mathrm{~g}$ premix consisted of $24.0 \mathrm{mg}$ vitamin $\mathrm{A}(500000 \mathrm{IU} / \mathrm{g}), 6.0 \mathrm{mg}$ vitamin $\mathrm{D}_{3}(100000 \mathrm{IU} / \mathrm{g})$, $60.0 \mathrm{mg}$ vitamin $\mathrm{E}(500 \mathrm{lU} / \mathrm{g}), 6.6 \mathrm{mg}$ vitamin $\mathrm{K}_{3}$ (purity, $22.7 \%$ ), $100.0 \mathrm{mg}$ vitamin $\mathrm{B}_{12}$ (purity, $0.1 \%$ ), $2000.0 \mathrm{mg}$ biotin (purity, $0.01 \%$ ), $1100.0 \mathrm{mg}$ choline chloride (purity, 50\%), $1.1 \mathrm{mg}$ folic acid (purity, 90\%), $65.2 \mathrm{mg}$ nicotinic acid (purity, 100\%), $16.3 \mathrm{mg}$ d-pantothenate (purity, 92\%), $4.5 \mathrm{mg}$ vitamin $\mathrm{B}_{6}$ (purity, 100\%), $12.5 \mathrm{mg}$ riboflavin (purity, 80\%), $2.5 \mathrm{mg}$ vitamin $\mathrm{B}_{1}$ (purity, 100\%), $32.00 \mathrm{mg}$ $\mathrm{CuSO}_{4} \cdot 5 \mathrm{H}_{2} \mathrm{O}$, $333.20 \mathrm{mg} \mathrm{FeSO} \cdot \mathrm{H}_{2} \mathrm{O}, 166.80 \mathrm{mg} \mathrm{MnO}, 1.0 \mathrm{mg} \mathrm{Na} \mathrm{SeO}_{3} \cdot 5 \mathrm{H}_{2} \mathrm{O}, 220.00 \mathrm{mg}$ $\mathrm{ZnSO}_{4} \cdot \mathrm{H}_{2} \mathrm{O}, 4.80 \mathrm{mg} \mathrm{CoSO}{ }_{4} \cdot 7 \mathrm{H}_{2} \mathrm{O}, 0.56 \mathrm{mg} \mathrm{KI}, 100.00 \mathrm{mg}$ ethoxyquin, and $5742.94 \mathrm{mg}$ corn meal as carrier.

${ }^{2}$ Calculated.

${ }^{3}$ Analyzed (g methyl ester/100 g total methyl esters). 
period, sampling was done at random and after the second period, the remaining birds were sampled. Blood was obtained by heart puncture. Plasma was obtained by centrifugation and stored at $-70^{\circ} \mathrm{C}$ until lipid analyses. Immediately after blood sampling, the birds were killed by cervical dislocation. Then, the intestinal tract was removed, and pancreas, liver and abdominal fat were sampled. The weights of liver and pancreas were recorded. The intestinal tract was removed to obtain digesta by gentle finger stripping of the intestinal segments. Duodenum plus jejunum was defined as the segment from the pylorus to Meckel's diverticulum, and ileum as the part between Meckel's diverticulum and ileocecal junction. Individual intestinal content from duodenum plus jejunum was used for measuring digestive enzymes whereas that from ileum was pooled per pen prior to chemical analysis. Adipose tissue samples were stored at $-20^{\circ} \mathrm{C}$.

\section{Analyses and measurements}

Intestinal duodenum plus jejunum contents and pancreases were individually homogenized in 4 and 10 volumes of ice-cold distilled water, respectively, and centrifuged at $1500 \mathrm{~g}$ for $15 \mathrm{~min}$. Aliquots of the supernatants were stored at $-20^{\circ} \mathrm{C}$. The concentration of protein in pancreatic extracts was measured according to the method of Lowry et al. (1951) using bovine serum albumin (BSA, Sigma Chemical Co., St. Louis, Mo., USA) as a standard.

Amylase (EC 3.2.1.1) activity was measured by the method of Bernfeld (1955), which determines the groups liberated from starch that reduce 3,5dinitrosalicylic acid (Sigma Chemical Co.) at $\mathrm{pH} 6.9$ and $37^{\circ} \mathrm{C}$. One unit amylase activity was defined as the hydrolysis of $1 \mathrm{mg}$ of maltose per minute. Lipase (EC 3.1.1.3) was assayed by aerobically incubating, in a buffered medium with $\mathrm{pH} 8.5$, the pancreatic homogenates together with olive oil (Sigma Chemical Co.) suspended in saline, and letting react the free fatty acids released with copper nitrate. The copper-bound free fatty acids were extracted into chloroform and then determined by a color-yielding reaction with diethyl dithiocarbamate (Schmidt et al., 1974). One unit was defined as $1 \mu \mathrm{mol}$ of free fatty acid released per minute.

Activation of trypsinogen to trypsin (EC 3.4.21.4) in pancreas samples was performed by the method of Glazer and Steer (1977) with some modifications. Briefly, homogenized supernatants were diluted 100 times in $50 \mathrm{mM}$ Tris- $\mathrm{HCl}$ containing $100 \mu \mathrm{g} \mathrm{BSA} / \mathrm{mL}, 50 \mathrm{mmol} \mathrm{CaCl}_{2} / \mathrm{L}(\mathrm{pH}$ 8.1). Subsequently, $1 \mathrm{~mL}$ 
containing 0.1\% purified enterokinase (EC 3.4.21.9; Sigma Chemical Co.) in 154 $\mathrm{mmol} \mathrm{NaCl} / \mathrm{L}$ was added to $1 \mathrm{~mL}$ of diluted pancreatic extract, and then incubated at $30^{\circ} \mathrm{C}$ for 20 min. Trypsin activity was measured by the method of Hummel (1959). The rate of hydrolysis of $p$-toluenesulfonyl-L-arginine methyl ester (TAME, Sigma Chemical Co.) was measured by the increase in absorbancy at $247 \mathrm{~nm}$. One unit of trypsin activity was defined as $1 \mu \mathrm{mol}$ of TAME hydrolysed per minute at $37^{\circ} \mathrm{C}$ and $\mathrm{pH} 8.1$ in the presence of $10 \mathrm{mmol} \mathrm{CaCl} / \mathrm{L}$.

Activation of chymotrypsinogen to chymotrypsin (EC 3.4.21.1) was based on the method of Glazer and Steer (1977) with some modifications. Briefly, homogenates were diluted 100 times in $50 \mathrm{mM}$ Tris- $\mathrm{HCl}$ containing $100 \mu \mathrm{g} \mathrm{BSA} / \mathrm{mL}$, $10 \mathrm{mmol} \mathrm{CaCl} / \mathrm{L}(\mathrm{pH}$ 8.1). Subsequently, $1 \mathrm{~mL}$ containing $1 \mathrm{mg}$ purified bovine trypsin (Sigma Chemical Co.) in $1 \mathrm{mmol} \mathrm{HCl} / \mathrm{L}$ was added to $1 \mathrm{~mL}$ of diluted pancreatic extracts so that the final concentration of total protein was $20 \%(\mathrm{w} / \mathrm{w})$ and then the mixture was incubated at $4^{\circ} \mathrm{C}$ for $1 \mathrm{hr}$. Aliquots of $0.1 \mathrm{~mL}$ were taken for chymotrypsin activity according to the method of Hummel (1959). The rate of hydrolysis of benzoyl-L-tyrosine ethyl ester (BTEE; Sigma Chemical Co.) was measured by the change in absorbancy at $256 \mathrm{~nm}$. One unit of chymotrypsin activity was defined as $1 \mu \mathrm{mol}$ of BTEE hydrolysed per minute at $\mathrm{pH} 7.8$ and $37^{\circ} \mathrm{C}$.

The activities of trypsin and chymotrypsin from the small intestinal chyme were assayed as described for pancreas extracts. All enzyme activities were measured spectrophotometrically (PU 8720 UV/VIS Scanning Spectrophotometer, Pye Unicam, UK).

Plasma concentrations of total and high density lipoprotein (HDL) cholesterol, triglycerides and phospholipids were measured enzymatically using an autoanalyzer (Cobas Bio, Roche, Switzerland) as described elsewhere (Beynen et al., 2000).

To determine the fatty acid composition of the control diet, a 10-g sample was extracted with a chloroform:methanol $(2: 1, \mathrm{v} / \mathrm{v})$ mixture according to the method of Folch et al. (1957). Then, $20-25 \mathrm{mg}$ of the extracted fat was saponified with $0.5 \mathrm{M}$ methanolic sodium hydroxide and methylated with boronitrifluoride-methanol (Product no. 49370, Pierce, Illinois, USA) according to the method of Metcalfe et al. (1966). The methylesters obtained were determined by gas chromatography (GC). Approximately $15 \mathrm{mg}$ of adipose tissue was saponified and methylated according to Metcalfe et al. (1966) and fatty acid methyl esters were measured by GC. Total lipid contents of the feed and the pooled excreta were determined by extraction of the samples with diethyl ether and petroleum ether after boiling in $8 \mathrm{M}$ hydrochloric acid for $30 \mathrm{~min}$ (AOAC, 1975). 
Nitrogen in ileal digesta and diet samples was analyzed with the Kjeldahl method. Crude protein content (g) was calculated by $6.25 \times \mathrm{N}(\mathrm{g})$. Starch contents of diets and ileal chyme were determined enzymatically using amyloglucosidase (EC 3.2.1.3) from Aspergillus niger (Boehringer Mannheim Diagnostica, Mannheim, Germany) according to the method of Cone and Vlot (1990). Chromium contents of diet samples and ileal chyme were determined according to the method of Murthy et al. (1971), as outlined in the manual of the AAS 3300 (Perkin-Elmer Corp., Connecticut, USA).

The apparent ileal digestibility coefficients of protein and starch were calculated as: $D_{\text {diet }}=\left(1-\left[\left(\mathrm{Cr}_{\text {diet }} / \mathrm{Cr}_{\text {ileum }}\right) \times\left(\mathrm{P}, \mathrm{S}_{\text {ileum }} / \mathrm{P}, \mathrm{S}_{\text {diet }}\right)\right]\right)$ where $\mathrm{DC}_{\text {diet }}=$ apparent digestibility coefficients of either crude protein $(\mathrm{P})$ or starch (S) in the diet; $\mathrm{Cr}_{\text {diet }}=$ concentration of chromium in the diet; $\mathrm{Cr}_{\text {ileum }}=$ concentration of chromium in the ileal contents; $\mathrm{P}, \mathrm{S}_{\text {ileum }}=$ concentration of either crude protein or starch in the ileal contents; $\mathrm{P}, \mathrm{S}_{\text {diet }}=$ concentration of either crude protein or starch in the diet.

\section{Statistical analysis}

All data for each variable were subjected to one-way analysis of variance (Steel and Torrie, 1980). When significant treatment effects were disclosed, statistically significant differences among treatment means were identified by the multiple range test of Duncan (1955). The level of statistical significance was pre-set at $P<0.05$.

\section{Results}

There was no mortality during the experiment. One bird from the control group showed abnormal proventriculus hypertrophy and one bird from the group fed CRINA $^{\circledR}$ Poultry developed leg abnormalities. The two animals were excluded from the chemical analyses.

From 0 to 21 days, body weight gain, feed intake, and feed conversion ratio were not significantly different among the four treatments (Table 2). Birds fed the diet containing cinnamaldehyde consumed significantly less water than those fed either the control diet or the diet with CRINA ${ }^{\circledR}$ Poultry. As a result, the water:feed ratio was low in cinnamaldehyde-treated birds. Dry matter contents in excreta appeared 
numerically higher by on average $13 \%(P>0.05)$ in birds fed cinnamaldehyde than those fed either control diet or the diet with CRINA ${ }^{\circledR}$ Poultry.

Table 2 Growth performance, digestibility coefficients of protein, starch and lipid in female broiler chickens fed the experimental diets for 21 days

\begin{tabular}{lllll}
\hline \multicolumn{1}{c}{ Diet : Control } & Thymol & $\begin{array}{l}\text { Cinnam- } \\
\text { aldehyde }\end{array}$ & CRINA ${ }^{\circledR}$ Poultry \\
Measure & & & \\
\hline Chicken performance (days $0-21)$ & & & \\
Daily weight gain, g/d & $35.7 \pm 0.73^{1}$ & $36.2 \pm 1.37$ & $34.8 \pm 1.48$ & $36.2 \pm 2.06$ \\
Daily feed intake, g/d & $51.0 \pm 0.92$ & $51.4 \pm 1.38$ & $50.2 \pm 3.06$ & $51.3 \pm 2.95$ \\
Daily water intake, g/d & $104.7 \pm 2.38^{\mathrm{a}}$ & $99.8 \pm 2.14^{\mathrm{ab}}$ & $95.1 \pm 4.71^{\mathrm{b}}$ & $104.2 \pm 4.58^{\mathrm{a}}$ \\
Feed : gain ratio, g:g & $1.43 \pm 0.03$ & $1.42 \pm 0.03$ & $1.44 \pm 0.03$ & $1.42 \pm 0.02$ \\
Water : feed ratio, g:g & $2.06 \pm 0.07^{\mathrm{a}}$ & $1.94 \pm 0.05^{\mathrm{ab}}$ & $1.90 \pm 0.03^{\mathrm{b}}$ & $2.04 \pm 0.10^{\mathrm{a}}$ \\
& & & & \\
lleal digestibilities, coefficient & $0.99 \pm 0.003$ & $0.99 \pm 0.001$ & $0.99 \pm 0.004$ & $0.99 \pm 0.002$ \\
Starch & $0.93 \pm 0.014$ & $0.92 \pm 0.012$ & $0.94 \pm 0.010$ & $0.93 \pm 0.012$ \\
Crude protein & & & & \\
& & & & \\
Faecal digestibility, coefficient & $0.86 \pm 0.005$ & $0.85 \pm 0.016$ & $0.86 \pm 0.007$ & $0.86 \pm 0.004$ \\
Lipids & $19.6 \pm 2.86$ & $22.4 \pm 1.23$ & $22.5 \pm 1.15$ & $19.6 \pm 2.16$ \\
Dry matter contents of & & & & \\
Excreta, \% & & & & \\
\hline
\end{tabular}

1 Values are means \pm SD $(n=4)$

${ }^{a, b}$ Values with different superscripts in the same row differ significantly $(P<0.05)$.

From days 18-21, faecal lipid digestibility and the ileal digestibilities of crude protein and starch did not differ between treatments (Table 2). Feeding thymol to the chickens caused an increase in liver weight by $13 \%(P<0.05)$ and in pancreas weight by $8 \%(P>0.05)$ when compared to the control group and when expressed relative to body weight (Table 3). After 21 days, the relative weight of pancreas was lowest in birds fed cinnamaldehyde. There were no significant differences in protein contents of pancreas (data not shown). Pancreatic enzyme activities were not differently 
affected by the dietary treatments (Table 3 ). Amylase activity in the intestinal chyme of birds given CRINA ${ }^{\circledR}$ poultry showed a significant increase by $30 \%$ when compared

Table 3 Organ weights and digestive enzyme activities in pancreases and intestinal contents in female broiler chickens fed the experimental diets for 21 days

\begin{tabular}{lllll}
\hline \multicolumn{1}{c}{ Diet : Control } & Thymol & $\begin{array}{l}\text { Cinnam- } \\
\text { aldehyde }\end{array}$ & CRINA ${ }^{\circledR}$ Poultry \\
Measure & & & \\
\hline Organ weight, g/100 g of body weight & & & \\
Liver & $2.30 \pm 0.11^{\mathrm{b}}$ ( & $2.59 \pm 0.16^{\mathrm{a}}$ & $2.45 \pm 0.11^{\mathrm{ab}}$ & $2.45 \pm 0.09^{\mathrm{ab}}$ \\
Pancreas & $0.26 \pm 0.024^{\mathrm{ab}}$ & $0.28 \pm 0.014^{\mathrm{a}}$ & $0.24 \pm 0.022^{\mathrm{b}}$ & $0.26 \pm 0.014^{\mathrm{ab}}$ \\
Pancreas enzyme activity, unit/mg of protein of pancreas & & \\
Amylase & $22 \pm 1.7$ & $23 \pm 4.3$ & $21 \pm 2.9$ & $19 \pm 3.4$ \\
Lipase & $8.7 \pm 1.0$ & $11.2 \pm 1.4$ & $9.1 \pm 2.0$ & $8.9 \pm 4.3$ \\
Trypsin & $1.07 \pm 0.28$ & $1.26 \pm 0.31$ & $1.10 \pm 0.10$ & $1.09 \pm 0.32$ \\
Chymotrypsin & $1.00 \pm 0.23$ & $1.14 \pm 0.25$ & $1.01 \pm 0.17$ & $0.80 \pm 0.10$ \\
& & & \\
Intestinal enzyme activity, unit/g of wet intestinal contents & & $144 \pm 19^{\mathrm{a}}$ \\
Amylase & $111 \pm 25^{\mathrm{b}}$ & $129 \pm 9^{\mathrm{ab}}$ & $111 \pm 18^{\mathrm{b}}$ & $51 \pm 13$ \\
Lipase & $40 \pm 7$ & $40 \pm 13$ & $43 \pm 6$ & $15.9 \pm 2.5$ \\
Trypsin & $14.1 \pm 3.2$ & $13.3 \pm 2.5$ & $14.0 \pm 1.3$ & $6.55 \pm 0.83$ \\
Chymotrypsin & $6.70 \pm 1.06$ & $6.32 \pm 0.64$ & $6.50 \pm 0.37$ & \\
\hline
\end{tabular}

${ }^{1}$ Means $\pm \operatorname{SD}(n=4)$.

${ }^{\mathrm{a}, \mathrm{b}, \mathrm{c}}$ Different superscripts in the same row differ significantly $(P<0.05)$.

to either the control or cinnamaldehyde group. Birds fed thymol showed intermediate intestinal amylase activities. At 21 days of age, the fatty acid composition of adipose tissue and the plasma lipid concentrations showed no significant differences between dietary treatments except that there was slightly less palmitic acid (C16:0) in the adipose tissue of chickens fed CRINA ${ }^{\circledR}$ Poultry (Table 4). Fatty acid composition of adipose tissue (Table 4) represented that of dietary fat (Table 1). Linoleic (C18:2n-6) and oleic acid (C18:1n-9) were most prominent followed by 
palmitic acid. At 40 days of age, the results for growth performance (Table 5) showed a similar pattern as that seen at 21 days of age. Weight gain and feed intake did not differ between the groups. Water intake was significantly higher with CRINA ${ }^{\circledR}$ Poultry when compared to cinnamaldehyde. The effect of thymol on organ weights had disappeared at 40 days of age (Table 6). Group mean trypsin and chymotrypsin activities in pancreas were lower in the group given CRINA ${ }^{\circledR}$ Poultry, but the lowering did not reach statistical significance (Table 6). Intestinal trypsin activity was significantly lower in the birds fed either cinnamaldehyde or CRINA ${ }^{\circledR}$ Poultry $(P<0.05)$ when compared with the thymol group. The birds fed CRINA ${ }^{\circledR}$ Poultry showed the lowest group mean ileal digestibility of crude protein, but the variation was high due to a cage displaying only a crude protein digestibility coefficient of 0.81 . At the end of the experiment, faecal digestibility of fat and ileal digestibility of starch did not differ between treatments (Table 5). Table 7 shows that at 40 days of age the concentrations of plasma lipids and the fatty acid composition of adipose tissue were not different among the four treatments.

Table 4 Fatty acid compositions of adipose tissue and plasma lipid concentrations in female broiler chickens fed the experimental diets for 21 days

\begin{tabular}{|c|c|c|c|c|}
\hline & Control & Thymol & $\begin{array}{l}\text { Cinnam- } \\
\text { aldehyde }\end{array}$ & CRINA ${ }^{\circledR}$ Poultry \\
\hline \multicolumn{5}{|c|}{ Fatty acids, g methyl ester/100 g total methyl esters } \\
\hline C16:0 & $18.7 \pm 0.30^{\mathrm{a} 1}$ & $18.9 \pm 0.34^{\mathrm{a}}$ & $18.5 \pm 0.25^{\mathrm{a}}$ & $18.0 \pm 0.35^{b}$ \\
\hline C16:1 & $2.8 \pm 0.16$ & $2.6 \pm 0.36$ & $2.7 \pm 0.27$ & $2.5 \pm 0.07$ \\
\hline C18:0 & $5.2 \pm 0.28$ & $5.6 \pm 0.45$ & $5.4 \pm 0.50$ & $5.3 \pm 0.33$ \\
\hline C18:1n-9 & $34.3 \pm 0.40$ & $33.7 \pm 1.65$ & $34.1 \pm 1.24$ & $34.5 \pm 0.25$ \\
\hline C18:2n-6 & $33.9 \pm 0.66$ & $34.4 \pm 1.54$ & $34.3 \pm 1.05$ & $34.5 \pm 0.88$ \\
\hline C18:3n-3 & $0.9 \pm 0.04$ & $0.9 \pm 0.07$ & $0.9 \pm 0.03$ & $0.9 \pm 0.01$ \\
\hline \multicolumn{5}{|c|}{ Plasma lipids, mmol/L } \\
\hline Total cholesterol & $3.16 \pm 0.097$ & $3.17 \pm 0.311$ & $3.19 \pm 0.240$ & $3.27 \pm 0.083$ \\
\hline Phospholipids & $3.04 \pm 0.093$ & $3.05 \pm 0.272$ & $3.12 \pm 0.263$ & $3.15 \pm 0.098$ \\
\hline Triglycerides & $0.35 \pm 0.026$ & $0.38 \pm 0.021$ & $0.42 \pm 0.048$ & $0.42 \pm 0.066$ \\
\hline HDL cholesterol & $2.15 \pm 0.182$ & $2.28 \pm 0.268$ & $2.24 \pm 0.080$ & $2.25 \pm 0.197$ \\
\hline
\end{tabular}


Table 5 Growth performance, digestibility coefficients of protein, starch and lipid in female broiler chickens fed the experimental diets for 40 days

\begin{tabular}{|c|c|c|c|c|}
\hline Measure & Control & Thymol & $\begin{array}{l}\text { Cinnam- } \\
\text { aldehyde }\end{array}$ & CRINA $^{\circledR}$ Poultry \\
\hline \multicolumn{5}{|c|}{ Chicken performance (days $0-40$ ) } \\
\hline Daily weight gain, g/d & $52.1 \pm 3.16^{1}$ & $52.7 \pm 2.31$ & $50.9 \pm 4.15$ & $53.4 \pm 2.70$ \\
\hline Daily feed intake, $\mathrm{g} / \mathrm{d}$ & $83.4 \pm 4.70$ & $82.8 \pm 5.30$ & $81.2 \pm 6.66$ & $85.7 \pm 4.99$ \\
\hline Daily water intake, g/d & $197 \pm 11.8^{\mathrm{ab}}$ & $184 \pm 19.1^{\mathrm{ab}}$ & $176 \pm 12.6^{b}$ & $203 \pm 12.8^{\mathrm{a}}$ \\
\hline Feed : gain ratio, g:g & $1.60 \pm 0.04$ & $1.57 \pm 0.06$ & $1.60 \pm 0.03$ & $1.60 \pm 0.04$ \\
\hline Water : feed ratio, g:g & $2.36 \pm 0.14$ & $2.22 \pm 0.16$ & $2.17 \pm 0.06$ & $2.38 \pm 0.17$ \\
\hline \multicolumn{5}{|c|}{ Ileal digestibilities, coefficient } \\
\hline Starch & $0.99 \pm 0.002$ & $0.99 \pm 0.003$ & $0.99 \pm 0.003$ & $0.99 \pm 0.001$ \\
\hline Crude protein & $0.90 \pm 0.008$ & $0.91 \pm 0.019$ & $0.89 \pm 0.019$ & $0.88 \pm 0.048$ \\
\hline \multicolumn{5}{|c|}{ Faecal digestibility, coefficient } \\
\hline Lipids & $0.85 \pm 0.012$ & $0.85 \pm 0.008$ & $0.85 \pm 0.011$ & $0.86 \pm 0.010$ \\
\hline $\begin{array}{l}\text { Dry matter contents of } \\
\text { excreta, } \%\end{array}$ & $21.2 \pm 2.15$ & $20.3 \pm 3.63$ & $20.3 \pm 1.42$ & $17.9 \pm 2.06$ \\
\hline
\end{tabular}

1 Values are means $\pm \operatorname{SD}(n=4)$.

${ }^{a, b}$ Different superscripts in the same row differ significantly $(P<0.05)$.

\section{Discussion}

It was expected that feeding of the commercial preparation of essential oil and the antimicrobial principles, thymol and cinnamaldehyde, would stimulate growth performance in the broiler chickens. However, the supplements did not influence weight gain, feed intake and feed conversion. The dietary inclusion level of thymol and cinnamaldehyde was considered to be sufficiently high on the basis of in vitro 
experiments showing their antimicrobial activity (Didry et al., 1994; Helander et al., 1998; Lee and Ahn, 1998; Cosentino et al., 1999; Dorman and Deans, 2000). The inclusion level of $\mathrm{CRINA}^{\circledR}$ Poultry also was sufficiently high according to the manufacturer's recommendation. The lack of effect of the supplements may relate to the composition of the basal diet and/or the environmental conditions. The diet contained well-digestible ingredients so that bacterial growth in the intestine probably was limited. Antimicrobial agents may have more impact when the diet used is less digestible. In addition, it is known that well-nourished, healthy chicks do not respond to antibiotic supplements provided that they are housed under clean and disinfected conditions. Our chickens were kept in a clean environment, possibly leading to diminished efficacy, if any, of the dietary additives.

Table 6 Organ weights and digestive enzyme activities in pancreases and intestinal contents in female broiler chickens fed the experimental diets for 40 days

Diet : Control Thymol Cinnamaldehyde $\quad$ CRINA $^{\circledR}$ Poultry

Measure

Organ weight, $\mathrm{g} / 100 \mathrm{~g}$ of body weight

$\begin{array}{lllll}\text { Liver } & 1.91 \pm 0.20^{1} & 1.86 \pm 0.17 & 1.87 \pm 0.11 & 1.94 \pm 0.11 \\ \text { Pancreas } & 0.18 \pm 0.014 & 0.19 \pm 0.026 & 0.19 \pm 0.021 & 0.17 \pm 0.014\end{array}$

Pancreas enzyme activity, unit/mg of protein of pancreas

$\begin{array}{lllll}\text { Amylase } & 39 \pm 1.9 & 38 \pm 3.1 & 37 \pm 1.9 & 38 \pm 2.4 \\ \text { Lipase } & 33 \pm 6.5 & 36 \pm 7.5 & 32 \pm 9.2 & 32 \pm 1.4 \\ \text { Trypsin } & 0.96 \pm 0.14 & 1.00 \pm 0.23 & 1.02 \pm 0.15 & 0.84 \pm 0.25 \\ \text { Chymotrypsin } & 0.97 \pm 0.14 & 1.13 \pm 0.11 & 1.02 \pm 0.09 & 0.84 \pm 0.19\end{array}$

Intestinal enzyme activity, unit/g of wet intestinal contents

$\begin{array}{lllll}\text { Amylase } & 136 \pm 51 & 118 \pm 22 & 133 \pm 50 & 93 \pm 34 \\ \text { Lipase } & 58 \pm 6 & 57 \pm 8 & 53 \pm 15 & 53 \pm 27 \\ \text { Trypsin } & 12.9 \pm 2.52^{\mathrm{ab}} & 16.3 \pm 4.48^{\mathrm{a}} & 10.1 \pm 2.46^{\mathrm{b}} & 9.2 \pm 4.01^{\mathrm{b}} \\ \text { Chymotrypsin } & 6.85 \pm 0.66 & 6.59 \pm 1.02 & 5.80 \pm 0.89 & 4.88 \pm 2.42\end{array}$

${ }^{1}$ Means \pm SD $(n=4)$.

${ }^{a, b}$ Different superscripts in the same row differ significantly $(P<0.05)$. 
Table 7 Fatty acid compositions of adipose tissue and plasma lipid concentrations in female broiler chickens fed the experimental diets for 40 days

\begin{tabular}{lllll}
\hline Diet : & Control & Thymol & \multicolumn{1}{l}{ Cinnamaldehyde } & CRINA ${ }^{\circledR}$ Poultry \\
\hline \multicolumn{1}{l}{ Fatty acids, g methyl ester/100 g total methyl esters } & & \\
C16:0 & $18.7 \pm 0.60^{1}$ & $18.2 \pm 0.61$ & $18.0 \pm 0.88$ & $18.4 \pm 0.35$ \\
C16:1 & $2.4 \pm 0.28$ & $2.2 \pm 0.23$ & $2.1 \pm 0.25$ & $2.1 \pm 0.44$ \\
C18:0 & $5.7 \pm 0.13$ & $5.5 \pm 0.30$ & $6.0 \pm 0.40$ & $5.9 \pm 0.46$ \\
C18:1n-9 & $33.0 \pm 0.70$ & $33.4 \pm 0.88$ & $32.7 \pm 0.52$ & $33.0 \pm 1.68$ \\
C18:2n-6 & $35.4 \pm 0.93$ & $35.9 \pm 1.18$ & $36.7 \pm 1.21$ & $36.0 \pm 1.99$ \\
C18:3n-3 & $0.9 \pm 0.02$ & $0.9 \pm 0.04$ & $0.9 \pm 0.06$ & $0.9 \pm 0.07$ \\
& & & & \\
Plasma lipids, mmol/L & & & & \\
Total cholesterol & $2.90 \pm 0.059$ & $3.12 \pm 0.195$ & $2.99 \pm 0.269$ & $3.08 \pm 0.191$ \\
Phospholipids & $2.90 \pm 0.084$ & $3.10 \pm 0.104$ & $2.87 \pm 0.214$ & $2.94 \pm 0.284$ \\
Triglycerides & $0.45 \pm 0.124$ & $0.42 \pm 0.082$ & $0.38 \pm 0.087$ & $0.39 \pm 0.063$ \\
HDL cholesterol & $2.17 \pm 0.151$ & $2.26 \pm 0.065$ & $2.08 \pm 0.304$ & $2.21 \pm 0.135$ \\
\hline
\end{tabular}

1 Values are means $\pm \operatorname{SD}(n=4)$.

As to water intake, an interesting finding emerged from this study. The intake of cinnamaldehyde systemically lowered water consumption, the decrease being on average $10 \%$ when compared with the control treatment. The depression by cinnamaldehyde of water intake did not affect growth performance. The mechanism underlying the cinnamaldehyde-induced decrease in water intake is not known. Water intake by broilers will affect the water content of excreta. Indeed, dry matter contents of excreta at 21 days of age were apparently higher in birds fed diet containing cinnamaldehyde than those fed either control diet or the diet with CRINA ${ }^{\circledR}$ Poultry (Table 2). In broiler production, low water concentrations in excreta are considered advantageous because litter quality which is influenced by moisture contents in excreta can thus be improved. Wet litter is known to cause downgrades of broiler carcasses at the slaughterhouse due to the increased incidence of breast blisters, skin burns, bruising, and condemnations, and also to increase ammonia production in broiler house. 
Platel and Srinivasan (2000) reported that the active principles of certain spices, namely capsaicin, piperin and curcumin, when fed at dietary concentrations of 150,200 and 5000 ppm, respectively, stimulated pancreatic enzymes in rats without affecting feed intake and body weight. Recently, Engberg et al. (2000) have shown that dietary antibiotics appear to stimulate the activities of amylase and chymotrypsin in pancreatic tissue from broilers fed wheat-soybean based feed. In this experiment, the dietary supplements tested did not equally affect the activities of digestive enzymes in pancreatic tissue and intestinal digesta at 21 and 40 days of age. After 21 days, CRINA ${ }^{\circledR}$ Poultry had significantly raised amylase activity in digesta, when compared with either the control feed or cinnamaldehyde as dietary supplement. The effect was not seen after 40 days, but at that time point thymol had significantly elevated trypsin activity in intestinal contents when compared with either cinnamaldehyde or CRINA ${ }^{\circledR}$ Poultry. It appears that the sensitivity of endogenous enzymes to dietary additives changes with the age of the birds. Under the conditions of this experiment, including the composition of the diet, the basal activities of digestive enzymes did not appear to limit macronutrient digestibility. In any event, the observed digestibilities of starch, protein and fat were rather high when compared with previous work (Smits et al., 1998; Langhout et al., 2000); under such circumstances any improvements in digestibilities would have been impossible to happen or difficult to be detected.

Various components of essential oils may exhibit a hypocholesterolaemic effect in chickens (Yu et al., 1994; Elson, 1995). The feeding of thymol at a dietary concentration of $150 \mathrm{ppm}$ to Leghorn chickens for 21 days significantly reduced serum cholesterol by $9 \%$ (Case et al., 1995). The cholesterol-lowering property of essential oil constituents has been ascribed to suppressing of 3-hydroxy-3methylglutaryl coenzyme A reductase (Elson, 1995), the enzyme that is considered to be rate limiting in cholesterol synthesis (Goldstein and Brown, 1990). In contrast to Case et al. (1995), our study failed to show hypocholesterolaemic effects of any of the supplements. However, it is well-known that the absence or presence of cholesterolaemic effects of dietary components in an animal depend on various factors such as breed, gender and age, and also on the composition of the feed.

In conclusion, the present study shows that the feeding of either thymol, cinnamaldehyde or CRINA ${ }^{\circledR}$ Poultry did not affect growth performance, macronutrient digestibilities and plasma lipids in female broiler chickens. It cannot be excluded that beneficial effects of the supplements would be seen under less hygienic housing conditions and/or when using a diet with less digestible diet. However, the observed 
cinnamaldehyde-induced reduction of spontaneous water intake could be commercially interesting and deserves further study.

\section{Acknowledgements}

The authors thank Hugo Wouterse, Robert Hovenier, Jan Van der Kuilen, and Inez Lemmens for their analytical assistance. This study has been sponsored by Crina S.A. and Kyung-Woo Lee was supported by the National Institute for International Education Development, Ministry of Education, South Korea.

\section{References}

AOAC Association of Official Analytical Chemists (1975) Official Methods of Analysis, 12th edn. (Arlington, VA, AOAC).

Bernfeld, P., 1955. Amylases, $\alpha$ and $\beta$, in: Colowick, S.P., and N.O. Kaplan, (Eds) Methods in Enzymology, vol. 1, pp. 149-158 (New York, Academic press).

Beynen, A.C., J. Th. Schonewille, and A.H.M. Terpstra, 2000. Influence of amount and type of dietary fat on plasma cholesterol concentrations in goats. Small Ruminant Research 35: 141-147.

Case, G.L., L.. He, H. Mo, and C.E. Elson, 1995. Induction of geranyl pyrophosphate pyrophosphatase activity by cholesterol-suppressive isoprenoids. Lipids 30: 357-359.

Cone, J.W., and M. Vlot, 1990. Comparison of degradability of starch in concentrates by enzymes and rumen fluid. Journal of Animal Physiology and Animal Nutrition 63: 142-148.

Cosentino, S., C.I.G. Tuberoso, B. Pisano, M. Satta, V. Mascia, E. Arzedi, and F. Palmas, 1999. Invitro antimicrobial activity and chemical composition of Sardinian Thymus essential oils. Letters in Applied Microbiology 29: 130-135.

Didry, N., L. Dubreuil, and M. Pinkas, 1994. Activity of thymol, carvacrol, cinnamaldehyde and eugenol on oral bacteria. Pharmaceutica Acta Helvetiae 69: 25-28.

Dorman, H.J.D., and S.G. Deans, 2000. Antimicrobial agents from plants: antibacterial activity of plant volatile oils. Journal of Applied Microbiology 88: 308-316.

Duncan, D.B., 1955. Multiple range and multiple F-test. Biometrics 11: 1-42. 
Elson, C.E., 1995. Suppression of mevalonate pathway activities by dietary isoprenoids: Protective roles in cancer and cardiovascular disease. Journal of Nutrition 125: 1666S-1672S.

Engberg, R.M., M.S. Hedemann, T.D. Leser, and B.B. Jensen, 2000. Effect of zinc bacitracin and salinomycin on intestinal microflora and performance of broilers. Poultry Science 79: 13111319.

Folch, J., M. Lees, and G.H.S. Stanley, 1957. A simple method for the isolation and purification of total lipids from animal tissues. Journal of Biological Chemistry 226: 497-509.

Glazer, Z., and M.L. Steer, 1977. Requirements for activation of trypsinogen and chymotrypsinogen in rabbit pancreatic juice. Analytical Biochemistry 77: 130-140.

Goldstein, J.L., and M.S. Brown, 1990. Regulation of the mevalonate pathway. Nature 343: 425-430.

Helander, I.M., H.-L. Alakomi, K. Latva-Kala, T. Mattila-Sandholm, I. Pol, E.J. Smid, L.G.M. Gorris, and A. Von Wright, 1998. Characterization of the action of selected essential oil components on Gram-negative bacteria. Journal of Agricultural and Food Chemistry 46: 3590-3595.

Hummel, B.C.W., 1959. A modified spectrophotometric determination of chymotrypsin, trypsin, and thrombin. Canadian Journal of Biochemistry and Physiology 37: 1393-1399.

Langhout, D.J., J.B. Schutte, J. De Jong, H. Sloetjes, M.W.A. Verstegen, and S. Tamminga, 2000. Effect of viscosity on digestion of nutrients in conventional and germ-free chicks. British Journal of Nutrition 83: 533-540.

Lee, H.-S., and Y.-J. Ahn, 1998. Growth-inhibiting effects of cinnamomum cassia bark-derived materials on human intestinal bacteria. Journal of Agricultural and Food Chemistry 46: 8-12.

Lowry, O.H., N.J. Rosenbrough, A.L. Farrand, and R.J. Randall, 1951. Protein measurement with the Folin phenol reagent. Journal of Biological Chemistry 193: 265-275.

Metcalfe, L.D., A.A. Schmitz, and J.R. Pelka, 1966. Rapid preparation of fatty acid esters from lipids for gaschromatographic analysis. Analytical Chemistry 38: 514-515.

Murthy, G.K., U. Rhea, and J.T. Peeler, 1971. Levels of antimony, cadmium, chromium, cobalt, manganese, and zinc in institutional total diets. Environmental Science and Technology 5: 436-442.

Platel, K., and K. Srinivasan, 2000. Influence of dietary spices and their active principles on pancreatic digestive enzymes in albino rats. Nahrung 44: 42-46.

Schmidt, F.H., H. Stork, and K.V. Dahl, 1974. Photometric assay, in: Bergmeyer, H.U. (Ed) Methods of Enzymatic Analysis, Vol. 2, pp. 819-823 (Weinheim, Verlag Chemie).

Smits, C.H.M., A. Veldman, H.J. Verkade, and A.C. Beynen, 1998. The inhibitory effect of carboxymethylcellulose with high viscosity on lipid absorption in broiler chickens coincides with reduced bile salt concentration and raised microbial numbers in the small intestine. Poultry Science 77: 1534-1539. 
Steel, R.G.D., and J.H. Torrie, 1980. Principles and Procedures of Statistics. A Biometrical Approach. 2nd edn. (New York, McGraw Hill Book Corp.).

Williams, P., and R. Losa, 2001. The use of essential oils and their compounds in poultry nutrition. World Poultry 17 (No 4): 14-15.

Yu, S.G., N.M. Abuirmeileh, A.A. Qureshi, and C.E. Elson, 1994. Dietary $\beta$-ionone suppresses hepatic 3-hydroxy-3-methylglutaryl coenzyme A reductase activity. Journal of Agricultural and Food Chemistry 42: 1493-1496. 


\section{Chapter 3}

\section{Dietary carvacrol lowers body-weight gain, but improves feed conversion in female broiler chickens}

K.-W. Lee, H. Everts, H. J. Kappert, K.-H. Yeom, A. C. Beynen 


\section{Summary}

We evaluated dietary carvacrol and thymol as potential feed additives in female broiler chickens. In addition, we tested the alleged hypocholesterolemic effect of carvacrol and thymol when the chickens were either fed cholesterol-free or cholesterol-rich diets. The experiment had a $2 \times 3$ factorial design with diets containing two levels of cholesterol ( 0 or $1 \%$ ) and either without feed additive or with either 200 ppm thymol or carvacrol. 72 one-day-old female chicks were used: there were 6 birds per cage and 2 cages per treatment. Diets and water were provided ad libitum for a period of 4 weeks. Dietary carvacrol lowered feed intake and weight gain, but also lowered the feed:gain ratio. Dietary cholesterol significantly increased plasma and liver cholesterol concentrations. Carvacrol lowered plasma triglyceride concentrations, but did not affect plasma cholesterol. It is concluded that thymol and its isomer carvacrol have different effects on growth performance and triglyceride metabolism in broiler chickens. The two compounds did not have hypocholesterolemic activity, irrespective of whether the diet was cholesterol free or rich in cholesterol. 


\section{Introduction}

In our studies with broilers to identify possible feed supplements alternative to antibiotics, we focus on essential oils and their pure components. Essential oils are derived mainly from spices and herbs and their constituents have antimicrobial effects in vitro (Deans and Ritchie 1987; Hammer et al., 1999). Thymol (Table 1), a major component of thyme essential oils, has been widely studied for its antimicrobial properties (Juven et al., 1994; Dorman and Deans 2000). It can be added to chewing gum at levels as high as $100 \mathrm{ppm}$ and to non-alcoholic beverages at concentrations of 2.5 to $11 \mathrm{ppm}$ (Furia and Bellanca 1975). The reported lethal dose $\left(L D_{50}\right)$ in the rat is $980 \mathrm{mg} / \mathrm{kg}$ of body weight, when given orally (Jenner et al., 1964). Carvacrol (Table 1), an isomer of thymol, is found in essential oils isolated from oregano, thyme, marjoram, and summer savory (Guenther 1949). Like thymol, carvacrol also displays antimicrobial activity (Didry et al., 1994; Juven et al., 1994; Helander et al., 1998). Carvacrol may be added to baked goods at levels as high as $120 \mathrm{ppm}$ and non-alcoholic beverages may contain up to $26 \mathrm{ppm}$ (Furia and Bellanca 1975). The $L D_{50}$ of carvacrol in rats is $810 \mathrm{mg} / \mathrm{kg}$ of body weight, when administered by gavage (Jenner et al., 1964). The chemical properties and structures of thymol and carvacrol are shown in Table 1.

Based on in-vitro antimicrobial studies (Didry et al., 1994; Juven et al., 1994; Helander et al., 1998; Dorman and Deans 2000), the minimum inhibitory concentrations of thymol and carvacrol range from 100 to $1000 \mathrm{ppm}$, yeasts being most sensitive and gram-negative bacteria being resistant.

Given their antimicrobial activity, it would be expected (Wenk 2000) that thymol and carvacrol have positive effects on growth performance by broilers. The main objective of the present study was to evaluate the potential of thymol and carvacrol as growth enhancers in female broilers. It has been reported that dietary thymol and carvacrol, at dietary concentrations of $150 \mathrm{ppm}$, reduce serum cholesterol in Leghorn chicks (Case et al., 1995). We wished to verify the hypocholesterolemic properties of thymol and carvacrol and thus we also measured plasma lipid concentrations in the broilers. To enhance the hypocholesterolemic action (Beynen and West 1989) of thymol and carvacrol, if any, we not only used cholesterol-free diets, but also fed broilers on diets with $1 \%$ of added cholesterol. 
Table 1 Chemical properties and structures of thymol and carvacrol

\begin{tabular}{|c|c|c|}
\hline & Thymol & Carvacrol \\
\hline Molecular weight & $150\left(\mathrm{C}_{10} \mathrm{H}_{14} \mathrm{O}\right)$ & $150\left(\mathrm{C}_{10} \mathrm{H}_{14} \mathrm{O}\right)$ \\
\hline Synonym & $\begin{array}{l}\text { 5-methyl-2-(1- } \\
\text { methylethyl)phenol }\end{array}$ & $\begin{array}{l}\text { 2-methyl-5-(1- } \\
\text { methylethyl)phenol }\end{array}$ \\
\hline FEMA ${ }^{1}$ & 3066 & 2245 \\
\hline FDA $^{2}$ & 21CFR 172.515 & 21CFR 172.515 \\
\hline Occurrence & Thyme (Lamiaceae, or Labiatae) & $\begin{array}{c}\text { Oregano (Lamiaceae, or } \\
\text { Labiatae) }\end{array}$ \\
\hline Appearance & White crystals & Colorless to pale yellow liquid \\
\hline Odor & Pungent, caustic taste & Thymol-like odor \\
\hline Boiling point, 으 & 233 & 237 \\
\hline Density, $\mathrm{g} / \mathrm{mL}$ & 0.969 & 0.976 \\
\hline Structure & & \\
\hline
\end{tabular}

${ }^{1}$ FEMA = The Flavor and Extract Manufacturers Association; code given refers to "generally recognized as safe" (GRAS) status for their use as food flavor.

${ }^{2} \mathrm{FDA}=$ Food and Drug Administration; code given refers to GRAS status for their use in food.

\section{Materials and methods}

The experimental protocol was approved by the animal experiments committee of the Utrecht Faculty of Veterinary Medicine.

\section{Animals, diets and experimental design}

72 one-day old female broilers (Cobbs) were purchased from a local hatchery. They were wing-banded, weighed on arrival, and randomly allocated to one of 6 
treatments. Each treatment consisted of 2 cages with 6 birds per cage. Feed and water were provided ad libitum. The temperature of the animal house was controlled and continuous lighting used throughout the entire experimental period. The experiment had a $2 \times 3$ factorial design with two levels of dietary cholesterol ( 0 and 1 $\%$ ) and 3 treatments with feed additives (none, thymol, and carvacrol). The composition of the basal diet is shown in Table 2. The basal diet served as control diet without cholesterol and additives. Cholesterol was introduced into the diet at the expense of an identical amount of corn starch. Thymol (99\% purity, Acros Organics, Geel, Belgium) and carvacrol (97\% purity, Fluka Chemie, Sigma-Aldrich Chemie BV, Zwijndrecht, The Netherlands) were dissolved in corn oil and gently mixed with either the cholesterol-free or cholesterol-rich diets so that the diets contained $5 \%$ corn oil and $200 \mathrm{ppm}$ of one of the two supplements. The cholesterol-free and cholesterolrich diets without additives were mixed with corn oil only. The experimental diets were prepared on a daily basis.

\section{Measurements}

Body weights were measured weekly. Feed provided and left overs were weighed daily for each cage. Individual, daily feed intake was calculated by dividing the amount of feed consumed by number of days and animals. At 28 days of age, the chickens were killed by cervical dislocation after blood had been collected by heart puncture. Plasma was obtained by centrifugation at $1700 \times \mathrm{g}$ for $15 \mathrm{~min}$. and stored at $-70 \stackrel{\circ}{\circ}$ until lipid analysis. Liver and pancreas were immediately sampled and weighed. Livers were stored at $-70^{\circ} \mathrm{C}$.

Plasma cholesterol (Allain et al., 1974), triglyceride (Bucolo and David 1973), and phospholipid concentrations (Takayama et al., 1977) were measured enzymatically on an autoanalyzer (Cobas Bio, Roche, Basel, Switzerland). Plasma very-low-density and low-density lipoproteins (LDL) were precipitated with phosphotungstic acid/ $\mathrm{MgCl}_{2}$ (Sigma Diagnostics, St Louis, MO, USA; Catalogue number 352-4) according to Assman et al. (1983), and the supernatant (high-density lipoproteins, HDL) was assayed for cholesterol. To extract liver total cholesterol, the thawed livers were homogenized with 4 volumes of ethanol and saponified with ethanolic $\mathrm{KOH}$ at $50{ }^{\circ} \mathrm{C}$ overnight. The cholesterol was then extracted with petroleum ether, dried under nitrogen and dissolved with ethanol prior to measurements as described for plasma cholesterol. The extraction of free cholesterol from liver was 
identical to that of total cholesterol, except for omission of the saponification step. Liver free cholesterol (Wybenga and Inkpen 1974) was then measured enzymatically on the autoanalyzer. Liver esterified cholesterol was calculated as the difference between total and free cholesterol.

Table 2 Ingredients and composition of the basal (control) diet

\begin{tabular}{lc}
\hline Ingredients & $\mathrm{g}$ \\
\hline Corn, yellow, g & 300 \\
Corn starch, g & 222 \\
Soybean meal (48\% crude protein), g & 375 \\
Corn oil, g & 50 \\
Sodium chloride, g & 5 \\
Calcium carbonate, g & 15 \\
Monocalcium phosphate, g & 19 \\
DL-methionine, g & 4 \\
Premix ${ }^{1}, \mathrm{~g}$ & 10 \\
Total, g & 1000 \\
& \\
Calculated contents & \\
Metabolizable energy, MJ/kg & \\
Crude protein, \% & 13.3 \\
Lysine, \% & 20.8 \\
Methionine+cystine, \% & 1.2 \\
Calcium, \% & 1.0 \\
Available phosphorus, \% & 1.0 \\
\hline
\end{tabular}

${ }_{1}^{1}$ Premix provided followings per kg of diet: vitamin A, $12000 \mathrm{IU}$; vitamin $\mathrm{D}_{3}, 3000 \mathrm{IU}$; DL- $\alpha$-tocopheryl acetate, $60 \mathrm{mg}$; menadione, $1.5 \mathrm{mg}$; cyanocobalamin, $0.1 \mathrm{mg}$; biotin, $0.2 \mathrm{mg}$; choline chloride, 744 $\mathrm{mg}$; folic acid, $1 \mathrm{mg}$; nicotinic acid, $65 \mathrm{mg}$; calcium pantothenate, $16.4 \mathrm{mg}$; pyridoxine hydrochloride, $5.4 \mathrm{mg}$; riboflavin, $10 \mathrm{mg}$; thiamin hydrochloride, $2.8 \mathrm{mg}$; copper, $8 \mathrm{mg}$; iron, $100 \mathrm{mg}$; manganese, 100 $\mathrm{mg}$; selenium, $0.3 \mathrm{mg}$; zinc, $80 \mathrm{mg}$; cobalt, $1 \mathrm{mg}$; iodine, $0.45 \mathrm{mg}$; ethoxyquin, $100 \mathrm{mg}$ and cornstarch to $10000 \mathrm{mg}$.

2 The values were calculated from NRC (1994).

\section{Statistical analysis}

Pen was considered as experimental unit. The data were evaluated by twoway ANOVA with feed additives and dietary cholesterol as factors and using the program Genstat ${ }^{\circledR}$ 4.2. There was no interaction between dietary cholesterol and 64 
feed additives. Thus, data are presented as overall means for each factor. Treatment means were tested for statistically significant differences according to the RPAIR procedures in Genstat ${ }^{\circledR}$ Release 4.2 for PC (Genstat Committee 2000). A P value $<0.05$ was preset as level of significance.

\section{Results}

\section{Growth performance and organ weights}

The experiment proceeded without problems. 4 chickens died on day 3 of the experiment. Growth performance is presented in Table 3. Chickens fed carvacrol gained significantly less weight than those fed thymol, whereas the controls showed intermediate weight gain. Carvacrol versus thymol reduced weight gain by on average $4.6 \%$. Feed intakes showed a similar pattern: the carvacrol group ate significantly less than the control and thymol group, the average difference being 5.1 and $6.7 \%$. The feed:gain ratio was lowest in the carvacrol group, the decrease being significant when compared with the controls. Carvacrol versus thymol tended $(P=0.073)$ to depress the feed:gain ratio, the mean decrease being $2.1 \%$. Dietary cholesterol had no effect on growth performance (Table 3).

Relative liver weight ( $\mathrm{g} / 100 \mathrm{~g}$ of body weight) was significantly increased by cholesterol feeding $(P<0.05)$, but the additives had no effect (Table 3$)$. The color of liver in chickens fed cholesterol was yellowish while that of their counterparts fed the diets without cholesterol was pinkish. Dietary cholesterol and additives did not affect pancreas weight (Table 3).

\section{Cholesterol metabolism}

No interaction between cholesterol and additives was found with regard to plasma and liver lipids. Cholesterol feeding significantly increased plasma cholesterol and triglycerides, but lowered phospholipids and the percentage of HDL cholesterol (Table 4). HDL cholesterol was not affected by cholesterol feeding. Dietary carvacrol significantly lowered triglycerides when compared to the control and thymol treatments, the lowering on average being $10.3 \%$. Carvacrol also 
decreased plasma phospholipids when compared with the control treatment. Plasma total and HDL cholesterol were not changed by the dietary additives. Cholesterol feeding drastically increased liver free and esterified cholesterol, but thymol and carvacrol had no effect (Table 4).

Table 3 Effect of dietary thymol and carvacrol on growth performance (days $0-28$ ) and organ weights (day 28) of female broiler chickens

\begin{tabular}{|c|c|c|c|c|c|c|c|}
\hline \multirow[b]{2}{*}{ Parameters } & \multicolumn{3}{|c|}{ Additives } & \multirow{2}{*}{$\begin{array}{l}\text { Pooled } \\
\text { SEM }{ }^{1}\end{array}$} & \multicolumn{2}{|c|}{ Cholesterol } & \multirow{2}{*}{$\begin{array}{l}\text { Pooled } \\
\text { SEM }{ }^{1}\end{array}$} \\
\hline & None & Carvacrol & Thymol & & - & + & \\
\hline $\begin{array}{l}\text { Weight gain, } \\
\text { g/day/bird }\end{array}$ & $42.4^{\mathrm{ab}}$ & $41.3^{\mathrm{b}}$ & $43.3^{\mathrm{a}}$ & 0.623 & 42.4 & 42.3 & 0.508 \\
\hline $\begin{array}{l}\text { Feed intake, } \\
\text { g/day/bird }\end{array}$ & $58.9^{a}$ & $55.9^{b}$ & $59.9^{a}$ & 0.832 & 58.3 & 58.2 & 0.679 \\
\hline Feed : gain, g:g & $1.389^{\mathrm{a}}$ & $1.354^{\mathrm{b}}$ & $1.383^{\mathrm{ab}}$ & 0.010 & 1.375 & 1.376 & 0.008 \\
\hline Liver ${ }^{2}$ & 2.39 & 2.32 & 2.39 & 0.081 & $2.14^{\mathrm{b}}$ & $2.59^{a}$ & 0.066 \\
\hline Pancreas ${ }^{2}$ & 0.21 & 0.22 & 0.21 & 0.004 & 0.22 & 0.21 & 0.003 \\
\hline
\end{tabular}

'SEM, standard error of mean.

${ }^{2}$ Values are expressed as $\mathrm{g} / 100 \mathrm{~g}$ of body weight.

${ }^{a b}$ Means in the same row sharing a common superscript are significantly different $(P<0.05)$.

\section{Discussion}

Chickens fed either the diet containing thymol or the control diet showed no significant difference in growth performance. However, dietary carvacrol at the level of $200 \mathrm{ppm}$ significantly lowered feed intake and weight gain when compared to thymol. Feed:gain ratio tended to be lower in the carvacrol group than in the thymol group. When compared with the control group, carvacrol feeding significantly 
lowered the feed:gain ratio. Thus, when comparing thymol and carvacrol in relation to growth performance, it appears that carvacrol suppressed feed intake, leading to lower weight gain in spite of improved feed conversion. Possibly, carvacrol affected feed intake by modulating appetite. Deyoe et al. (1962) showed that flavor of chicken's diets can stimulate or depress feed intake. The carvacrol effect on feed:gain ratio could relate to increased efficiency of feed utilization and/or altered carcass composition. Unfortunately, carcass composition of the chickens was not analysed.

Table 4 Effect of dietary thymol and carvacrol on plasma and liver lipids in female broiler chickens at 28 days of age

\begin{tabular}{|c|c|c|c|c|c|c|c|}
\hline \multirow[b]{2}{*}{ Parameters } & \multicolumn{3}{|c|}{ Additives } & \multirow{2}{*}{$\begin{array}{l}\text { Pooled } \\
\text { SEM }{ }^{1}\end{array}$} & \multicolumn{2}{|c|}{ Cholesterol } & \multirow{2}{*}{$\begin{array}{l}\text { Pooled } \\
\text { SEM }{ }^{1}\end{array}$} \\
\hline & None & Carvacrol & Thymol & & - & + & \\
\hline \multicolumn{8}{|l|}{ Plasma lipids ${ }^{2}$} \\
\hline Total cholesterol & 4.54 & 4.58 & 4.62 & 0.196 & $3.35^{\mathrm{b}}$ & $5.80^{\mathrm{a}}$ & 0.160 \\
\hline HDL cholesterol & 2.36 & 2.21 & 2.30 & 0.056 & 2.33 & 2.25 & 0.045 \\
\hline Triglycerides & $1.19^{\mathrm{a}}$ & $1.05^{b}$ & $1.15^{\mathrm{a}}$ & 0.030 & $0.91^{\mathrm{b}}$ & $1.34^{\mathrm{a}}$ & 0.024 \\
\hline Phospholipids & $3.11^{\mathrm{a}}$ & $2.90^{\mathrm{b}}$ & $3.01^{\mathrm{ab}}$ & 0.060 & $3.13^{\mathrm{a}}$ & $2.89^{b}$ & 0.049 \\
\hline $\begin{array}{l}\text { HDL cholesterol, \% } \\
\text { of total }\end{array}$ & 55.9 & 54.1 & 54.3 & 1.343 & $69.9^{a}$ & $39.9^{\mathrm{b}}$ & 1.096 \\
\hline \multicolumn{8}{|l|}{ Liver cholesterol $^{3}$} \\
\hline Free cholesterol & 23.0 & 23.8 & 22.8 & 0.955 & $16.0^{\mathrm{b}}$ & $30.3^{\mathrm{a}}$ & 0.780 \\
\hline Esterified cholesterol & 56.5 & 64.0 & 65.0 & 11.804 & $4.0^{\mathrm{b}}$ & $119.7^{\mathrm{a}}$ & 9.638 \\
\hline
\end{tabular}

'SEM, standard error of mean.

${ }^{2}$ Values are expressed as $\mathrm{mmol} / \mathrm{L}$ unless stated otherwise.

${ }^{3}$ Values are expressed as $\mu \mathrm{mol} / \mathrm{g}$ of liver.

${ }^{\mathrm{ab}}$ Means in the same row not sharing a common superscript are significantly different $(P<0.05)$. 
Case et al. (1995) reported that dietary carvacrol and thymol, at levels of 150 ppm, did not influence body-weight gain in cockerels with initial weight of $126 \mathrm{~g}$ and followed during a 21-day feeding trial. In another experiment with female broilers we also found a lack of effect of thymol on growth performance and digestive enzyme activity when fed at a level of 100 ppm for a period of 6 weeks (Lee et al. 2002). We suggested that the antimicrobial activity of thymol may be masked by diet composition and/or environment, in that no effect of thymol on growth performance is seen when feeding a well-balanced diet and keeping the birds in a clean environment as was done in this study.

It has been reported that dietary thymol and carvacrol lower serum cholesterol concentrations in chickens (Case et al., 1995). The hypocholesterolemic effect of thymol and carvacrol has been ascribed to inhibition of 3-hydroxy-3-methylglutaryl coenzyme A (HMG-CoA) reductase (Elson 1995), the rate controlling enzyme of the cholesterol synthetic pathway. We have attempted to demonstrate an interaction between dietary cholesterol and either thymol or carvacrol. It was reasoned that by inhibition of HMG-CoA reductase activity through cholesterol feeding (Youn et al., 1993) there would be no apparent hypocholesterolemic effects of thymol and carvacrol. However, the present experiment failed to reveal a hypocholesterolemic effect of either thymol or carvacrol, irrespective of whether the diet was cholesterolfree or rich in cholesterol. The concentrations of liver free and esterified cholesterol were not changed either by thymol and carvacrol. Dietary carvacrol did significantly lower plasma triglycerides and phospholipids by on average 12 and $7 \%$, respectively. It is unknown how carvacrol could exert an effect on triglyceride and phospholipid metabolism without having an effect on cholesterol metabolism.

In conclusion, thymol and its isomer carvacrol had different effects on feed intake and weight gain. Our observation implies that essential oils can contain compounds with different, or possibly even opposite effects on growth performance. This notion may have impact on the use of essential oils as growth enhancers.

\section{Acknowledgements}

The authors are indebted to A. Lankhorst for technical assistance. K.-W. Lee was supported by the South Korean Ministry of Education. 


\section{References}

Allain, C. C., L. S. Poon, C. G. S. Chen, W. Richmond, and P. Fu, 1974. Enzymatic determination of total serum cholesterol. Clinical Chemistry 20: 476-482.

Assman, G., H. Schriewer, G. Schmitz, and E.-O. Hagele, 1983. Quantification of high-density lipoprotein cholesterol by precipitation with phosphotungstic acid/ $\mathrm{MgCl}_{2}$. Clinical Chemistry 29: 2026-2030.

Beynen, A. C., and C. E. West, 1989. Mechanisms underlying nutritional effects on serum cholesterol concentrations. Pages 89-114 in Coronaries and Cholesterol. Cliff, W. J., and G. I. Schoefl, eds. Chapman and Hall Medical, London.

Bucolo, G., and H. David, 1973. Quantitative determination of serum triglycerides by the use of enzymes. Clinical Chemistry 19: 476-482.

Case, G. L., L. He, H. Mo, and C. E. Elson, 1995. Induction of geranyl pyrophosphate pyrophophatase activity by cholesterol-suppressive isoprenoids. Lipids 30: 357-359.

Deans, S. G., and G. Ritchie, 1987. Antibacterial properties of plant essential oils. International Journal of Food Microbiology 5: 165-180.

Deyoe, C. W., R. E. Davies, R. Krishnan, R. Khaund, and J. R. Couch, 1962. Studies on the taste preference of the chick. Poultry Science 41: 781-784.

Didry, N., L. Dubreuil, and M. Pinkas, 1994. Activity of thymol, carvacrol, cinnamaldehyde and eugenol on oral bacteria. Pharmaceutica Acta Helvetiae 69: 25-28.

Dorman, H. J. D., and S. G. Deans, 2000. Antimicrobial agents from plants: antibacterial activity of plant volatile oils. Journal of Applied Microbiology 88: 308-316.

Elson, C. E., 1995. Suppression of mevalonate pathway activities by dietary isoprenoids: Protective roles in cancer and cardiovascular disease. Journal of Nutrition 125: 1666S-1672S.

Furia, T. E., and N. Bellanca, 1975. Fenaroli's handbook of flavor ingredients. Vol 2. Adapted from the Italian language works of Prof. Dr. Giovanni Fenaroil. 2nd ed. CRC Press, Ohio.

Genstat Committee, 2000. Reference manual. Numerical algorithms group Ltd, Oxford.

Guenther, E., 1949. The essential oils. Vol 2. Van Nostrand, New York.

Hammer, K. A., C. F. Carson, and T. V. Riley, 1999. Antimicrobial activity of essential oils and other plant extracts. Journal of Applied Microbiology 86: 985-990.

Helander, I. M., H.-L. Alakomi, K. Latva-Kala, T. Mattila-Sandholm, I. Pol, E. J. Smid, L. G. M. Gorris, and A. Von Wright, 1998. Characterization of the action of selected essential oil components on Gram-negative bacteria. Journal of Agricultural and Food Chemistry 46: 3590-3595.

Jenner, P. M., E. C. Hagan, J. M. Taylor, E. L. Cook, and O. G. Fitzhugh, 1964. Food flavourings and compounds of related structure. I. Acute oral toxicity. Food Cosmetics Toxicology 2: 327-343. 
Juven, B. J., J. Kanner, F. Schved, and H. Weisslowicz, 1994. Factors that interact with the antibacterial action of thyme essential oil and its active constituents. Journal of Applied Bacteriology 76: 626-631.

Lee, K.-W., H. Everts, H. J. Kappert, M. Frehner, R. Losa, and A. C. Beynen. 2002. Effects of dietary essential oil components on growth performance, digestive enzymes and lipid metabolism in female broiler chickens. British Poultry Science, in press.

National Research Council (NRC), 1994. Nutrient Requirements of Poultry. 9th rev. ed. National Academy Press, Washington, DC.

Takayama, M., S. Itoh, T. Nagasaki, and I. Tanimizu, 1977. A new enzymatic method for determination of serum choline-containing phospholipids. Clinica Chimica Acta 79: 93-98.

Wenk, C., 2000. Recent advances in animal feed additives such as metabolic modifiers, antimicrobial agents, probiotics, and enzymes and highly available minerals. Review. Asian-Australasian Journal Animal Sciences 13: 86-95.

Wybenga, D. R., and J. A. Inkpen, 1974. Lipids. Pages 1421-1493 in: Clinical chemistry: Principles and Technics. Henry, R. J., D. C. Cannon, and J. W. Winkelman, eds. Haper \& Row, New York.

Youn, B.-S., K. Tanaka, S. Ohtani, and U. Santoso, 1993. Effect of dietary cholesterol on 3-hydroxy-3methylglutaryl CoA reductase activity of growing chicks. Animal Science and Technology (Jpn) 64: 1156-1162. 


\section{Chapter 4}

\section{Addition of $\beta$-ionone to the diet fails to affect growth performance in female broiler chickens}

K.-W. Lee, H. Everts, ÆE. Lankhorst ${ }^{1}$, H.J. Kappert, A.C. Beynen

Department of Nutrition and 'Department of Laboratory Animal Science, Faculty of Veterinary Medicine, Utrecht University, P.O. Box 80.152, 3508 TD Utrecht,

The Netherlands 


\section{Summary}

There is suggestive evidence that $\beta$-ionone has potential as alternative to antimicrobial growth enhancers. The compound may also have hypocholesterolaemic activity. The present experiment was conducted to investigate the effect of $\beta$-ionone on growth performance and cholesterol metabolism in female broiler chickens. The experiment had a $2 \times 2$ factorial design with diets containing 0 or $1 \%$ cholesterol and 0 or $200 \mathrm{ppm} \beta$-ionone. After feeding the diets to one-day old pullets for 26 days, weight gain, feed intake and feed:gain ratio were not affected by the dietary treatments. Thus, under the present experimental conditions, $\beta$-ionone failed to affect growth performance. Dietary cholesterol significantly increased plasma and liver cholesterol, and plasma triglyceride concentrations. Dietary $\beta$ ionone failed to affect the plasma lipid profile, irrespective of whether the diet was cholesterol free or cholesterol rich. 


\section{Introduction}

$\beta$-lonone (4-[2,6,6-trimethyl-1-cyclohexen-1-yl]-3-buten-2-one) may be isolated from volatile oil derived from Boronia megastigma Nees. (Brown boronia, Rutaceace), tea, tangelo and tomato (Naves, 1971). Antibacterial activity of $\beta$-ionone has been reported (Wilson et al., 1981; Gueldner et al., 1985; Kubo et al., 1992). In White Leghorn chicks aged either two or four weeks, dietary supplementation with 100 or 250 ppm of $\beta$-ionone enhanced weight gain by on average 10.6 and $22.3 \%$, respectively (Yu et al., 1994). The $\beta$-ionone-induced increase in body-weight-gain did not reach statistical significance, but the statistical power was low due to large interindividual variation. In the course of our studies concerning alternatives to antimicrobial growth enhancers, we decided to re-investigate the effect of $\beta$-ionone on growth performance in chickens. We used one-day-old female broiler chickens that were fed a diet without or with 200 ppm $\beta$-ionone for a period of 26 days.

$\beta$-lonone has been shown to lower serum cholesterol concentrations in chickens through inhibition of 3-hydroxy-3-methylglutaryl-coenzyme A (HMG-CoA) reductase (Yu et al., 1994; Elson, 1995), the rate-controlling enzyme in cholesterol synthesis. In this study on growth affecting activity of dietary $\beta$-ionone we also determined its effect on plasma cholesterol concentrations. It was reasoned that dietary cholesterol would attenuate the hypocholesterolaemic property of $\beta$-ionone because cholesterol feeding suppresses the activity of hepatic microsomal HMGCoA reductase (Santoso et al., 2000). Thus, the present experiment had a $2 \times 2$ factorial design in which we used diets without or with $1 \%$ cholesterol containing either no or 200 ppm $\beta$-ionone.

\section{Materials and methods}

The experimental protocol was approved by the animal experiments committee of the Utrecht Faculty of Veterinary Medicine.

\section{Animals, diets and experimental design}

Forty eight 1-day-old female broilers (Cobbs) were purchased from a local hatchery. They were weighed on arrival and randomly subjected to one of four dietary treatments. Each treatment consisted of 4 cages with 3 birds per cage. The 
temperature of the animal house was controlled and continuous lighting used throughout the entire experimental period. There were four experimental diets: control diet; diet $+200 \mathrm{ppm} \beta$-ionone; diet $+1 \%$ cholesterol; diet $+1 \%$ cholesterol + 200 ppm $\beta$-ionone. A powdered base diet was formulated. Cholesterol was included at the expense of an identical amount of corn starch. $\beta$-lonone (97\% purity, Sigma, St. Louis, MO, USA) was dissolved in corn oil prior to mixing with the cholesterol-free or cholesterol-rich base diet. Other portions of the cholesterol-free and cholesterolbase diet were mixed with corn oil only. Corn oil was added at the level of $5 \%$ in all four diets. Table 1 shows the composition of the control diet. Feed was prepared freshly on a daily basis. Water was provided ad libitum.

\section{Measurements}

Feed was supplied for ad libitum consumption and left overs were weighed for each cage. Body weights were measured at the beginning and the end of experiment. Feed intake per cage and weight gain per cage were used to calculate the feed:gain ratios. On the last day of the 26-day feeding trial, blood was collected by heart puncture. Plasma was obtained by centrifugation at $1700 \times \mathrm{g}$ for $15 \mathrm{~min}$. and stored at $-70^{\circ} \mathrm{C}$. Immediately after blood sampling, birds were killed by cervical dislocation. Liver was sampled, weighed and stored at $-20 \stackrel{\circ}{ } \mathrm{C}$.

\section{Analysis}

Plasma cholesterol (Allain et al., 1974), triglyceride (Bucolo and David, 1973), and phospholipid (Takayama et al., 1977) concentrations were measured enzymatically on an autoanalyzer (Cobas Bio, Roche, Basel, Switzerland). Plasma very-low-density and low-density lipoproteins were precipitated with phosphotungstic acid/ $\mathrm{MgCl}_{2}$ (Sigma Diagnostics, St Louis, MO, USA; Catalogue number 352-4) according to Assman et al. (1983), and the supernatant (high-density lipoprotein, HDL) was assayed for cholesterol.

To measure liver cholesterol, thawed liver was homogenized with 4 volumes of ethanol and saponified with ethanolic $\mathrm{KOH}$ at $50{ }^{\circ} \mathrm{C}$ overnight. The free cholesterol 
was then extracted with petroleum ether, dried under nitrogen and dissolved in ethanol prior to enzymatic measurement (Allain et al., 1974) on the autoanalyzer.

Table 1 The composition of the control diet

\begin{tabular}{lc}
\hline Ingredients & $\mathrm{g}$ \\
\hline Corn, yellow & 300 \\
Corn starch & 222 \\
Soybean meal, 48\% CP & 375 \\
Corn oil & 50 \\
Sodium chloride & 5 \\
Calcium carbonate & 15 \\
Monocalcium phosphate & 19 \\
DL-methionine & 4 \\
Premix ${ }^{1}$ & 10 \\
Total & 1000
\end{tabular}

1 The $10 \mathrm{~g}$ premix consisted of $24.0 \mathrm{mg}$ vitamin $\mathrm{A}(500000 \mathrm{IU} / \mathrm{g}), 6.0 \mathrm{mg}$ vitamin $D_{3}(100000 \mathrm{lU} / \mathrm{g})$, $60.0 \mathrm{mg}$ vitamin $\mathrm{E}(500 \mathrm{lU} / \mathrm{g}), 6.6 \mathrm{mg}$ vitamin $\mathrm{K}_{3}$ (purity, 22.7\%), $100.0 \mathrm{mg}$ vitamin $\mathrm{B}_{12}$ (purity, $0.1 \%$ ), $2000.0 \mathrm{mg}$ biotin (purity, $0.01 \%$ ), $1100.0 \mathrm{mg}$ choline chloride (purity, 50\%), $1.1 \mathrm{mg}$ folic acid (purity, 90\%), $65.2 \mathrm{mg}$ nicotinic acid (purity, 100\%), $16.3 \mathrm{mg}$ d-pantothenate (purity, 92\%), $4.5 \mathrm{mg}$ vitamin $\mathrm{B}_{6}$ (purity, 100\%), $12.5 \mathrm{mg}$ riboflavin (purity, $80 \%$ ), $2.5 \mathrm{mg}$ vitamin $\mathrm{B}_{1}$ (purity, $100 \%$ ), $32.00 \mathrm{mg}$ $\mathrm{CuSO}_{4} .5 \mathrm{H}_{2} \mathrm{O}$, $333.20 \mathrm{mg} \mathrm{FeSO}{ }_{4} \cdot \mathrm{H}_{2} \mathrm{O}, 166.80 \mathrm{mg} \mathrm{MnO}, 1.0 \mathrm{mg} \mathrm{Na} \mathrm{SeO}_{3} .5 \mathrm{H}_{2} \mathrm{O} ; 220.00 \mathrm{mg}$ $\mathrm{ZnSO}_{4} \cdot \mathrm{H}_{2} \mathrm{O} ; 4.80 \mathrm{mg} \mathrm{CoSO}_{4} .7 \mathrm{H}_{2} \mathrm{O} ; 0.56 \mathrm{mg} \mathrm{KI}, 100.00 \mathrm{mg}$ ethoxyquin and $5742.94 \mathrm{mg}$ corn meal as carrier.

\section{Statistical analysis}

Pen was considered the experimental unit. The data were evaluated by ANOVA with presence or absence of $\beta$-ionone and cholesterol as main effects, using the SPSS/PC+ program. There was no interaction between dietary cholesterol and $\beta$-ionone. Treatment means were tested for statistically significant differences with the use of Tukey test. A $P$ value $<0.05$ was the criterion of significance. 


\section{Results and discussion}

It is clear that $\beta$-ionone did not influence growth performance of the broiler chickens, irrespective of whether the diet was cholesterol free or contained $1 \%$ of cholesterol (Table 2). The lack of effect of $\beta$-ionone on weight gain was unexpected in the light of the promising results reported by $\mathrm{Yu}$ et al. (1994). Either the results of Yu et al. (1994) were spurious, which would be supported by the fact that they did not reach statistical significance, or the present results may be considered impactless. The latter is unlikely as the lack of effect of $\beta$-ionone cannot be readily explained by insufficient statistical power, low dose or short duration of the trial. With the observed variance and the number of chickens used, an increase in weight gain by $3.1 \%$ is detected at a statistical power of $80 \%$ and a $P$ value of 0.05 . This increase, which would have been reasonably detectable, may be considered of practical relevance and is much smaller than group mean increases in weight gain seen by Yu et al. (1994). In the present experiment, not even a tendency towards a stimulatory effect of $\beta$-ionone on body-weight gain was seen. The $\beta$-ionone dose of 200 ppm and 26-days feeding period may be considered effective: other studies have shown growth enhancing effects when essential oils were fed at similar dietary concentrations for similar periods (Anonymous, 1997; Langhout, 2000; Kamel, 2001).

Table 2 Growth performance and relative liver weight in female broiler chickens fed diets with $\beta$ ionone and/or cholesterol for 26 days

\begin{tabular}{|c|c|c|c|c|c|}
\hline \multicolumn{5}{|c|}{ Treatments } & \multirow{3}{*}{ Pooled S.E.M. } \\
\hline$\beta$-ionone & - & + & - & + & \\
\hline Cholesterol: & - & - & + & + & \\
\hline Weight gain, g/d/bird & 43.6 & 43.8 & 41.4 & 42.6 & 1.084 \\
\hline Feed intake, $g / d /$ bird & 59.8 & 61.0 & 57.9 & 58.6 & 1.566 \\
\hline Feed : gain, $g / g$ & 1.37 & 1.39 & 1.40 & 1.38 & 0.017 \\
\hline Liver, $\mathrm{g} / 100 \mathrm{~g}$ body weight & $2.11^{\mathrm{b}}$ & $2.11^{\mathrm{b}}$ & $2.42^{\mathrm{a}}$ & $2.39^{\mathrm{a}}$ & 0.065 \\
\hline
\end{tabular}

${ }^{\mathrm{ab}}$ Means in the same row not sharing a common superscript are significantly different $(P<0.05)$. 
The growth enhancing effect of $\beta$-ionone, if any, could be dependent on the strain of chicken and/or the background composition of the diet. In this study, rapidly growing broilers were used, whereas Yu et al. (1994) used slowly growing layer pullets. In this study and also that of Yu et al. (1994), corn-soybean meal based diets were used. It may be noted that the diets used in this study contained about 12000 IU of added vitamin A per $\mathrm{kg}$, whereas those used by $\mathrm{Yu}$ et al. (1994) contained $4500 \mathrm{IU}$ per $\mathrm{kg}$. $\beta$-lonone is a structural analog of $\beta$-carotene (Parodi, 1997), a precursor of vitamin $A$, the conversion into vitamin $A$ being subject to feed back inhibition (Helzlsouer et al., 1994). It could be suggested that conversion of $\beta$-ionone into some biologically active metabolite is inhibited by high intake of vitamin $A$. This highly speculative suggestion would then explain why $\beta$-ionone stimulates growth when vitamin A intake is low, but not when it is high.

Table 3 Plasma and liver lipids in female broiler chickens fed diets with $\beta$-ionone and/or cholesterol for 26 days

\begin{tabular}{|c|c|c|c|c|c|}
\hline & \multicolumn{4}{|c|}{ Treatments } & \multirow{3}{*}{ Pooled S.E.M } \\
\hline$\beta$-ionone : & - & + & - & + & \\
\hline Cholesterol: & - & - & + & + & \\
\hline \multicolumn{6}{|l|}{ Plasma lipids, mmol/L } \\
\hline Total cholesterol & $3.14^{\mathrm{b}}$ & $2.90^{\mathrm{b}}$ & $4.74^{\mathrm{a}}$ & $5.19^{\mathrm{a}}$ & 0.173 \\
\hline HDL cholesterol & 2.16 & 2.00 & 2.07 & 2.16 & 0.084 \\
\hline Phospholipids & 2.84 & 2.62 & 2.66 & 2.62 & 0.107 \\
\hline Triglycerides & $0.43^{\mathrm{b}}$ & $0.43^{b}$ & $0.64^{a}$ & $0.58^{\mathrm{ab}}$ & 0.049 \\
\hline $\begin{array}{l}\text { Liver cholesterol, } \mu \mathrm{mol} / \mathrm{g} \\
\text { of liver }\end{array}$ & $26.3^{\mathrm{b}}$ & $27.8^{\mathrm{b}}$ & $162.8^{\mathrm{a}}$ & $150.7^{\mathrm{a}}$ & 20.529 \\
\hline
\end{tabular}


As would be anticipated (Santoso et al., 2000) cholesterol feeding raised plasma and liver cholesterol concentrations and also plasma triglyceride levels (Table 3). Contrary to the results published by Yu et al. (1994), $\beta$-ionone did not lower plasma cholesterol. The discrepancy cannot be readily explained.

\section{Acknowledgement}

K.-W. Lee was supported by the South Korean Ministry of Education.

\section{References}

Anonymous, 1997. CRINA ${ }^{\circledR} \mathrm{HC}$ for poultry based on essential oils. Akzo Nobel.

Allain, C.C., Poon, L.S., Chen, C.G.S., Richmond, W., Fu, P., 1974. Enzymatic determination of total serum cholesterol. Clinical Chemistry 20: 476-482.

Assman, G., Schriewer, H., Schmitz, G., Hagele, E.O., 1983. Quantification of high-density lipoprotein cholesterol by precipitation with phophotungstic acid/ $\mathrm{MgCl}_{2}$. Clinical Chemistry 29: 20262030 .

Bucolo, G., David, H., 1973. Quantitative determination of serum triglycerides by the use of enzymes. Clinical Chemistry 19: 476-482.

Elson, C.E., 1995. Suppression of mevalonate pathway activities by dietary isoprenoids: Protective roles in cancer and cardiovascular disease. Journal of Nutritrion 125: 1666S-1672S.

Gueldner, R.C., Wilson, D.M., Heidt, A.R., 1985. Volatile compounds inhibiting Aspergillus flavus. Journal of Agricultural and Food Chemistry 33: 411-413.

Helzlsouer, K.J., Block, G., Blumberg, J., Diplock, A.T., Levine, M., Marnett, L.J., Schulplein, R.J., Spence, J.T., Simic, M.G., 1994. Summary of the round table discussion on strategies for cancer prevention: Diet, food, additives, supplements, and drugs. Cancer Research 54: 2044S-2051S.

Kamel, C., 2001. Tracing modes of action and the roles of plant extracts in non-ruminants. In: Garnsworthy, P.C., Wiseman, J., (Eds.), Recent Advances in Animal Nutrition. Nottingham University Press, Nottingham, pp. 135-150.

Kubo, I., Muroi, H., Himejima, M., 1992. Antimicrobial activity of green tea flavor components and their combination effects. Journal of Agricultural and Food Chemistry 40: 245-248.

Langhout, P., 2000. New additives for broiler chickens. World Poultry 16 (No 3): 22-27. 
Naves, Y.R., 1971. Some developments in the chemistry of ionones and their derivatives - a subject review. Journal of the Society of Cosmetics Chemistry 22: 439-456.

Parodi, P.W., 1997. Cows' milk fat components as potential anticarcinogenic agents. Journal of Nutrition 127: 1055-1060.

Santoso, U., Ohtani, S., Tanaka, K., 2000. Tu-chung leaf meal supplementation reduced an increase in lipid accumulation of chickens stimulated by dietary cholesterol. Asian-Australasian Journal of Animal Sciences 13: 1758-1763.

Takayama, M., Itoh, S., Nagasaki, T., Tanimizu, I., 1977. A new enzymatic method for determination of serum choline-containing phospholipids. Clinica Chimica Acta 79: 93-98.

Wilson, D.M., Gueldner, R.C., McKinney, J.K., Lievsay, R.H., Evans, B.D., Hill, R.A., 1981. Effect of $\beta$ ionone on Aspergillus flavus and Aspergillus parasiticus growth, sporulation, morphology and aflatoxin production. Journal of the American Oil Chemists' Society 58: 959A-961A.

Yu, S.G., Abuimeileh, N.M., Qureshi, A.A., Elson, C.E., 1994. Dietary $\beta$-ionone suppresses hepatic 3hydroxy-3-methylglutaryl coenzyme A reductase activity. Journal of Agricultural Food Chemistry 42: 1493-1496. 
Chapter 5

\section{Cinnamaldehyde, but not thymol, counteracts the carboxymethylcellulose-induced growth depression in female broiler chickens}

K.-W. Lee, H. Everts, H. J. Kappert, H. Wouterse, M. Frehner ${ }^{1}$, A. C. Beynen

Department of Nutrition, Faculty of Veterinary Medicine, Utrecht University, 3508 TD, Utrecht, The Netherlands 'CRINA S.A., Akzo Nobel, Gland, Switzerland 


\section{Summary}

The question addressed was whether dietary essential oils could antagonize the negative effect of carboxymethylcellulose $(\mathrm{CMC})$ on growth performance in broilers. Diets without or with $1 \%$ CMC, and CMC containing diet with either $100 \mathrm{ppm}$ thymol, cinnamaldehyde or a commercial essential oil blend were fed to female broiler chickens for 40 days. Chicks receiving the $\mathrm{CMC}$ diet showed significantly depressed weight gain for the period of $0-21$ days. Addition of cinnamaldehyde or commercial essential oil to the CMC diet partially counteracted the negative effect on growth performance. Group mean feed intake was lower in CMC-fed chicks, but was raised when cinnamaldehyde or the commercial oil was added to the diet. Intestinal viscosity was increased by CMC inclusion, but was not lowered by the additives. Fat digestibility was significantly reduced by $\mathrm{CMC}$, but cinnamaldehyde or commercial oil inclusion partially reversed this effect. This study indicates that cinnamaldehyde, but not thymol, may antagonize the negative effects of $\mathrm{CMC}$ on growth performance which may relate to improving fat digestibility. 


\section{Introduction}

The antimicrobial activity of essential oils derived from spices and herbs (Deans and Ritchie 1987; Hammer et al., 1999) is of interest as these oils could be used as feed additives alternative to antibiotics (Taylor, 2001). We have addressed the question whether selected principles derived from essential oils, i.e. thymol, carvacrol, beta-ionone and cinnamaldehyde, would stimulate growth performance in broiler chickens (Chapter 2, 3 and 4). Under the conditions of our experiments, i.e. using female broiler chickens kept in a clean environment and fed a highly digestible diet, the compounds did not affect growth. It was reasoned that dietary essential oils could stimulate growth performance in broiler chickens fed a suboptimal diet. We decided to use a diet containing carboxymethylcellulose (CMC), which is a nonfermentable, viscous fiber that raises the viscosity of intestinal chyme and lowers growth performance in broiler chickens which is explained by depressed digestibility of macronutrients (Van Der Klis and Van Voorst, 1993; Smits et al., 1997). There is suggestive evidence that dietary essential oils may enhance macronutrient digestibility (Williams and Losa, 2001). Thymol (5-methyl-2-(1-methylethyl)phenol) is a major component of essential oils from thyme and cinnamaldehyde (3-phenyl-2propenal) is a major component of that from cinnamon. In this study we investigated whether dietary thymol, cinnamaldehyde or a commercial blend of essential oil compounds would be able to counteract the CMC-induced growth depression in broiler chickens.

\section{Materials and methods}

The experimental protocol was approved by the animal experiments committee of the Utrecht Faculty of Veterinary Medicine.

\section{Experimental design}

45 one-day old female broiler chickens (Cobbs) were obtained from a local hatchery. They were wing-banded, weighed and randomly allocated to one of 5 treatments. Each treatment had 3 pens with 3 chicks each so that there were 9 chicks per treatment. The 5 dietary treatments were as follows: base diet, base diet + 
1\% CMC (Akzo Nobel, Arnhem, The Netherlands), base diet + CMC + 100 ppm thymol, base diet $+\mathrm{CMC}+100$ ppm cinnamaldehyde, and base diet + CMC + 100 ppm commercial essential oil. The commercial preparation used was CRINA ${ }^{\circledR}$ Poultry (Akzo Nobel, Crina S.A., Switzerland); it contains $29 \%$ of active components, the composition being proprietary. The base diet contained $0.04 \%$ chromic oxide as a marker (Table 1) and 1\% CMC was included at the expense of cellulose. The CMC preparation used has high viscosity and is not fermented (Smits et al., 1997). Corn oil was used as fat source and included at the level of $5 \%$ (Table 1). Thymol $(99 \%$ purity, Acros Organics, Geel, Belgium), cinnamaldehyde (99\% purity, Acros Organics), and the commercial essential oil blend were dissolved in corn oil and then gently mixed with the diets to arrive at $5 \%$ corn oil and $100 \mathrm{ppm}$ of additives in the diet. The diets were prepared freshly each day. To compose the additive-free diets, the base and CMC-containing ingredients were mixed with corn oil only. Feed and water were provided for ad libitum consumption. The temperature of the room with the pens was $34{ }^{\circ} \mathrm{C}$ on arrival of the chickens and was gradually decreased to $25{ }^{\circ} \mathrm{C}$ after 3 weeks and then was kept constant. Lighting was on continuously. Individual body weights, feed and water intakes per pen were monitored weekly. Feed and water intake were calculated as $\mathrm{g} / \mathrm{day} / \mathrm{bird}$ and used to calculate the feed:gain ratio.

From days 37-39, excreta were collected quantitatively, weighed and dried at $60 \stackrel{\circ}{ } \mathrm{C}$ until weight was constant. Dried excreta were pooled per pen and ground to pass a 1-mm sieve. On day 40, blood was collected by heart puncture. Plasma was obtained by centrifugation at $1700 \times \mathrm{g}$ at $15 \mathrm{~min}$ and stored at $-70 \stackrel{\circ}{\circ} \mathrm{C}$ prior to analysis. Immediately after blood sampling, the birds were killed by cervical dislocation. Liver and pancreas were removed and weighed. Intestinal contents between Meckel's diverticulum and the ileocecal junction were collected in tubes on ice by gentle stripping of the segments. The samples were pooled per pen. Immediately after obtaining the digesta, the samples were mixed thoroughly, divided into several portions for various chemical analyses and stored at $-20{ }^{\circ} \mathrm{C}$. For determination of the intestinal viscosity, one portion was kept on ice and processed on the day of sampling.

\section{Measurements}

For viscosity measurements, the ice-cold digesta samples were centrifuged at $12000 \times \mathrm{g}$ for $2 \mathrm{~min}$. The viscosity of approximately $0.5 \mathrm{~mL}$ of supernatant was 
measured using a cone/plate geometry (cone angle, $1^{\circ}$ and diameter, $40 \mathrm{~mm}$ ) at 37 ${ }^{\circ} \mathrm{C}$ in a Bohlin CS 50 Rheometer (Bohlin Reologi, Mühlacker, Germany). The shear stress was varied from 19 to $0.1 \mathrm{~Pa}$. The measurement started at high shear stress, and was decreased stepwise to $0.1 \mathrm{~Pa}$ and then increased again to the initial value (down/up measurement). The viscosity at a shear stress of $1 \mathrm{~Pa}$ was taken as the viscosity value.

Table 1 Ingredient composition of the base diet and CMC-containing diets

\begin{tabular}{lc}
\hline Ingredient & $\mathrm{g}$ \\
\hline Corn, yellow & 300 \\
Corn starch & 211.6 \\
Soybean meal, 48\% CP & 375 \\
Corn oil & 50 \\
Sodium chloride & 5 \\
Calcium carbonate & 15 \\
Monocalcium phosphate & 19 \\
DL-Methionine & 4 \\
Premix ${ }^{1}$ & 10 \\
Cellulose ${ }^{2}$ & $0 / 10$ \\
CMC ${ }^{3}$ & $10 / 0$ \\
Chromic oxide & 0.4 \\
Total & 1000 \\
\hline
\end{tabular}

1The $10 \mathrm{~g}$ premix consisted of $24.0 \mathrm{mg}$ vitamin $\mathrm{A}(500000 \mathrm{IU} / \mathrm{g}) ; 6.0 \mathrm{mg}$ vitamin $\mathrm{D}_{3}(100000 \mathrm{lU} / \mathrm{g})$; $60.0 \mathrm{mg}$ vitamin $\mathrm{E}(500 \mathrm{lU} / \mathrm{g}) ; 6.6 \mathrm{mg}$ vitamin $\mathrm{K}_{3}$ (purity, 22.7\%); $100.0 \mathrm{mg}$ vitamin $\mathrm{B}_{12}$ (purity, $0.1 \%$ ); $2000.0 \mathrm{mg}$ biotin (purity, $0.01 \%$ ); $1100.0 \mathrm{mg}$ choline chloride (purity, 50\%); $1.1 \mathrm{mg}$ folic acid (purity, 90\%); $65.2 \mathrm{mg}$ nicotinic acid (purity, 100\%); $16.3 \mathrm{mg}$ d-pantothenate (purity, 92\%); $4.5 \mathrm{mg}$ vitamin $\mathrm{B}_{6}$ (purity, 100\%); $12.5 \mathrm{mg}$ riboflavin (purity, $80 \%$ ); $2.5 \mathrm{mg}$ vitamin $\mathrm{B}_{1}$ (purity, $100 \%$ ); $32.00 \mathrm{mg}$ $\mathrm{CuSO}_{4} .5 \mathrm{H}_{2} \mathrm{O} ; 333.20 \mathrm{mg} \mathrm{FeSO}{ }_{4} \cdot \mathrm{H}_{2} \mathrm{O} ; 166.80 \mathrm{mg} \mathrm{MnO} ; 1.0 \mathrm{mg} \mathrm{Na} \mathrm{SeO}_{3} .5 \mathrm{H}_{2} \mathrm{O} ; 220.00 \mathrm{mg}$ $\mathrm{ZnSO}_{4} \cdot \mathrm{H}_{2} \mathrm{O} ; 4.80 \mathrm{mg} \mathrm{CoSO}{ }_{4} .7 \mathrm{H}_{2} \mathrm{O} ; 0.56 \mathrm{mg} \mathrm{KI}, 100.00 \mathrm{mg}$ ethoxyquin and $5742.94 \mathrm{mg}$ corn meal as carrier.

${ }^{2}$ Arbocel (Akzo Nobel, Arnhem, The Netherlands).

${ }^{3} \mathrm{CMC}$ of high viscosity (AF 2805, Akzo Chemicals, Arnhem, The Netherlands). 
Isoprenoids such as carvacrol, thymol and $\beta$-ionone may influence plasma cholesterol concentrations (Case et al., 1995), which prompted us to determine plasma lipids in this study. Plasma total cholesterol, phospholipids, high-density lipoprotein (HDL) cholesterol, and triglycerides were measured as described (Beynen et al., 2000).

Nitrogen in the ileal digesta and diet samples was analyzed with the Kjeldahl method. Crude protein content was calculated as $6.25 \times \mathrm{N}(\mathrm{g})$. Starch contents in diet and ileal chyme were determined enzymatically using amyloglucosidase (EC 3.2.1.4) from Aspergillus niger (Boehringer Mannheim Diagnostica, Mannheim, Germany) according to the method of Cone and Vlot (1990). For crude fat determination, diet and excreta were first treated with $3 \mathrm{~N}$ hydrochloric acid for $1 \mathrm{hr}$ and then overnight extracted with diethylether. Extracted fat was measured after evaporating the solvent at $101{ }^{\circ} \mathrm{C}$. Chromium contents in diet and ileal chyme were determined according to Murthy et al. (1971) as outlined in the manual of the AAS 3300 (Perkin-Elmer Corp., Connecticut, USA).

The apparent ileal digestibilities of protein and starch were calculated as: $D C_{\text {diet }}=\left(1-\left[\left(\mathrm{Cr}_{\text {diet }} / \mathrm{Cr}_{\text {ileum }}\right) \times\left(\mathrm{P}, \mathrm{S}_{\text {ileum }} / \mathrm{P}, \mathrm{S}_{\text {diet }}\right)\right]\right) \times 100$, where $D \mathrm{C}_{\text {diet }}=$ apparent digestibility of either crude protein $(\mathrm{P})$ or starch $(\mathrm{S})$ in the diet; $\mathrm{Cr}_{\text {diet }}=$ concentration of chromium in the diet; $\mathrm{Cr}_{\text {ileum }}=$ concentration of chromium in the ileal content; $\mathrm{P}, \mathrm{S}_{\text {ileum }}=$ concentration of either crude protein or starch in the ileal content; $\mathrm{P}, \mathrm{S}_{\text {diet }}=$ concentration of either crude protein or starch in the diet.

\section{Statistical analysis}

Pooled SEMs were calculated by one-way ANOVA. Treatment means were evaluated for statistically significant differences using Tukey test. A P-value $<0.05$ was preset as criterion of statistical significance.

\section{Results}

For the period of $0-21$ days, daily weight gain was significantly lowered in CMC-fed birds when compared to those fed the CMC-free base diet (Table 2). When 
the additives were introduced into the CMC diet, the CMC-induced depression of weight gain was either not affected or partially counteracted. Birds fed the CMC diets with cinnamaldehyde or the commercial essential oil performed better than those fed the diet with CMC only, but the group differences did not reach statistical significance. Thymol did not counteract the CMC effect. Feed intakes for the period 0-21 days showed a pattern similar to that of weight gain, but without statistical significance (Table 2). Feed:gain ratio was lowest for the chickens fed the base diet and highest for the CMC group. The feed:gain ratio for the period 0-21 days when expressed as percentage increase versus that for the CMC-free base diet was 6.8 , 2.1, 2.1, and $4.5 \%$ for $\mathrm{CMC}$ alone and for $\mathrm{CMC}$ in combination with either thymol, cinnamaldehyde or the commercial essential oil, respectively.

The statistically significant treatment effect on weight gain seen for the period 0 - 21 days was not found for the period 0 - 40 days. Water consumption was not significantly different among treatments. Birds fed the commercial essential oil blend exhibited the highest group mean water intake and those given cinnamaldehyde showed the lowest intake.

Relative organ weights and ileal viscosity are presented in Table 3. Liver and pancreas weight were not affected by dietary treatment. Group mean ileal viscosity was markedly increased by $\mathrm{CMC}$ inclusion, but due to the high inter-individual variation the increase was not statistically significant. The additives did not influence the viscosity of ileal contents. Fecal fat digestibility was affected by dietary treatment: chickens fed the diet containing CMC only and those fed the CMC diet with thymol had significantly lower in fat digestibility than the control group (Table 3). The inhibitory effect of CMC on fat digestibility was partially counteracted by either cinnamaldehyde or the commercial essential oil, but the counteractive effect was not statistically significant. Ileal digestibilities of starch and crude protein were not significantly different between dietary treatments (Table 3). Both macronutrients were well digested at the level of the ileum, the apparent digestibility ranging from 92 to $95 \%$ for crude protein and being about $99 \%$ for starch. Plasma total cholesterol did not differ between dietary treatments (Table 4). Group mean triglycerides were somewhat lowered by the diets containing CMC, but the lowering was not statistically significant. HDL cholesterol and phospholipids were not influenced by the dietary variables. 
Essential oils and carboxymethylcellulose

Table 2 Effects of essential oils on growth performance in female broiler chickens fed on diets containing CMC

\begin{tabular}{|c|c|c|c|c|c|c|c|}
\hline \multirow[b]{2}{*}{ Measure } & \multicolumn{5}{|l|}{ Diet } & \multirow[b]{2}{*}{ SEM } & \multirow[b]{2}{*}{$P$ value } \\
\hline & Base & $\mathrm{CMC}$ & $\mathrm{CMC}+$ thymol & $\begin{array}{l}\mathrm{CMC}+ \\
\text { Cinnam- } \\
\text { aldehyde }\end{array}$ & $\begin{array}{l}\mathrm{CMC}+ \\
\text { commercial } \\
\text { preparation }\end{array}$ & & \\
\hline \multicolumn{8}{|l|}{$0-21$ days } \\
\hline Weight gain, $g / d /$ bird & $38.4^{\mathrm{a}_{1}}$ & $32.1^{\mathrm{b}}$ & $33.3^{\mathrm{b}}$ & $36.5^{\mathrm{ab}}$ & $36.6^{\mathrm{ab}}$ & 1.320 & 0.038 \\
\hline Feed intake, $g / d / b i r d$ & 54.2 & 48.4 & 48.0 & 52.5 & 54.0 & 1.841 & 0.092 \\
\hline Water intake, $g / d /$ bird & 113 & 106 & 114 & 105 & 132 & 9.398 & 0.332 \\
\hline Feed:gain, g / g & 1.412 & 1.508 & 1.441 & 1.441 & 1.475 & 0.023 & 0.108 \\
\hline Water:feed, g / g & 2.087 & 2.185 & 2.357 & 2.005 & 2.442 & 0.130 & 0.173 \\
\hline \multicolumn{8}{|l|}{0 - 40 days } \\
\hline Weight gain, g/d/bird & 51.4 & 47.0 & 44.3 & 47.6 & 49.2 & 1.916 & 0.182 \\
\hline Feed intake, $g / d /$ bird & 88.5 & 83.1 & 77.5 & 86.4 & 88.0 & 3.123 & 0.156 \\
\hline Water intake, g/d/bird & 181 & 178 & 174 & 166 & 206 & 12.331 & 0.278 \\
\hline Feed:gain, g / g & 1.720 & 1.769 & 1.752 & 1.815 & 1.789 & 0.021 & 0.069 \\
\hline Water:feed, g / g & 2.032 & 2.138 & 2.245 & 1.931 & 2.339 & 0.116 & 0.117 \\
\hline
\end{tabular}

${ }^{1}$ Results are expressed as means of three replicates per dietary group.

a.b Means having different superscripts within a same row differ significantly $(P<0.05)$. 
Table 3 Effects of essential oils on organ weights, ileal viscosity, and digestibilities of nutrients in female broiler chickens

\begin{tabular}{|c|c|c|c|c|c|c|c|}
\hline \multirow{2}{*}{ Measure at 40 days } & \multicolumn{5}{|l|}{ Diet } & \multirow[b]{2}{*}{ SEM } & \multirow[b]{2}{*}{$P$ value } \\
\hline & Base & $\mathrm{CMC}$ & $\mathrm{CMC}+$ thymol & $\begin{array}{l}\mathrm{CMC}+ \\
\text { cinnam- } \\
\text { aldehyde }\end{array}$ & $\begin{array}{l}\text { CMC + } \\
\text { commercial } \\
\text { preparation }\end{array}$ & & \\
\hline Liver, g / 100 g b.w. ${ }^{2}$ & $1.847^{1}$ & 1.707 & 1.742 & 1.841 & 1.834 & 0.090 & 0.719 \\
\hline Pancreas, g / 100 g b.w. ${ }^{2}$ & 0.157 & 0.159 & 0.155 & 0.172 & 0.153 & 0.009 & 0.621 \\
\hline Viscosity, mPa.s & 1.56 & 8.20 & 8.83 & 9.17 & 10.30 & 2.076 & 0.078 \\
\hline \multicolumn{8}{|l|}{ Ileal digestibilities } \\
\hline Crude protein, \% & 92.42 & 95.38 & 94.49 & 93.72 & 94.05 & 1.279 & 0.594 \\
\hline \multicolumn{8}{|l|}{ Fecal digestibility } \\
\hline Crude fat, \% & $88.90^{\mathrm{a}}$ & $86.77^{b}$ & $86.68^{b}$ & $87.23^{\mathrm{ab}}$ & $87.45^{\mathrm{ab}}$ & 0.432 & 0.028 \\
\hline
\end{tabular}

${ }^{1}$ Results are expressed as means of three replicates per dietary group.

2 b.w. = body weight. 
Essential oils and carboxymethylcellulose

Table 4 Effects of dietary essential oils on plasma lipids in female broiler chickens fed diet containing CMC at 40 days

\begin{tabular}{|c|c|c|c|c|c|c|c|}
\hline \multirow[b]{2}{*}{ Measure at 40 days } & \multicolumn{5}{|l|}{ Diet } & \multirow[b]{2}{*}{ SEM } & \multirow[b]{2}{*}{$P$ value } \\
\hline & Base & CMC & $\mathrm{CMC}+$ thymol & $\begin{array}{l}\mathrm{CMC}+ \\
\text { cinnam- } \\
\text { aldehyde }\end{array}$ & $\begin{array}{l}\text { CMC + } \\
\text { commercial } \\
\text { preparation }\end{array}$ & & \\
\hline Total cholesterol, mmol/L & $3.183^{1}$ & 3.232 & 2.934 & 3.102 & 3.104 & 0.142 & 0.660 \\
\hline Triglycerides, mmol/L & 0.469 & 0.387 & 0.354 & 0.392 & 0.356 & 0.051 & 0.527 \\
\hline HDL cholesterol, mmol/L & 2.852 & 2.742 & 2.586 & 2.771 & 2.787 & 0.156 & 0.805 \\
\hline
\end{tabular}

${ }^{1}$ Results are expressed as means of three replicates per dietary group. 


\section{Discussion}

The present experiment was conducted to investigate the effect of thymol and cinnamaldehyde on growth performance in female broiler chickens fed a suboptimal diet. CMC was added to the diet in order to depress growth performance as was reported earlier (Smits et al., 1997, 1998). Indeed, the diet containing 1\% CMC was found to lower weight gain by $16 \%$ during days $0-21$ and by $9 \%$ during days $0-40$. CMC is a non-fermentable, viscous fiber (Smits et al., 1997) and in the present study ileal viscosity rose on average 5 -fold when CMC was added to the diet. This observation corroborates earlier studies (Van Der Klis et al., 1993; Smits et al., 1997). As would be expected (Smits et al., 1997), CMC significantly lowered fat digestibility, albeit that the lowering was relatively small (Smits et al., 2000). Unlike earlier observations (Smits et al., 1997) CMC feeding did not decrease the ileal digestibilities

of starch and crude protein, which may be explained by the relatively small CMCinduced increase in viscosity of ileal digesta in this study as opposed to other studies (Van Der Klis et al., 1993; Smits et al., 1997, 2000). The decrease in macronutrient digestibility as mediated by CMC consumption is explained by the increase in viscosity of ileal digesta (Smits et al., 1997). In any event, the observed effects of CMC generally agree with those reported earlier.

For the period of $0-21$ days, the CMC-induced decrease in weight gain tended to be partially antagonized by either cinnamaldehyde or the commercial preparation in the diet. Weight gain in animals fed the CMC-containing diets with either cinnamaldehyde or the commercial preparation did not differ significantly from that in the birds fed the CMC-free base diet. Thymol was less effective in antagonizing the $\mathrm{CMC}$ effect than was either cinnamaldehyde or the commercial preparation. Feed intake showed the same pattern as weight gain, but the treatment effect failed to reach statistical significance. For the period 0 - 40 days, the CMC effect on weight gain was not statistically significant and the effect of cinnamaldehyde had disappeared. Group mean feed intakes for 0 - 40 days still showed the initial pattern in that CMC reduced group-mean feed intake and that cinnamaldehyde and the commercial preparation, but not thymol, tended to counteract the $\mathrm{CMC}$ effect. It is suggested that in the present experiment statistical power was not high enough to substantiate the observed treatment effects by statistical significance. 
It is concluded tentatively that both cinnamaldehyde and the commercial preparation partially counteracted the $\mathrm{CMC}$-induced reduction in weight gain and feed intake for the period of $0-21$ days. The question then arises as to the possible underlying mechanisms. The inhibitory effect of CMC on growth performance is explained by raising the viscosity of ileal contents and subsequent decrease in digestibility of macronutrients (Smits et al., 1997). However, cinnamaldehyde and the commercial preparation of essential oils did not lower the viscosity of ileal contents and thus had another mode of action. The CMC preparation used is not fermentable, but may raise microbial growth by increasing available substrates for microorganisms by inhibiting protein and starch digestibility (Smits et al., 1997). In this study, ileal digestibility of starch and protein was not lowered by CMC, which may relate to the highly digestible ingredients in the purified diet. Thus, under the conditions of this study, cinnamaldehyde and the commercial essential oil may not have counteracted the $\mathrm{CMC}$ effect by inhibiting $\mathrm{CMC}$-induced proliferation of the gut microflora. CMC feeding significantly decreased apparent crude fat digestibility which may be explained by a reduced availability of bile salts for the process of fat digestion (Smits et al., 1998). Fortification of the CMC diets with either cinnamaldehyde or the commercial essential oil blend raised fat digestibility to values not significantly different from those in the birds fed the CMC-free diet. It is thus likely that the CMC-antagonizing effect of cinnamaldehyde and the commercial preparation on growth performance relates to maintaining fat digestibility at a higher efficiency. This reasoning is reinforced by the observation that thymol did not counteract the CMC effect and did not affect fat digestibility. The stimulatory effect of cinnamaldehyde on fat digestibility may relate to stimulation of bile secretion as shown in rat (Harada and Yano 1975).

CMC has been reported to increase water intake and also the water:feed ratio in chickens (Van Der Klis and Van Voorst 1993; Van Der Klis et al., 1993; Smits et al., 1997, 1998). It is not clear why CMC did not stimulate water intake in this study. Moisture contents of ileal chyme were 82.8 and $85.0 \%$ for the control and CMC-fed chickens, indicating that water absorption in the birds fed CMC was impaired (Van Der Klis et al., 1993) and that CMC exhibited its water-holding capacity (Smits et al., 1998). The commercial blend of essential oils tended to raise water consumption, which agrees with earlier work (Chapte 2). However, cinnamaldehyde did not lower water consumption as seen earlier (Chapter 2), but it should be noted that in this study cinnamaldehyde was fed together with CMC. 
CMC failed to lower plasma cholesterol levels, but plasma triglycerides were on average $18 \%$ lower in CMC-fed chickens. CMC may reduce plasma cholesterol and triglycerides as a secondary feature to a low bile salt availability (Smits et al., 1997). The lack of effect of CMC feeding on plasma cholesterol in this study could relate to the use of corn oil as fat source. Dietary corn oil has hypocholesterolemic activity (Beynen and West, 1989) which may have masked any effect of CMC. Addition of either thymol, cinnamaldehyde or the commercial essential oil to the $\mathrm{CMC}$ diet did not affect plasma lipids. Isoprenoids such as thymol, carvacrol and $\beta$ ionone have been shown to lower plasma cholesterol concentrations in chickens (Case et al., 1995). It is not clear why this study failed to show a hypocholesterolemic effect of thymol.

In conclusion, the present study shows that cinnamaldehyde, but not thymol, might counteract the negative effect of $\mathrm{CMC}$ on growth performance in broiler chickens. The counteractive effect of cinnamaldehyde may be explained by the relief of the CMC-induced inhibition of fat digestion, but the molecular basis remains unknown.

\section{Acknowledgments}

We thank G. Lankhorst and Jan Van Der Kuilen for their analytical help and J. F. M. Coopmans and J. De Haas of Akzo Nobel Chemicals B. V. for viscosity measurements. Kyung-Woo Lee was supported by South Korean Ministry of Education.

\section{References}

Beynen, A. C., J. T. Schonewille, and A. H. M. Terpstra, 2000. Influence of amount and type of dietary fat on plasma cholesterol concentrations in goats. Small Ruminant Research 35: 141-147.

Beynen, A. C.; West, C. E., 1989: Mechanisms underlying nutritional effects on serum cholesterol concentrations. In: Cliff, w. j.; Schoefl, g. i. (eds.), Coronaries and Cholesterol. Chapman and Hall Medical, London, pp. 89-114.

Case G. L., L. He, H. Mo, and C. E. Elson, 1995. Induction of geranyl pyrophosphate pyrophosphatase activity by cholesterol-suppressive isoprenoids. Lipids 30: 357-359. 
Cone, J. W., and M. Vlot, 1990. Comparison of degradability of starch in concentrates by enzymes and rumen fluid. Journal of Animal Physiology and Animal Nutrition 63: 142-148.

Deans, S. G., and G. Ritchie, 1987. Antibacterial properties of plant essential oils. International Journal of Food Microbiology 5: 165-180.

Hammer, K. A., C. F. Carson, and T. V. Riley, 1999. Antimicrobial activity of essential oils and other plants extracts. Journal of Applied Microbiology 86: 985-990.

Harada, M., and S. Yano, 1975. Pharmacological studies on Chinese cinnamon. II. Effects of cinnamaldehyde on the cardiovascular and digestive system. Chemical and Pharmaceutical Bulletin 23: 941-947.

Murthy, G. K., U., Rhea, and J. T. Peeler, 1971. Levels of antimony, cadmium, chromium, cobalt, manganese, and zinc in institutional total diets. Environmental Science and Technology 5: 436-442.

Smits, C. H. M., P. J. Moughan, and A. C. Beynen, 2000. The inhibitory effect of a highly viscous carboxymethylcellulose on dietary fat digestibility in the growing chicken is dependent on the type of fat. Journal of Animal Physiology and Animal Nutrition 83: 231-238.

Smits, C. H. M., A. Veldman, H. J. Verkade, and A. C. Beynen, 1998. The inhibitory effect of carboxymethylcellulose with high viscosity on lipid absorption in broiler chickens coincides with reduced bile salt concentration and raised microbial numbers in the small intestine. Poultry Science 77: 1534-1539.

Smits, C. H. M., A. Veldman, M. W. A. Verstegen, and A. C. Beynen, 1997. Dietary carboxymethylcellulose with high instead of low viscosity reduces macronutrient digestion in broiler chickens. Journal of Nutrition 127: 483-487.

Taylor, D. J., 2001. Effects of antimicrobials and their alternatives. British Poultry Science 42 (Suppl): 67-68.

Van Der Klis, J. D., A. Van Voorst, and C. Van Cruyningen, 1993. Effect of a soluble polysaccharide (carboxy methyl cellulose) on the physico-chemical conditions in the gastrointestinal tract of broilers. British Poultry Science 34: 971-983.

Van Der Klis, J. D., and A. Van Voorst, 1993. The effect of carboxy methyl cellulose (a soluble polysaccharide) on the rate of marker excretion from the gastrointestinal tract of broilers. Poultry Science 72: 503-512.

Williams, P., and R. Losa, 2001. The use of essential oils and their compounds in poultry nutrition. World Poultry 17 (No 4): 14-15. 


\section{Chapter 6}

\section{Effects of dietary essential oil components on growth performance, fat digestibility, intestinal viscosity and plasma cholesterol in female broiler chickens fed a diet rich in rye}

K.-W. Lee, H. Everts, H. J. Kappert, J. Van Der Kuilen, A. G. Lemmens", M. Frehner², A. C. Beynen

Department of Nutrition and 'Department of Laboratory Animal Science, Faculty of Veterinary Medicine, Utrecht University, P.O. Box 80.152, 3508 TD Utrecht,

The Netherlands

${ }^{2}$ CRINA S.A. Akzo Nobel, Gland, Switzerland 


\section{Summary}

The present experiment was conducted to investigate the effects of dietary essential oil components, i.e., thymol, cinnamaldehyde and a commercial blend of essential oil components (CRINA ${ }^{\circledR}$ Poultry) on growth performance, fat digestibility, intestinal viscosity and plasma cholesterol in female broiler chickens fed on a diet rich in rye. Corn and rye base diets were formulated to be isoenergetic and isonitrogenous. There were 5 dietary treatments: corn diet, rye diet, rye diet +100 ppm thymol, rye diet +100 ppm cinnamaldehyde, and rye diet +100 ppm CRINA ${ }^{\circledR}$ Poultry. Each treatment consisted of 3 cages with 5 birds per cage. Feed and water were provided for ad libitum consumption. Birds fed on the rye versus corn diet showed a significantly impaired weight gain at 14 days of age. At 21 and 33 days of age, weight gain was superior in birds fed on the corn diet as compared to those fed on the rye diet, but statistical significance was not observed. The suppressed weight gain at 14 days of age as induced by rye consumption was partially overcome by dietary cinnamaldehyde. Feed intake did not differ statistically significant between the dietary treatments, but birds fed on the rye diet ate less than those fed on the corn diet. Birds fed cinnamaldehyde tended to consume more feed than those fed on thymol. The water:feed ratio was increased by feeding rye to the chickens, irrespectively of the feed additives. Jejunal and ileal viscosities of chickens fed on the rye diet as compared to the corn diet were significantly elevated, by $6-$ and 19fold, respectively. There was no indication of dietary essential oil components counteracting the rye-induced increase in ileal viscosity. Fecal fat digestibility was significantly lowered in birds fed on the rye diet without this effect not being modified by the additives. Plasma cholesterol tended to be increased in birds fed rye when compared to those fed corn. Birds fed cinnamaldehyde showed a significant increase in plasma cholesterol; phospholipids and HDL cholesterol were also elevated by dietary cinnamaldehyde. The present experiment indicates that dietary cinnamaldehyde tended to counteract the suppression of growth performance in female broiler chickens as induced by the feeding of a diet rich in rye. 


\section{Introduction}

It is well documented (Smits, 1996; Langhout, 1998) that soluble non-starch polysaccharides (NSPs) in barley, rye and wheat are known to lower animal performance by increasing intestinal viscosity and microflora as a secondary effect. Based on the latter observation, it is possible that the nutritive value of diets containing rye and barley could be improved by introducing antimicrobial compounds. Indeed, dietary antibiotics increased growth performance in chickens fed rye-based diet (Fernandez et al., 1973; Wagner et al., 1977; Marusich et al., 1978; Misir and Marquardt, 1978).

In the digestive trials with rye in chickens (Antoniou and Marquardt, 1982; Fengler et al., 1988), lipid digestibility was significantly improved by dietary antibiotics. The authors suggested that fat retention values were a good indicator of the overall nutritional value of rye-based diet. The evidence that microflora can deconjugate bile salts (Feighner and Dashkevicz, 1988), followed by reduction in bile acid pool (Smits et al., 1998) supports the negative effect of soluble NSPs on fat digestion in broiler chickens.

Earlier, we found that dietary cinnamaldehyde, but not thymol, at the level of $100 \mathrm{ppm}$ reversed the growth-suppressive effect of carboxymethylcellulose (CMC) in female broiler chickens (Chapter 5). This purified non-fermentable fiber was a tool to raise and study intestinal viscosity per se by separating contributory role of fermentability of fiber (Smits et al., 1997) on animal performance. Based on this earlier observation, we tested again two pure essential oil components, i.e. thymol and cinnamaldehyde whether they could counteract the growth-suppressive effect of rye in female broiler chickens. Thymol (5-methyl-2-(1-methylethyl)phenol) and cinnamaldehyde (3-phenyl-2-propenal), which is a main component of thymol and cinnamon essential oils, respectively were selected for their evaluation as possible feed supplements in poultry.

It was thus aimed to see whether dietary essential oil could improve nutritive value of rye and whether such an effect would be associated with a reduction in viscosity of jejunal and ileal contents and an increase in fat digestibility.

\section{Materials and methods}

The experiment protocol was approved by the animal experiments committee of the Utrecht Faculty of Veterinary Medicine. 
Table 1 The composition of basal diets

\begin{tabular}{|c|c|c|}
\hline Ingredients & Corn & Rye \\
\hline Corn $(85 \mathrm{~g} / \mathrm{kg} \mathrm{CP}), \mathrm{g}$ & 400 & 0 \\
\hline Rye (93 g/kg CP), g & 0 & 400 \\
\hline Corn starch, g & 0 & 186.5 \\
\hline Wheat $(115 \mathrm{~g} / \mathrm{kg} \mathrm{CP}), \mathrm{g}$ & 180 & 0 \\
\hline Soybean meal (485 g/kg CP), g & 205 & 180 \\
\hline Soybean isolate $(841 \mathrm{~g} / \mathrm{kg} \mathrm{CP}), \mathrm{g}$ & 74 & 108 \\
\hline Tallow, g & 40 & 40 \\
\hline Corn oil, g & 20 & 34 \\
\hline lodized salt, g & 4.2 & 4.2 \\
\hline Calcium carbonate, $\mathrm{g}$ & 16 & 16 \\
\hline Monocalcium phosphate, $\mathrm{g}$ & 17 & 17 \\
\hline DL-methionine, $\mathrm{g}$ & 3.5 & 3.9 \\
\hline L-threonine, $g$ & 0.3 & 0.4 \\
\hline Premix ${ }^{1}, g$ & 10 & 10 \\
\hline Cellulose $^{2}, \mathrm{~g}$ & 30 & 0 \\
\hline Total, g & 1000 & 1000 \\
\hline \multicolumn{3}{|l|}{ Calculated contents } \\
\hline Metabolizable energy, MJ/kg & 13.2 & 13.2 \\
\hline Crude protein, \% & 21.6 & 21.6 \\
\hline Crude fat, \% & 8.2 & 8.2 \\
\hline Lysine, \% & 1.2 & 1.3 \\
\hline Methionine+cystine, \% & 0.9 & 0.9 \\
\hline Calcium, \% & 1.0 & 1.0 \\
\hline Available phosphorus, \% & 0.5 & 0.5 \\
\hline
\end{tabular}

${ }^{1}$ The $10 \mathrm{~g}$ premix consisted of $24.0 \mathrm{mg}$ vitamin $\mathrm{A}(500000 \mathrm{lU} / \mathrm{g}) ; 6.0 \mathrm{mg}$ vitamin $\mathrm{D}_{3}(100000 \mathrm{lU} / \mathrm{g})$; $60.0 \mathrm{mg}$ vitamin $\mathrm{E}\left(500 \mathrm{lU} / \mathrm{g}\right.$ ); $6.6 \mathrm{mg}$ vitamin $\mathrm{K}_{3}$ (purity, $22.7 \%$ ); $100.0 \mathrm{mg}$ vitamin $\mathrm{B}_{12}$ (purity, $0.1 \%$ ); $2000.0 \mathrm{mg}$ biotin (purity, $0.01 \%$ ); $2000.0 \mathrm{mg}$ choline chloride (purity, 50\%); $1.1 \mathrm{mg}$ folic acid (purity, 90\%); $65.2 \mathrm{mg}$ nicotinic acid (purity, 100\%); $16.3 \mathrm{mg}$ d-pantothenate (purity, 92\%); $4.5 \mathrm{mg}$ vitamin $\mathrm{B}_{6}$ (purity, 100\%); $12.5 \mathrm{mg}$ riboflavin (purity, $80 \%$ ); $2.5 \mathrm{mg}$ vitamin $\mathrm{B}_{1}$ (purity, $100 \%$ ); $32.00 \mathrm{mg}$ $\mathrm{CuSO}_{4} .5 \mathrm{H}_{2} \mathrm{O} ; 333.20 \mathrm{mg} \mathrm{FeSO}{ }_{4} \cdot \mathrm{H}_{2} \mathrm{O} ; 166.80 \mathrm{mg} \mathrm{MnO} ; 1.0 \mathrm{mg} \mathrm{Na} \mathrm{SeO}_{3} .5 \mathrm{H}_{2} \mathrm{O} ; 220.00 \mathrm{mg}$ $\mathrm{ZnSO}_{4} . \mathrm{H}_{2} \mathrm{O} ; 4.80 \mathrm{mg} \mathrm{CoSO}{ }_{4} .7 \mathrm{H}_{2} \mathrm{O} ; 0.56 \mathrm{mg} \mathrm{KI}, 100.00 \mathrm{mg}$ ethoxyquin and $4842.94 \mathrm{mg}$ corn meal as carrier.

${ }^{2}$ Arbocel (Akzo Nobel, Arnhem, The Netherlands). 


\section{Animals, diets and experimental design}

75 one-day old female broiler chickens (Cobbs) were purchased from a local hatchery. They were weighed on arrival and randomly subjected to one of five dietary treatments. Each treatment consisted of 3 cages with 5 birds per cage. The temperature of the animal house was controlled and continuous lighting used throughout the entire experimental period.

Corn and rye diets were formulated isoenergetically and isonitrogenously (Table 1). The respective grain was added at the level of $40 \%$. They were in a powdered form. Fatty acid composition of corn and rye diet was analyzed and found to be similar (Table 2). Thus, two basal diets may differ in concentration of type of fiber between corn and rye diets. According to Smits and Annison (1997), rye contained $4.6 \%$ DM soluble NSPs and $3.4 \%$ DM as arabinoxylans. It can be calculated that the present rye diet could possess $16 \mathrm{~g} \mathrm{NSPs} / \mathrm{kg}$ of diet and arabinoxylans amounted to approximately $12 \mathrm{~g} / \mathrm{kg}$ of diet. A $10 \mathrm{~g}$ of corn oil $/ \mathrm{kg}$ of diet was used to formulate experimental diets. There were five experimental diets; corn diet; rye diet; rye diet +100 ppm thymol (99\% purity, Acros Organics, Geel, Belgium); rye diet +100 ppm cinnamaldehyde (99\% purity, Acros Organics); rye diet +100 ppm CRINA ${ }^{\circledast}$ Poultry. CRINA ${ }^{\circledast}$ Poultry (Akzo Nobel, Crina S.A., Gland, Switzerland) is a commercially available essential oil-based product. Feed supplements were first mixed with corn oil and then added to rye diet to reach at a dietary concentration of $100 \mathrm{ppm}$. Rye and corn control diets were blended with corn oil only. Birds were fed on their respective diets for 33 days of age. Birds were weighed individually on a weekly basis. Feed and water intake were weighed per pen weekly. Feed:gain and water:feed ratio were determined for each cage. Feed and water were provided for ad libitum consumption.

\section{Sampling}

From 31-33 days, total excreta were collected, dried at $60^{\circ} \mathrm{C}$ for three days, weighed and pooled per pen. At the end of experimental periods, birds were individually weighed and blood was collected by heart puncture. Plasma was obtained by centrifugation at $1700 \times \mathrm{g}$ for $15 \mathrm{~min}$ and measured for plasma lipids. Immediately after blood sampling, birds were killed by cervical dislocation. Then, the intestinal tract was removed to obtain digesta by gentle finger stripping of the 
intestinal segments, and livers and pancreases were sampled and weighed. Jejunum was defined as the segment from the end of the duodenum to Meckel's diverticulum, and ileum as the part between Meckel's diverticulum and ileocecal junction. The respective intestinal digesta were pooled per pen, homogenized thoroughly and centrifuged at $12000 \mathrm{~g}$ for $5 \mathrm{~min}$ to obtain supernatants. They were kept on ice prior to viscosity measurement.

Table 2 Analyzed fatty acid compositions in the experimental diets

\begin{tabular}{lcc}
\hline & Corn & Rye \\
\hline C16:0, palmitic acid (\%) & 20.8 & 19.1 \\
C18:0, stearic acid (\%) & 5.8 & 5.4 \\
C18:1, oleic acid (\%) & 32.8 & 32.7 \\
C18:2, linoleic acid (\%) & 26.8 & 31.7 \\
C18:3, $\alpha$-linolenic acid (\%) & 1.2 & 1.8 \\
\hline
\end{tabular}

${ }_{1}^{1}$ Percentage fatty acid methyl ester of total fatty acid methyl esters.

\section{Analysis}

For viscosity measurements, the supernatants obtained were measured using a cone/plate geometry, cone angle $1^{\circ}$ and diameter $40 \mathrm{~mm}$ at $37^{\circ} \mathrm{C}$ in a Bohlin CS 50 Rheometer (Bohlin Reologi, Mühlacker, Germany). The shear stress was varied from 19 to $0.1 \mathrm{~Pa}$. The measurement started at high shear stress, and decreased stepwise to $0.1 \mathrm{~Pa}$ and then increased again to the initial value (down/up measurement). The viscosity at a shear stress of $1 \mathrm{~Pa}$ was taken as the viscosity value.

Plasma cholesterol (Allain et al., 1974), triglycerides (Bucolo and David, 1973), and phospholipids (Takayama et al., 1977) were measured enzymatically on an autoanalyzer (Cobas Bio, Roche, Switzerland). Plasma very-low-density and lowdensity lipoproteins were precipitated with phosphotungstic acid/ $\mathrm{MgCl}_{2}$ (Sigma Diagnostics, St Louis, MO, USA, Catalogue number 352-4) according to Assman et 
al. (1983), and the supernatant (high-density lipoprotein, HDL) was assayed for cholesterol.

Crude fat in diet and excreta was first treated with $3 \mathrm{~N}$ hydrochloric acid for 1 $\mathrm{hr}$ and further extracted with diethylether overnight. Total crude fat extracted was then measured after drying at $101^{\circ} \mathrm{C}$ overnight.

To determine the fatty acid composition of the corn and rye diets, a 10-g sample was extracted with a chloroform:methanol $(2: 1, \mathrm{v} / \mathrm{v})$ mixture according to the method of Folch et al. (1957). Then, $20-25 \mathrm{mg}$ of the extracted fat was saponified with $0.5 \mathrm{M}$ methanolic sodiumhydroxide and methylated with boronitrifluoridemethanol (Product no. 49370, Pierce, Illinois, USA) according to the method of Metcalfe et al. (1966). The methylesters obtained were determined by gas chromatography.

\section{Statistical analysis}

Pen was considered the experimental unit. The data obtained were evaluated by ANOVA using the SPSS/PC+ program. Treatment means were tested for statistically significant differences with the multiple range test of Duncan using the SPSS/PC+ program. The level of statistical significance was pre-set at $P<0.05$.

\section{Results}

\section{Growth performance}

Weight gain of birds fed a diet containing rye instead of corn was significantly lowered by on average $15.6 \%$ at 14 days of age (Table 3 ). The rye-suppressed weight gain was persisted at either 21 or 33 days of age by on average 11.6 and $6.9 \%$, respectively however they did not reach statistical significance due to the large inter-individual variances. When dietary essential oils were introduced into rye diet, birds fed on cinnamaldehyde tended to overcome the growth-suppressive effect of rye at 14 days of age $(P>0.05)$. This tendency was still seen in birds fed on cinnamaldehyde at 21 and 33 days of age by increasing average weight-gain of 10.1 and $8.5 \%$ when compared to those fed on rye only. On the other hand, birds fed on thymol and CRINA ${ }^{\circledR}$ Poultry were not shown any sign of improvement. Chickens fed 
on rye diet tended to lower daily feed intake ( $P>0.05)$ by on average 12.8 and $11.4 \%$ at 14 and 21 days of age as compared to those fed on corn diet. When dietary essential oil components were supplemented into rye diet, dietary cinnamaldehyde partially $(P>0.05)$ increased daily feed intake whereas thymol seemed to lower feed intake. Feed:gain ratio was not significantly different between corn and rye group. However, thymol versus cinnamaldehyde tended to lower feed:gain ratio. Daily water intake of birds fed on rye was increased by on average 24.3, 20.1 and $18.9 \%$ at 14 , 21 and 33 days of age, respectively as compared to that of those fed on corn, however they did not reach statistical significance. Rye versus corn significantly $(P<0.05)$ increased water:feed ratio during the experimental periods. However, there were no sign of effect of dietary essential oil components on water:feed ratio.

\section{Organ weighs and intestinal viscosity}

Wet liver weights in birds fed a diet rich in rye were tended to be lighter than those fed on corn diet (Table 4). The rye-mediated reduction in liver weight was reversed by dietary cinnamaldehyde, but not by thymol and CRINA ${ }^{\circledR}$ Poultry. Wet pancreas weights were significantly lowered by rye as compared to corn. The reduction was not affected by dietary essential oils. Relative liver weight ( $\mathrm{g} / 100 \mathrm{~g}$ of body weight) was followed the trends as reported in wet liver weights. However, relative pancreas weights were not different between dietary treatments. Birds fed on rye instead of corn exhibited significantly higher jejunal viscosities by on average 6fold (Table 4). Ileal viscosity was more pronounced by increasing 19-fold due to rye inclusion. However, there was no sign of lowering viscosity by dietary inclusion of essential oil components.

\section{Fat digestibility and plasma lipids}

Fecal fat digestibility was presented in Table 5. It is apparent that rye significantly impaired fat digestibility by on average $9 \%$ as compared to corn. The rye-mediated inhibition of fat digestion was not overcome by dietary essential oil components. Excreta of chickens fed on a diet rich in rye irrespective of additives were clearly brownish (personal observation). 
Table 3 Effect of dietary essential oils on growth performance in female broiler chickens

\begin{tabular}{|c|c|c|c|c|c|c|c|}
\hline \multirow[b]{2}{*}{ Parameters } & \multicolumn{5}{|c|}{ Treatments ${ }^{1}$} & \multirow[b]{2}{*}{$\begin{array}{l}\text { Pooled } \\
\text { SEM }^{2}\end{array}$} & \multirow[b]{2}{*}{$P$ value } \\
\hline & Corn & Rye & $\begin{array}{l}\text { Rye + } \\
\text { Thymol }\end{array}$ & $\begin{array}{c}\text { Rye + } \\
\text { Cinnam- } \\
\text { aldehyde }\end{array}$ & $\begin{array}{l}\text { Rye + Crina } \\
\text { Poultry }\end{array}$ & & \\
\hline \multicolumn{8}{|c|}{ Weight gain, g/d/bird } \\
\hline Day 14 & $25.0 \mathrm{a}$ & $21.1 \mathrm{~b}$ & $20.2 b$ & $22.7 a b$ & $20.6 b$ & 0.837 & 0.013 \\
\hline Day 21 & 33.6 & 29.7 & 29.8 & 32.7 & 30.0 & 1.361 & 0.204 \\
\hline Day 33 & 46.5 & 43.3 & 44.4 & 47.0 & 43.7 & 1.796 & 0.510 \\
\hline \multicolumn{8}{|c|}{ Feed intake, $g / d / b i r d$} \\
\hline Day 14 & $31.2 \mathrm{a}$ & $27.2 a b c$ & $25.1 \mathrm{c}$ & $30.1 \mathrm{ab}$ & $26.9 \mathrm{bc}$ & 1.247 & 0.036 \\
\hline Day 21 & 44.6 & 39.5 & 38.2 & 44.2 & 40.0 & 1.642 & 0.067 \\
\hline Day 33 & 69.1 & 66.0 & 64.4 & 71.8 & 65.8 & 2.460 & 0.275 \\
\hline \multicolumn{8}{|c|}{ Water intake, $g / d /$ bird } \\
\hline Day 14 & 71.1 & 88.4 & 76.1 & 89.5 & 81.1 & 7.551 & 0.411 \\
\hline Day 21 & 97.4 & 117.5 & 103.2 & 121.5 & 110.6 & 8.187 & 0.282 \\
\hline Day 33 & 141.5 & 168.2 & 158.3 & 174.3 & 162.4 & 8.751 & 0.168 \\
\hline \multicolumn{8}{|c|}{ Feed:gain, g:g } \\
\hline Day 14 & 1.25 & 1.29 & 1.24 & 1.32 & 1.31 & 0.021 & 0.071 \\
\hline Day 21 & 1.33 & 1.33 & 1.28 & 1.35 & 1.33 & 0.017 & 0.167 \\
\hline Day 33 & 1.49 & 1.52 & 1.45 & 1.53 & 1.51 & 0.027 & 0.335 \\
\hline \multicolumn{8}{|c|}{ Water:feed, g:g } \\
\hline Day 14 & 2.28 & 3.22 & 3.02 & 2.98 & 3.01 & 0.209 & 0.074 \\
\hline Day 21 & 2.20 & 2.95 & 2.70 & 2.76 & 2.76 & 0.166 & 0.076 \\
\hline Day 33 & $2.05 b$ & $2.54 a$ & $2.46 a$ & $2.43 a$ & $2.47 a$ & 0.085 & 0.017 \\
\hline
\end{tabular}

2SEM = Standard error of means.

${ }^{a b}$ Means in the same row with different letters are significantly different $(P<0.05)$. 
Table 4 Effect of dietary essential oils on organ weights and intestinal viscosity in female broiler chickens

\begin{tabular}{|c|c|c|c|c|c|c|c|}
\hline \multirow[b]{2}{*}{ Parameters } & \multicolumn{5}{|c|}{ Treatments } & \multirow{2}{*}{$\begin{array}{l}\text { Pooled } \\
\text { SEM }^{2}\end{array}$} & \multirow[b]{2}{*}{$P$ value } \\
\hline & Corn & Rye & $\begin{array}{l}\text { Rye + } \\
\text { Thymol }\end{array}$ & $\begin{array}{c}\text { Rye + } \\
\text { Cinnam- } \\
\text { aldehyde }\end{array}$ & $\begin{array}{l}\text { Rye + Crina } \\
\text { Poultry }\end{array}$ & & \\
\hline \multicolumn{8}{|c|}{ Wet organ weight } \\
\hline Liver, $g$ & $34.4 a b$ & $30.9 b$ & $32.8 \mathrm{~b}$ & $37.3 a$ & $32.6 b$ & 1.171 & 0.027 \\
\hline Pancreas, g & $3.87 a$ & $3.38 b$ & $3.44 b$ & $3.55 a b$ & $3.36 b$ & 0.105 & 0.033 \\
\hline \multicolumn{8}{|c|}{ Relative organ weight ${ }^{1}$} \\
\hline Liver & 2.20 & 2.11 & 2.18 & 2.35 & 2.21 & 0.065 & 0.183 \\
\hline Pancreas & 0.25 & 0.23 & 0.23 & 0.23 & 0.23 & 0.013 & 0.732 \\
\hline \multicolumn{8}{|c|}{ Viscosity, mPa.s } \\
\hline Jejunum & $1.26 b$ & $7.82 \mathrm{a}$ & $7.40 \mathrm{a}$ & $8.65 a$ & $8.03 a$ & 0.650 & 0.000 \\
\hline Ileum & $1.62 b$ & $30.7 a$ & $22.5 a$ & $24.2 a$ & $33.2 \mathrm{a}$ & 5.449 & 0.016 \\
\hline
\end{tabular}

${ }^{1} \mathrm{~g} / 100 \mathrm{~g}$ of body weight

2 SEM = Standard error of means

${ }^{a b}$ Means in the same row with different letters are significantly different $(P<0.05)$ 
Table 5 Effects of dietary essential oils on fecal digestibility of nutrients and plasma lipid profiles in female broiler chickens fed diet containing corn and rye based diets

\begin{tabular}{|c|c|c|c|c|c|c|c|}
\hline \multirow[b]{2}{*}{ Parameters } & \multicolumn{5}{|c|}{ Treatments } & \multirow[b]{2}{*}{$\begin{array}{l}\text { Pooled } \\
\text { S.E.M }{ }^{1}\end{array}$} & \multirow[b]{2}{*}{$P$ value } \\
\hline & Corn & Rye & $\begin{array}{l}\text { Rye + } \\
\text { Thymol }\end{array}$ & $\begin{array}{l}\text { Rye + } \\
\text { Cinnam- } \\
\text { aldehyde }\end{array}$ & $\begin{array}{l}\text { Rye + } \\
\text { Crina } \\
\text { Poultry }\end{array}$ & & \\
\hline \multicolumn{8}{|l|}{$\begin{array}{l}\text { Fecal digestibility, } \\
\% \text { of intake }\end{array}$} \\
\hline Crude fat & $81.8 \mathrm{a}$ & $74.6 b$ & $76.9 b$ & $74.1 b$ & $75.3 b$ & 1.077 & 0.003 \\
\hline \multicolumn{8}{|l|}{ Plasma lipids } \\
\hline Total cholesterol, $\mathrm{mmol} / \mathrm{L}$ & $2.94 \mathrm{c}$ & $3.14 b c$ & $3.17 b$ & $3.40 \mathrm{a}$ & $3.16 b c$ & 0.065 & 0.009 \\
\hline Triglycerides, $\mathrm{mmol} / \mathrm{L}$ & 0.38 & 0.40 & 0.40 & 0.47 & 0.35 & 0.041 & 0.382 \\
\hline Phospholipids, mmol/L & 2.72 & 2.91 & 2.90 & 3.14 & 2.94 & 0.087 & 0.074 \\
\hline HDL cholesterol, $\mathrm{mmol} / \mathrm{L}$ & $2.04 \mathrm{c}$ & $2.20 \mathrm{abc}$ & $2.17 b c$ & $2.36 a$ & $2.23 a b$ & 0.052 & 0.017 \\
\hline HDL cholesterol, $\%$ of total & 69.3 & 70.1 & 68.6 & 69.5 & 70.6 & 1.174 & 0.791 \\
\hline
\end{tabular}

${ }^{1}$ SEM $=$ Standard error of means

${ }^{a b c}$ Means in the same row with different letters are significantly different $(P<0.05)$ 
Plasma cholesterol was higher in rye-fed chickens as compared to corn-fed counterparts ( $P>0.05$; Table 5 ). Chickens fed on cinnamaldehyde at the level of 100 ppm significantly increased plasma cholesterol by 15.6 and $8.3 \%$ as compared to those fed on corn and rye, respectively $(P<0.05)$. However, addition of thymol and $\mathrm{CRINA}^{\circledR}$ Poultry into a diet rich in rye failed to affect plasma cholesterol. Plasma phopholipids and HDL cholesterol were numerically elevated by dietary cinnamaldehyde, but statistical siginificances were not found. Plasma triglycerides were not affected by dietary treatments. Relative HDL cholesterol (\% of total) was amounted to approximately $70 \%$ of total cholesterol, irrespective of dietary treatments.

\section{Discussion}

The present experiment was conducted to investigate whether dietary essential oil components, thymol, cinnamaldehyde and CRINA ${ }^{\circledR}$ Poultry could overcome the anti-nutritional effect of rye. As would be expected, chickens fed a diet containing rye versus corn were significantly lighter being daily weight gain lowered by on average $15.6 \%$ at 14 days of age. The rye-mediated retardation in weight gain continued to 21 and 33 days of age by being lowered on average $11.6 \%$ and $6.9 \%$, but the reductions were not statistically significant because of insufficient statistical power caused by a large inter-individual variation. Daily feed intakes of chicks fed on rye versus corn were lower $(P>0.05)$ by 12.8 and $11.4 \%$ at 14 and 21 days of age. Feeding rye to chickens caused a significant increase in water:feed ratio during the entire experimental periods. In addition, jejunal and ileal viscosities were significantly elevated by rye inclusion. Furthermore, fecal fat digestibilities of chickens fed a diet rich in rye were significantly low as compared to those fed a corn diet. In this regard, the present results confirm the detrimental effect of rye in terms of growth performance, intestinal viscosity and fat digestibility as reported previously elsewhere (MacAuliffe and McGinnis, 1971; Misir and Marquardt, 1978; Patel et al., 1980; Antoniou and Marquardt, 1982; Honeyfield et al., 1983; Bedford et al., 1991).

When dietary essential oil components, i.e. thymol, cinnamaldehyde, and CRINA $^{\circledR}$ Poultry were supplemented into a rye diet, the growth-suppressive effect of rye was partially overcome. Especially, birds fed a diet containing cinnamaldehyde at the level of 100 ppm improved ( $P>0.05)$ weight gain and feed intake at 14 and 21 
days of age. On the other hand, water intake, water:feed ratio, intestinal viscosity and fecal crude fat digestibility were not affected by dietary cinnamaldehyde. Birds fed on a diet containing thymol showed a low feed:gain ratio $(P>0.05)$ without changing weight gain and feed intake. However, the statistical power was low so that the present study could not substantiate the observed treatment effects by statistical significance.

It is generally accepted that the antinutritional effect of rye is presumably mediated by NSPs, which arabinoxylans (pentosans) corresponded to approximately 3.4\% DM (Smits and Annison, 1997). These NSPs are known to increase gut viscosity (Smits and Annison, 1997; Smits et al., 1997) and to alter microflora (Smits et al., 1998; Langhout et al., 1999). In this regard, either lowering gut viscosity or balancing microflora would help overcome the antinutritional effect of rye. The present study however failed to lower gut viscosity by any of additives. Then, the effect on intestinal microflora might be a putative mode of action. This statement could be reasonably derived from the fact that thymol and cinnamaldehyde posses the well-known in vitro antimicrobial activities, thus simulating the effect of dietary infeed antibiotics. Dietary antibiotics is reported to increase growth performance in chickens fed on a rye-based diet (Fernandez et al., 1973; Wagner et al., 1978; Marusich et al., 1978; Misir and Marquardt, 1978). It is however worthwhile to note that cinnamaldehyde improved weight gain of rye-fed chickens, but thymol and CRINA $^{\circledR}$ Poultry did not. The present results may indicate that dietary essential oil components were responded in a different fashion to dietary stimuli induced by feeding a diet rich in rye. Thus, the biological activities of dietary essential oil components seem to be diverse. Earlier, we found that dietary cinnamaldehyde improved CMC-mediated inhibition of fat digestibility and thus weight gain (Chapter 5). We suggested that cinnamaldehyde could stimulate secretion of bile acid, leading to compensating the loss of bile salts in intestine. The restoration of fat digestion by dietary essential oil components however was not repeated in the present study.

It was reported that feeding rye to chickens was predisposed of overpopulation of specific microorganism, capable of de-conjugating bile salts (Feighner and Dashkevicz, 1988). This leads to lower bile salt availability and consequently impair fat digestion as reported earlier (Smits et al., 1997 and 1998) and seen in the present study. Microbial complication on fat digestibility of chickens fed on soluble NSPs can be verified that supplementation of dietary antibiotics into rye diet improved fat digestibility (Antoniou and Marquardt, 1982; Fengler et al., 1988) and such an effect was not found in germ-free chickens (Smits and Annison, 1997; 
Langhout et al., 2000). In addition, the fact that supplementation of bile salts into rye diet improved fat digestibility (Campbell et al., 1983; Fengler et al., 1988) indicates that birds fed a diet rich in rye were unable to counteract the loss of bile salt. Unexpectedly, fat digestibility of chickens fed on cinnamaldehyde was hardly affected when compared to that on rye. However, it should be considered (Langhout et al., 1997) that fat digestibility as measured at the end of the trial may not represent the overall growth performance. In this regard, it is likely that birds could adapt the rye diet during the 33-feeding trials. According to Wagner et al. (1978), catch-up growth was occurred in chicks fed rye only but not in those fed rye supplemented with dietary antibiotics. At 21 days thereafter, differences in weight gain and feed intake between chickens fed on rye and cinnamaldehyde were narrowed. It is also possible that fat digestibility of birds fed on rye could be improved with age (Langhout et al., 1997) and reached to the value to those fed on cinnamaldehyde.

It might be worthwhile to note that thymol versus cinnamaldehyde systematically lowered weight gain and feed intake, but improved feed:gain ratio. This may indicate that dietary thymol, contrary to cinnamaldehyde might have effect on better nutrient utilization. On the other hand, cinnamaldehyde seems to continuously stimulate feed intake. It can be postulated that birds fed on cinnamaldehyde ate more than those fed on thymol due to their characteristic flavors. This statement however can not be verified based on the earlier reports that the effect of flavor on poultry performance was regarded negligible (Moran, 1982), and cinnamon flavor was relatively less preferential to chickens (Deyoe et al., 1962). The factors that are responsible for this difference would provide the explanation of the result of the present study, of which needs to be answered.

In the light of the hypocholesterolemic effect of dietary soluble fiber reported in chickens (Fadel et al., 1987; Newman et al., 1991; Pettersson and Åman, 1991; Martinez et al., 1992; Wang et al., 1992), the present experiment is obviously puzzled by observing non-significant cholesterol-lowering effects of rye. It is generally regarded that intestinal viscosity caused by soluble NSPs is responsible for hypocholesterolemic effect (Wang et al., 1992). The cholesterol-lowering effect of soluble fiber was not confirmed in the present study even though intestinal viscosity in birds fed on rye instead of corn elevated 6- and 19-fold at jejunum and ileum, respectively. This contrasting result may be the consequence of whether exogenous cholesterol was present in the diet or not. Those studies showing hypocholesterolemic effects (Fadel et al., 1987; Newman et al., 1991; Pettersson and Åman, 1991; Martinez et al., 1992; Wang et al., 1992) contained exogenous 
cholesterol, ranging from 0.3 to $1.0 \%$ in the experimental diet. Indeed, Arjmandi et al. (1992) reported in the rat study that serum and liver cholesterol were lowered by dietary pectin when diet contained $0.3 \%$ exogenous cholesterol whereas unchanged under cholesterol-free diet. The latter result was also observed with swine (Fisher et al., 1966). In this regard, hypocholesterolemic effect of rye in this study could be less effective in the absence of added cholesterol. In addition, excreta of birds fed on rye versus corn were apparently brownish, possibly due to drainage of bile acid beyond the enterohepatic recirculation (Boros et al., 1985). This loss of bile acids might have been led to lower plasma cholesterol significantly or at least marginally (Seal and Mathers, 2001), but the present result indicates that birds fed on rye have been adapted this loss by increasing de-novo synthesis of bile acids.

Interestingly, supplementation of dietary cinnamaldehyde into rye diet significantly increased plasma cholesterol by on average $8.3 \%$ as compared to rye. The present study indicates that dietary cinnamaldehyde might either directly stimulate de novo cholesterol synthesis, led a large flux of cholesterol into blood or indirectly increase fat absorption. After all, significant liver weights in birds fed on cinnamaldehyde may reflect the consequences. Concurrent increases in HDL cholesterol and phospholipid indicate that as reported in goat (Beynen et al., 2000) most phospholipids are located in HDL, of which lipoproteins carrying a substantial portion of plasma cholesterol in chickens.

The present study confirmed that feeding rye to chickens significantly affected growth performance. As would be expected, birds fed on rye increased intestinal viscosity at both jejunum and ileum, and lowered fat digestibility. When dietary essential oil components were introduced into rye diet, cinnamaldehyde at the level of $100 \mathrm{ppm}$ showed the positive result. It partially overcame the antinutritional effect of rye by increasing weight gain and feed intake. However, it did not lower gut viscosity nor improve fat digestibility. It was monitored that dietary thymol and cinnamaldehyde responded in a different fashion to dietary stimuli induced by a diet rich in rye.

\section{Acknowledgements}

The authors are indebted to C. Yuangklang and S. Jittakhot for their help on chyme collection, and J. F. M. Coopmans and J. De Haas, Akzo Nobel, Arnhem for 
their excellent viscosity measurements. K.-W. Lee was supported by the National Institute for International Education Development, Ministry of Education, South Korea.

\section{References}

Allain, C. C., L. S. Poon, C. G. S. Chen, W. Richmond, and P. Fu, 1974. Enzymatic determination of total serum cholesterol. Clinical Chemistry 20: 476-482.

Antoniou, T. C., and R. R. Marquardt, 1982. Utilization of rye diets by chicks as affected by lipid type and level and penicillin supplementation. Poultry Science 61: 107-116.

Arjmandi, B. H., J. Ahn, S. Nathani, and R. D. Reeves, 1992. Dietary soluble fiber and cholesterol affect serum cholesterol concentration, hepatic portal venous short-chain fatty acid concentrations and fecal sterol excretion in rats. Journal of Nutrition 122: 246-253.

Assman, G., H. Schriewer, G. Schmitz, and E. O. Hagele, 1983. Quantification of high-density lipoprotein cholesterol by precipitation with phosphotungstic acid/ $\mathrm{MgCl}_{2}$. Clinical Chemistry 29: 2026-2030.

Bedford, M. R., H. L. Classen, and G. L. Campbell, 1991. The effect of pelleting, salt, and pentosanase on the viscosity of intestinal contents and the performance of broilers fed rye. Poultry Science 70: 1571-1577.

Beynen, A. C., J. Th. Schonewille, and A. H. M. Terpstra, 2000. Influence of amount and type of dietary fat on plasma cholesterol concentrations in goats. Small Ruminant Research 35: 141 147.

Boros, D., M. Rakowska, K. Raczynska-Bojanowska, and K. Kozazynski, 1985. The response of Japanese quails and chicks to the water-soluble antinutritive compounds from rye grain. Nutritional Reports International 32: 827-836.

Bucolo, G., and H. David, 1973. Quantitative determination of serum triglycerides by the use of enzymes. Clinical Chemistry 19: 476-482.

Campbell, G. L., L. D. Campbell, and H. L. Classen, 1983. Utilisation of rye by chickens: Effect of microbial status, diet gamma irradiation and sodium taurocholate supplementation. British Poultry Science 24: 191-203.

Deyoe, C.W., R.E. Davies, R. Krishnan, R. Khaund and J.R. Couch, 1962. Studies on the taste preference of the chick. Poultry Science 41: 781-784. 
Fadel, J. G., R. K. Newman, C. W. Newman, and A. E. Barnes, 1987. Hypocholesterolemic effects of beta-glucans in different barley diets to broiler chicks. Nutritional Reports International 35: 1049-1058.

Feighner, S. D., and M. P. Dashkevicz, 1988. Effect of dietary carbohydrates on bacterial cholytaurine hydrolase in poultry intestinal homogenates. Applied and Environmental Microbiology 54: 337-342.

Fengler, A. I., J. R. Pawlik, and R. R. Marquardt, 1988. Improvement in nutrient retention and changes in excreta viscosities in chicks fed rye-containing diets supplemented with fungal enzymes, sodium taurocholate and penicillin. Canadian Journal of Animal Science 68: 483-491.

Fernandez, R., E. Lucas, and J. McGinnis, 1973. Influence of diet composition on chick growth response to different antibiotics, feed additives and combination of the additives. Poultry Science 52: 2299-2305.

Fisher, H., G. W. Van Der Noot, W. S. Mc Grath, and P. Griminger, 1966. Dietary pectin and plasma cholesterol in swine. Journal of Atherosclerosis Research 6: 190-191.

Folch, J., M. Lees, and G. H. S. Stanley, 1957. A simple method for the isolation and purification of total lipids from animal tissues. Journal of Biological Chemistry 226: 497-509.

Honeyfield, D. C., J. A. Froseth, and J. McGinnis, 1983. Comparative feeding value of rye for poultry and swine. Nutritional Reports International 28: 1253-1260.

Langhout, D. J., 1998. The role of the intestinal flora as affected by non-starch polysaccharides in broiler chicks. Ph.D. thesis. Wageningen Agricultural University.

Langhout, D. J., J. B. Schutte, C. Geerse, A. K. Kies, J. De Jong, and M. W. A. Verstegen, 1997. Effects on chick performance and nutrient digestibility of an endo-xylanase supplementation to a wheat and rye based diet in relation to fat source. British Poultry Science 38: 557-563.

Langhout, D. J., J. B. Schutte, P. Van Leeuwen, J. Wiebenga, and S. Tamminga, 1999. Effect of dietary high- and low-methylated citrus pectin on the activity of the ileal microflora and morphology of the small intestinal wall of broiler chicks. British Poultry Science 40: 340-347.

Langhout, D. J., J. B. Schutte, J. De Jong, H. Slotjes, M. W. V. Verstegen, and S. Tamminga, 2000. Effect of viscosity on digestion of nutrients in conventional and germ-free chicks. British Journal of Nutrition 83: 533-540.

MacAuliffe, T., and J. McGinnis, 1971. Effect of antibiotic supplements to diets containing rye on chick growth. Poultry Science 50: 1130-1134.

Martinez, V. M., R. K. Newman, and C. W. Newman, 1992. Barley diets with different fat sources have hypocholesterolemic effects in chicks. Journal of Nutrition 122: 1070-1076.

Marusich, W. L., E. F. Ogrinz, N. Camerlengo, and M. Mitrovic, 1978. Use of a rye-soybean ration to evaluate growth promotants in chickens. Poultry Science 57: 1297-1304. 
Metcalfe, L. D., A. A. Schmitz, and J. R. Pelka, 1966. Rapid preparation of fatty acid esters from lipids for gaschromatographic analysis. Analytical Chemistry 38: 514-515.

Misir, R., and R. R. Marquardt, 1978. Factors affecting rye (Secale Cereale L.,) utilization in growing chicks. II. The influence of protein type, protein level and penicillin. Canadian Journal of Animal Science 58: 703-715.

Moran, E. T. Jr., 1982. Comparative nutrition of fowl and swine. The gastrointestinal systems. University of Guelph.

Newman, R. K., C. W. Newman, P. J. Hofer and A. E. Barnes, 1991. Growth and lipid metabolism as affected by feeding of hull-less barleys with and without supplemental $\beta$-glucanase. Plant Foods for Human Nutrition 41: 371-380.

Patel, M. B., M. S. Jami, and J. McGinnis, 1980. Effect of gamma irradiation, penicillin, and/or pectic enzyme on chick growth depression and fecal stickiness caused by rye, citrus pectin, and guar gum. Poultry Science 59: 2105-2110.

Petterson, D., and P. Åman, 1991. Production results, serum cholesterol concentration and carcass composition of boiler chickens fed diets based on bran or inner endosperm from oats with and without enzyme supplementation. Journal of the Science of Food and Agriculture 57: 273286.

Seal, C. J., and J. C. Mathers, 2001. Comparative gastrointestinal and plasma cholesterol responses of rats fed on cholesterol-free diets supplemented with guar gum and sodium alginate. British Journal of Nutrition 85: 317-324.

Smits, C. H. M., 1996. Viscosity of dietary fiber in relation to lipid digestibility in broiler. Ph.D. thesis. Wageningen Agricultural University.

Smits, C. H. M., and G. Annison, 1996. Non-starch plant polysaccharides in broiler nutrition - towards a physiologically valid approach to their determination. World's Poultry Science Journal 52: 203-221.

Smits, C. H. M., A. Veldman, H. J. Verkade, and A. C. Beynen, 1998. The inhibitory effect of carboxymethylcellulose with high viscosity on lipid absorption in broiler chickens coincides with reduced bile salt concentration and raised microbial numbers in the small intestine. Poultry Science 77: 1534-1539.

Smits, C. H. M., A. Veldman, M. W. A. Verstegen, and A. C. Beynen, 1997. Dietary carboxymethylcellulose with high instead of low viscosity reduces macronutrient digestion in broiler chickens. Journal of Nutrition 127:483-487.

Takayama, M., S. Itoh, T. Nagasaki, and I. Tanimizu, 1977. A new enzymatic method for determination of serum choline-containing phospholipids. Clinica Chimica Acta 79:93-98.

Wagner, D. D., and O. P. Thomas, 1977. A rye type growth depression of chicks fed pectin. Poultry Science 56: 615-619. 
Wagner, D. D., O. P. Thomas, and G. Graber, 1978. An adaptive growth response of chicks fed rye. Poultry Science 57: 230-234.

Wang, L., R. K. Newman, C. W. Newman, and P. J. Hofer, 1992. Barley $\beta$-glucans alter intestinal viscosity and reduce plasma cholesterol concentrations in chicks. Journal of Nutrition 122: 2292-2297. 
Chapter 7

\title{
Effect of a mixture of carvacrol and cinnam- aldehyde on growth performance in female broiler chickens fed a diet containing carboxymethylcellulose
}

\author{
K.-W. Lee, H. Everts, H. J. Kappert, A. C. Beynen
}

Department of Nutrition, Faculty of Veterinary Medicine, Utrecht University, 3508 TD, Utrecht, The Netherlands 


\section{Summary}

The present experiment was conducted to investigate whether dietary essential oil components when used either separately or together would affect growth performance. In addition, it was monitored the effects of essential oil components on the weight of small intestine and plasma lipids. There were 5 dietary treatments: base diet, base diet $+1 \%$ carboxymethylcellulose $(\mathrm{CMC})$; base diet $+1 \%$ $\mathrm{CMC}+200$ ppm carvacrol; base diet $+1 \% \mathrm{CMC}+200$ ppm cinnamaldehyde; base diet $+1 \%$ CMC +100 ppm carvacrol and 100 cinnamaldehyde. Daily weight gain was not significantly different between birds fed on CMC versus CMC-free diet. Birds fed a diet containing CMC with a blend of carvacrol and cinnamaldehyde gained significantly less weight when compared those fed on the CMC-free diet. Feeding of $\mathrm{CMC}$ to chickens caused a hypertrophy of small intestine. No significant treatment differences were observed as to plasma lipids. The present results suggest that a blend of essential oil components can impair growth performance when birds are fed a diet with the soluble fiber, CMC. 


\section{Introduction}

In the course of studies on looking for alternatives to in-feed antibiotics, experiments were carried out to investigate the effect of essential oil components on performance of broiler chickens. It was found that individual essential oil component numerically improved growth performance when chickens were fed a diet containing soluble viscous fiber, carboxymethylcellulose (CMC). For instance, dietary cinnamaldehyde counteracted the CMC-induced weight depression by $14 \%$ (Chapter 5). In another trial, birds fed a diet containing carvacrol at the level of $200 \mathrm{ppm}$ ate less feed, however feed:gain ratio was significantly improved as compared to those fed a corn-soybean based control diet (Chapter 3 ). It appears that dietary essential oil components could improve nutrient utilization or counteract the antinutrients.

Cinnamaldehyde, which is a main component of cinnamon essential oils, and carvacrol, isomer of thymol, which is found in thyme and oregano essential oils exhibit a wide range of in vitro antimicrobial activities (Helander et al., 1998). Biological properties of individual compounds including carvacrol and cinnamaldehyde can be obtained via online databases (Agricultural Research Services, http://www.ars-grin.gov/duke/). It has been a common feature in in vitro antimicrobial studies (Didry et al., 1994; Montes-Belmont and Carvajal, 1998) that essential oil components interacted synergistically when combined together.

In practice, dietary feed additives based on essential oil components are marketed and claimed to enhance growth performance and health. The commercial products are being produced by blending a variety of essential oil components. It is expected that a blend may be more effective in improving growth performance than the identical amounts of an individual compound can be. The present experiment was conducted to test the present expectation with the selected compounds, carvacrol and cinnamaldehyde.

In addition, it was monitored intestinal weight and length, and plasma lipids in the present study. It is reasoned that dietary antibiotics lowered intestinal weight (Jukes et al., 1956; Hill et al., 1957). Hypocholesterolemic effect of essential oil components has been reported by Case et al. (1995) and prompted us to measure plasma cholesterol.

To enhance treatment contrasts as with Chapter 5, CMC was supplemented at the concentration of $1 \%$ of which level is known to affect growth performance in broiler chickens (Van der Klis et al., 1993). It is reported that feeding of CMC to 
chickens elevated intestinal viscosity (Smits et al., 1997). In addition, Smits et al. (1998) found a significant increase in colony forming unit of intestinal microflora when birds were fed on a diet containing CMC.

\section{Materials and methods}

The experiment protocol was approved by the animal experiments committee of the Utrecht Faculty of Veterinary Medicine.

\section{Animals, diets and experimental design}

75 one-day old female broiler chickens (Cobbs) were obtained from a local hatchery. They were wing-banded, weighed on arrival and randomly allocated to one of 5 treatments. Each treatment had 3 pens with 5 chicks each so that there were 15 chicks per treatment. The 5 dietary treatments were as follows: base diet, base diet + 1\% CMC (AF 2805, Akzo Nobel, Arnhem, The Netherlands), base diet + CMC +200 ppm carvacrol, base diet $+\mathrm{CMC}+200$ ppm cinnamaldehyde, and base diet $+\mathrm{CMC}$ +100 ppm carvacrol + 100 ppm cinnamaldehyde, respectively. The CMC preparation used has high viscosity and is not fermented (Smits et al., 1997). Beef tallow and corn oil were used as fat sources, and included at the level of 5 and $1 \%$, respectively (Table 1). Carvacrol (97\% purity, Fluka Chemie, Sigma-Aldrich Chemie BV, Zwijndrecht, The Netherlands) and cinnamaldehyde (99\% purity, Acros Organics, Geel, Belgium) were dissolved in corn oil and then gently mixed with the diets to arrive at $1 \%$ corn oil and 200 ppm of additives in the diet. The diets were prepared freshly each day. The base and CMC control diet were mixed with corn oil only. Feed and water were provided for ad libitum consumption. The temperature of the room with the pens was $34^{\circ} \mathrm{C}$ on arrival of the chickens and was gradually decreased to reach $25^{\circ} \mathrm{C}$ at 3 weeks. Lighting was on continuously. Individual body weights, feed and water intakes per pen were monitored weekly. Feed and water intake were calculated as $\mathrm{g} / \mathrm{d} / \mathrm{bird}$ and used to calculate the feed:gain ratio.

On day 21, blood was collected by heart puncture. Plasma was obtained by centrifugation at $1700 \times \mathrm{g}$ for $15 \mathrm{~min}$ and stored at $-70^{\circ} \mathrm{C}$ prior to analysis. Immediately after blood sampling, the birds were killed by cervical dislocation. Liver 
was removed and weighed. Small intestine defined as segments between gizzard and the ileocecal junction was removed and extended on a table, and measured for length. The pancreas was removed. The intestine was slit longitudinally and the intestinal contents were removed. The intestine was then weighed.

Table 1 Ingredient composition of base diet

\begin{tabular}{lcc}
\hline Ingredients & Base & CMC $^{3}$ \\
\hline Corn, yellow & 322 & 322 \\
Corn Starch & 210 & 210 \\
Soybean meal, 48\% CP & 260 & 260 \\
Soybean protein isolate & 85 & 85 \\
Beef tallow & 50 & 50 \\
Corn oil & 10 & 10 \\
Sodium chloride & 5 & 5 \\
Calcium carbonate & 17 & 17 \\
MonoCalcium phosphate & 17 & 17 \\
DL-Methionine $^{-}$ & 4 & 4 \\
Premix $^{1}$ & 10 & 10 \\
Cellulose $^{2}$ & 10 & 0 \\
CMC $^{3}$ & 0 & 10 \\
Total & 1000 & 1000 \\
\hline
\end{tabular}

${ }^{1}$ The $10 \mathrm{~g}$ premix consisted of $24.0 \mathrm{mg}$ vitamin $\mathrm{A}(500000 \mathrm{IU} / \mathrm{g}) ; 6.0 \mathrm{mg}$ vitamin $\mathrm{D}_{3}(100000 \mathrm{IU} / \mathrm{g})$; $60.0 \mathrm{mg}$ vitamin $\mathrm{E}(500 \mathrm{lU} / \mathrm{g}) ; 6.6 \mathrm{mg}$ vitamin $\mathrm{K}_{3}$ (purity, 22.7\%); $100.0 \mathrm{mg}$ vitamin $\mathrm{B}_{12}$ (purity, $0.1 \%$ ); $2000.0 \mathrm{mg}$ biotin (purity, $0.01 \%$ ); $1100.0 \mathrm{mg}$ choline chloride (purity, 50\%); $1.1 \mathrm{mg}$ folic acid (purity, 90\%); $65.2 \mathrm{mg}$ nicotinic acid (purity, 100\%); $16.3 \mathrm{mg}$ d-pantothenate (purity, 92\%); $4.5 \mathrm{mg}$ vitamin $\mathrm{B}_{6}$ (purity, $100 \%$ ); $12.5 \mathrm{mg}$ riboflavin (purity, $80 \%$ ); $2.5 \mathrm{mg}$ vitamin $\mathrm{B}_{1}$ (purity, 100\%); $32.00 \mathrm{mg}$ $\mathrm{CuSO}_{4} .5 \mathrm{H}_{2} \mathrm{O} ; 333.20 \mathrm{mg} \mathrm{FeSO}{ }_{4} \cdot \mathrm{H}_{2} \mathrm{O} ; 166.80 \mathrm{mg} \mathrm{MnO} ; 1.0 \mathrm{mg} \mathrm{Na} \mathrm{SeO}_{3} .5 \mathrm{H}_{2} \mathrm{O} ; 220.00 \mathrm{mg}$ $\mathrm{ZnSO}_{4} \cdot \mathrm{H}_{2} \mathrm{O} ; 4.80 \mathrm{mg} \mathrm{CoSO}{ }_{4} .7 \mathrm{H}_{2} \mathrm{O} ; 0.56 \mathrm{mg} \mathrm{KI}, 100.00 \mathrm{mg}$ ethoxyquin and $5742.94 \mathrm{mg}$ corn meal as carrier.

${ }^{2}$ Arbocel (Akzo Nobel, Arnhem, The Netherlands).

${ }^{3}$ Carboxymethylcellulose (AF 2805, Akzo Chemicals, Arnhem, The Netherlands). 


\section{Measurements}

Plasma total cholesterol, phospholipids, high-density lipoprotein (HDL) cholesterol, and triglycerides were measured as described (Beynen et al., 2000).

\section{Statistical analysis}

The data were analyzed for the main effect of treatments using the general linear model (SPSS for Windows, Version 9.0.0; SPSS Inc. Chicago, IL). Treatment means were evaluated for statistically significant differences using Tukey test. In some instances, multiple comparisons were conducted to compare means between treatments. A $P$-value $<0.05$ was preset as criterion of statistical significance.

\section{Results}

For a period of 21 days, daily weight gain was not significantly different $(P>0.500)$ between birds fed on base versus CMC diet (Table 2). When dietary essential oil components were added to the CMC diet, no statistically differences in weight gain between dietary treatments were observed. Neither feed and water intake, nor feed:gain ratio was statistically affected by dietary treatments. Birds fed a diet with $\mathrm{CMC}+$ blend performed the least among treatments without reaching statistical sinficances. However, multiple comparisons revealed that statistical significance in relation to weight gain was monitored between birds fed on base diet and those fed on CMC + blend diet.

Birds fed on CMC significantly increased relative intestinal weight as compared to those fed on CMC-free control (Table 2). The CMC-induced hypertrophy of small intestine was not modified by supplementation of dietary essential oil components. Relative intestinal length was longer in birds fed on CMC only than those fed on CMC-free diet. When the additives were added to CMC diet, no significant differences were observed in relative length of small intestine. No 
significant differences were detected in relative liver weight between dietary treatments (Table 2).

Plasma lipids were presented in Table 3. Total cholesterol was ranged from 2.9 to $3.4 \mathrm{mmol} / \mathrm{L}$ between dietary treatments without statistical differences. phospholipids, triglycerides and HDL cholesterol did not differ between dietary treatments.

\section{Discussion}

The present experiment lasted 21 days. In a previous study (Chapter 5), CMC had a negative effect on daily weight gain at 21 days of age $(P=0.043)$ but not at 40 days of age $(P>0.500)$. Based on the earlier observation, 21-day-feeding was chosen and assumed to be enough to repeat the $\mathrm{CMC}$-induced growth depression. On the contrary, the present study failed to induce a growth depression at 21 days of age by the use of $1 \%$ CMC. As compared to the earlier result (Chapter 5), group-mean weight gain of birds fed CMC shown in the present experiment diet were comparable. However, standard deviation of birds fed CMC became larger, being the value 5.10 in the present study as compared to 0.87 found in Chapter 5 (data not shown). It is not know how the birds responded variably to dietary CMC.

Soluble fiber such as CMC is known to increase intestinal viscosity, which could affect intestinal digestion by limiting the diffusion of digestive enzymes and nutrients (Choct et al., 1996). Langhout et al. (2000) proved that intestinal viscosity did not have effects on macronutrient digestion in germ-free chicks whereas it did have effects in conventional counterparts. The latter study obviously provides the evidence that intestinal environment can be a determinant factor where soluble fiber has a negative effect on growth performance. In any events, the well-known antinutritional effect of $\mathrm{CMC}$ in relation to weight gain was not clearly induced in this study. On the other hand, the present study showed that CMC significantly caused hypertrophy of small intestine. The latter observation was reported both in germ-free (Pell et al., 1995; Smits, 1996) and conventionally raised animals (Van der Klis and Van Voorst, 1993; Smits et al., 1997), indicating that CMC possess a mechanical effect on the intestinal tract. It appears that feeding CMC to chickens more effectively affected on intestine rather than on overall growth performance in the present study. 
Table 2 Effects of dietary essential oil components on growth performance and weights of small intestine and liver in female broiler chickens fed on $\mathrm{CMC}^{1}$

\begin{tabular}{|c|c|c|c|c|c|c|c|}
\hline \multirow[b]{2}{*}{ Measure } & \multicolumn{5}{|l|}{ Diet } & \multirow[b]{2}{*}{$\mathrm{SEM}^{2}$} & \multirow[b]{2}{*}{$P$ value } \\
\hline & Base & $\mathrm{CMC}^{3}$ & $\begin{array}{c}\mathrm{CMC}+ \\
\text { Carvacrol }\end{array}$ & $\begin{array}{c}\mathrm{CMC}+ \\
\text { Cinnam- } \\
\text { aldehyde }\end{array}$ & $\begin{array}{c}\mathrm{CMC}+ \\
\text { Blend }\end{array}$ & & \\
\hline \multicolumn{8}{|l|}{ Growth performance } \\
\hline Weight gain, $g / d /$ bird & 35.9 & 32.3 & 34.3 & 32.7 & 27.2 & 1.817 & 0.060 \\
\hline Feed intake, $\mathrm{g} / \mathrm{d} / \mathrm{bird}$ & 46.7 & 42.7 & 46.2 & 45.6 & 37.3 & 2.123 & 0.053 \\
\hline Water intake, g/d/bird & 91.8 & 90.6 & 97.6 & 106.8 & 87.2 & 5.032 & 0.125 \\
\hline Feed:gain, g:g & 1.30 & 1.33 & 1.35 & 1.40 & 1.37 & 0.029 & 0.252 \\
\hline Water:feed, g:g & $1.97 b$ & $2.13 a b$ & $2.12 \mathrm{ab}$ & $2.34 a$ & $2.34 a$ & 0.075 & 0.023 \\
\hline \multicolumn{8}{|l|}{ Small intestine } \\
\hline Weight, g/100g BW & $3.45 b$ & $3.95 a$ & $3.72 \mathrm{ab}$ & $3.74 a b$ & $4.09 a$ & 0.100 & 0.011 \\
\hline Length, $\mathrm{cm} / 100 \mathrm{~g} \mathrm{BW}$ & $17.14 b$ & $21.04 a b$ & $20.09 a b$ & $21.15 a b$ & $23.69 a$ & 1.009 & 0.013 \\
\hline Liver, g/100g BW & 2.40 & 2.41 & 2.18 & 2.22 & 2.28 & 0.109 & 0.511 \\
\hline
\end{tabular}

${ }^{1}$ Results are expressed as means of three replicates per dietary group.

${ }^{2} \mathrm{SEM}=$ pooled standard error of mean.

${ }^{3}$ Carboxymethylcellulose.

${ }^{\text {a.b }}$ Means having different letters within a same row differ significantly $(P<0.05)$. 
Table 3 Effect of dietary essential oil components on plasma lipids in female broiler chickens fed diet containing CMC at 21 days ${ }^{1}$

\begin{tabular}{|c|c|c|c|c|c|c|c|}
\hline \multirow[b]{2}{*}{ Measure } & \multicolumn{5}{|l|}{ Diet } & \multirow[b]{2}{*}{ SEM $^{2}$} & \multirow[b]{2}{*}{$P$ value } \\
\hline & Base & $\mathrm{CMC}^{3}$ & $\begin{array}{c}\mathrm{CMC}+ \\
\text { Carvacrol }\end{array}$ & $\begin{array}{l}\mathrm{CMC}+ \\
\text { Cinnam- } \\
\text { aldehyde }\end{array}$ & $\begin{array}{c}\mathrm{CMC}+ \\
\text { Blend }\end{array}$ & & \\
\hline Total cholesterol, $\mathrm{mmol} / \mathrm{L}$ & 3.25 & 3.15 & 3.36 & 2.91 & 3.13 & 0.113 & 0.140 \\
\hline Phospholipids, mmole/L & 2.75 & 2.53 & 2.68 & 2.39 & 2.40 & 0.083 & 0.070 \\
\hline Triglycerides, mmol/L & 0.41 & 0.37 & 0.39 & 0.42 & 0.35 & 0.031 & 0.475 \\
\hline $\mathrm{HDL}$ cholesterol, $\mathrm{mmol} / \mathrm{L}$ & 2.35 & 2.25 & 2.49 & 2.06 & 2.23 & 0.097 & 0.102 \\
\hline
\end{tabular}

${ }^{1}$ Results are expressed as means of three replicates per dietary group.

${ }^{2} \mathrm{SEM}=$ pooled standard error of mean.

${ }^{3}$ Carboxymethylcellulose. 
An unexpected result was appeared from the present study. Birds fed on a blend of essential oil components gained less $(P=0.044)$ than those fed on CMC-free base diet. On the other hand, no significant differences were observed in birds fed on either carvacrol $(P>0.500)$ or cinnamaldehyde $(P>0.500)$ as compared to those fed on CMC-free base. Daily weight gain of birds fed on carvacrol $(P=0.112)$ and cinnamaldehyde $(P=0.284)$ was numerically high as compared to those fed on a blend of two components. It is not known how birds fed on a blend of carvacrol and cinnamaldehyde were performed in a negative way whereas those fed on individual compound were not. The present study suggests the existence of negative interaction between a blend of essential oil components and $\mathrm{CMC}$ on growth performance.

Addition of dietary essential oil components into CMC diet did not strongly affect the small intestine of birds. Feed additives containing antibiotic activity such as in-feed antibiotics (Jukes et al., 1956; Hill et al., 1957), and lactoferrin and lysozyme (Humphrey et al., 2002) have been reported to affect small intestine, thus leading to better nutrient digestion and absorption. However, it seems that dietary essential oil components have no effect on physiological property of CMC. The previous study (Chapter 5) showed that dietary essential oil components did not lower intestinal viscosity induced by CMC.

The present study showed that dietary CMC versus CMC-free did not significantly modulate plasma cholesterol. This is contrary to the early observation with hamsters which reported that non-fermentable hydroxypropyl methylcellulose significantly lowered plasma cholesterol (Gallaher et al., 1993). Even though there is a tendency of lowering total cholesterol and triglycerides in birds fed on CMC versus CMC-free in this study and also by Smits et al. (1997), reduction was less apparent as compared to that of Smits et al. (1997). On the other hand, the present study is in line with our previous study showing non-significant differences of plasma lipids of birds fed on CMC versus CMC-free diet (Chapter 5). When dietary essential oil components were added to $\mathrm{CMC}$ diet, no systematic effects on plasma lipids were observed. This result is contrary to that of Case et al. (1995) who reported that birds fed on carvacrol significantly lowered plasma cholesterol as compared to those fed on no-added diet. Earlier, we found that dietary essential oil components - thymol (isomer of carvacrol) and cinnamaldehyde - did not lower plasma cholesterol of birds fed on CMC as seen in the present study. The apparent difference between the present study and that of Case et al. (1995) would be the strain of chickens used fast-growing versus slow-growing chickens. It seems that meat-type chickens used 
in this study might respond less sensitive to dietary stimuli than slow growing type of chickens did as seen in study of Case et al. (1995).

In conclusion, the present experiment showed that birds fed on a blend of carvacrol and cinnamaldehyde performed the least. It can be inferred from the present study that a combination of two or more essential oil components can impair growth performance of chickens fed a diet containing CMC.

\section{Acknowledgements}

The skillful technical assistance of A. G. Lemmens and G. Lankhorst is greatly appreciated. The authors would like to thank J. De Haas, Akzo Nobel, Arnhem for the gift of carboxymethylcellulose. K.-W. Lee was supported by the National Institute for International Education Development, Ministry of Education, South Korea.

\section{References}

Beynen, A. C., J. Th. Schonewille, and A. H. M. Terpstra, 2000. Influence of amount and type of dietary fat on plasma cholesterol concentrations in goats. Small Ruminant Research 35: 141 147.

Case, G. L., L. He, H. Mo, and C. E. Elson, 1995. Induction of geranyl pyrophosphate pyrophosphatase activity by cholesterol-suppressive isoprenoids. Lipids 30: 357-359.

Choct, M., R. G. Hughes, J. Wang, M. R. Bedford, A. J. Morgan, and G. Annison, 1996. Increased small intestinal fermentation is partly responsible for the anti-nutritive activity of non-starch polysaccharides in chickens. British Poultry Science 37: 609-621.

Didry, N., L. Dubreuil, and M. Pinkas, 1994. Activity of thymol, carvacrol, cinnamaldehyde and eugenol on oral bacteria. Pharmaceutica Acta Helvetiae 69: 25-28.

Gallaher, D. D., C. A. Hassel, and K.-J. Lee, 1993. Relationships between viscosity of hydroxypropyl methylcellulose and plasma cholesterol in hamsters. Journal of Nutrition 123: 1732-1738.

Helander, I. M., H.-L. Alakomi, K. Latva-Kala, T. Mattila-Sandholm, I. Pol, E. J. Smid, L. G. M. Gorris, and A. Von Wright, 1998. Characterization of the action of selected essential oil components on Gram-negative bacteria. Journal of Agricultural and Food Chemistry 46: 3590-3595.

Hill, C. H., A. D. Keeling, and J. W. Kelly, 1957. Studies on the effect of antibiotics on the intestinal weights of chicks. Journal of Nutrition 62: 255-267. 
Humphrey, B. D., N. Huang, and K. C. Klasing, 2002. Rice expressing lactoferrin and lysozyme has antibiotic-like properties when fed to chicks. Journal of Nutrition 132: 1214-1218.

Jukes, H. G., D. C. Hill, and H. D. Branion, 1956. Effect of feeding antibiotics on the intestinal tract of the chick. Poultry Science 35: 716-723.

Langhout, D. J., J. B. Schutte, J. de Jong, H. Sloetjes, M. W. A. Verstegen, and S. Tamminga, 2000. Effect of viscosity on digestion of nutrients in conventional and germ-free chicks. British Journal of Nutrition 83: 533-540.

Montes-Belmont, R., and M. Carvajal, 1998. Control of Aspergillus flavus in maize with plant essential oils and their components. Journal of Food Protection 61: 616-619.

Pell, J. D., I. T. Johnson, and R. A. Goodlad, 1995. The effects of and interactions between fermentable dietary fiber and lipid in germfree and conventional mice. Gastroenterology 108: 1745-1752.

Smits, C. H. M., 1996. Viscosity of dietary fiber in relation to lipid digestibility in broiler chickens. Ph.D. thesis. Wageningen Agricultural University.

Smits, C. H. M., A. Veldman, H. J. Verkade, and A. C. Beynen, 1998. The inhibitory effect of carboxymethylcellulose with high viscosity on lipid absorption in broiler chickens with reduced bile salt concentration and raised microbial numbers in the small intestine. Poultry Science 77: 1534-1539.

Smits, C. H. M., A. Veldman, M. W. A. Verstegen, and A. C. Beynen, 1997. Dietary carboxymethylcellulose with high instead of low viscosity reduces macronutrient digestion in broiler chickens. Journal of Nutrition 127: 483-487.

Van der Klis, J. D., A. Van Voorst, 1993. The effect of carboxy methyl cellulose (a soluble polysaccharide) on the rate of marker excretion from the gastrointestinal tract of broilers. Poultry Science 72: 503-512.

Van der Klis, J. D., A. Van Voorst, and C. Van Kruyningen, 1993. Effect of a soluble polysaccharide (carboxy methyl cellulose) on the physico-chemical conditions in the gastrointestinal tract of broilers. British Poultry Science 34: 971-983. 


\section{General conclusions}


The main questions that were addressed in the thesis are as follows. What is the effect of dietary essential oils on growth performance in female broiler chickens? Do essential oils modulate plasma lipids? Can essential oils counteract the growth depression as induced by anti-nutritional factors? The major results and conclusions of the various chapters may be summarized as follows.

Dietary essential oil components do not have growth-enhancing effects in broiler chickens raised in a clean environment and fed a well-balanced diet.

There are literature data (Jamroz and Kamel, 2002; Williams and Losa, 2001) showing that dietary essential oil components improve performance of broiler chickens. In addition, the oil components may stimulate the activity of endogenous digestive enzymes. Thus, components of essential oils would improve birds' performance by enhancing macronutrient digestibility. However, the present results (Chapter 2) show no clear, systematic effect of essential oil components on the activity of digestive enzymes. In general, there was no effect of dietary essential oil components on growth performance and macronutrient digestibility. It is assumed that the housing conditions had low infectious pressure and that the diets used can be considered highly digestible which rendered the broiler chickens unresponsive to the dietary supplements (Chapters 2, 3, and 4).

Dietary cinnamaldehyde lowers water intake without a reduction in feed intake and weight gain, but this effect is not seen when the diet contains carboxymethylcellulose $(C M C)$.

Chickens fed on a diet with cinnamaldehyde consumed less water, which may be practically relevant (Chapter 2). Consequently, the dry matter content in excreta of broiler chickens fed on cinnamaldehyde was increased. This cinnamaldehydeinduced reduction of spontaneous water intake was not accompanied with a reduction in feed intake. When cinnamaldehyde was fed together with $\mathrm{CMC}$, water intake of the broiler chickens was not lowered (Chapter 5).

Dietary carvacrol lowers body weight gain, but improves feed conversion.

Carvacrol (Chapter 3) was evaluated as a potential feed additive in female broiler chickens. When broiler chickens were exposed to experimental diets for 28 
days, those fed carvacrol showed an improved feed:gain ratio when compared to those fed the control diet (Chapter 3). However, feed intake and weight gain were low in the chickens fed carvacrol. In the following study, when carvacrol was introduced into a CMC-containing diet, no significant effects of the essential oil components were observed (Chapter 7).

Dietary essential oils do not lower plasma cholesterol.

The alleged hypocholesterolemic properties of dietary essential oil components were tested. However, the studies failed to reveal a hypocholesterolemic effect of either thymol or carvacrol (Chapter 3 ), and also of $\beta$ ionone (Chapter 4), irrespective of whether the diet was cholesterol-free or rich in cholesterol. In addition, no cholesterol-lowering effect of thymol (Chapter 5) and carvacrol (Chapter 7) was observed when the diet contained CMC.

Cinnamaldehyde counteracts the CMC- and rye-induced growth depression in female broiler chickens.

It was suggested that any effect of dietary essential oil components on growth performance is masked when the base diet is composed of well-digestible ingredients and when the environment has low infectious pressure. With this suggestion in mind, anti-nutritional factors were introduced into the base diet. CMC (Chapter 5) and rye (Chapter 6) were used as ingredients with anti-nutritional activity. Dietary cinnamaldehyde tended to counteract the CMC- (Chapter 5 ) and ryeinduced (Chapter 6) depression of weight gain. Dietary cinnamaldehyde improved the CMC-mediated decrease in fat digestion (Chapter 5), but did not affect fat digestion when rye was present in the diet (Chapter 6). The increase in intestinal viscosity caused by the feeding of either CMC (Chapter 5) or rye (Chapter 6 ) was not counteracted by dietary cinnamaldehyde.

Dietary cinnamaldehyde increases plasma cholesterol when the diet contains rye.

Broiler chickens fed on a diet containing rye and cinnamaldehyde showed higher plasma cholesterol concentrations than to those fed on a rye-containing diet without cinnamaldehyde (Chapter 6). No lowering of intestinal viscosity was observed in chickens fed cinnamaldehyde so that the results are contrary to the 
notion that there is a negative correlation between intestinal viscosity and plasma cholesterol. The hypercholesterolemic effect of dietary cinnamaldehyde in chickens fed on a diet rich in rye was not observed when cinnamaldehyde was added to a well digestible diet (Chapter 2) or to a diet containing CMC (Chapters 5 and 7). The present results indicate that cinnamaldehyde can affect plasma cholesterol, but the effect appears to be dependent on the background composition of the diet.

A mixture of carvacrol and cinnamaldehyde impairs growth performance in female broiler chickens fed a diet containing CMC, but feeding the single components does not.

Based on the studies with carvacrol (Chapter 3) and cinnamaldehyde (Chapter 5), the effect of a mixture of the two components on growth performance in female broiler chickens was tested (Chapter 7 ). The main aim was to investigate whether two components can have synergistic effects on growth performance. CMC was added to the diets in an attempt to enhance the treatment contrasts. A mixture of carvacrol and cinnamaldehyde added to the CMC diet significantly impaired growth performance of the chickens. On the other hand, the individual compounds when added to the CMC diet had no apparent effects on growth performance. This particular study suggests that a combination of two or more essential oil components can impair growth performance of chickens.

Future studies should focus on the identification of appropriate mixtures of essential oil components.

Dietary feed additives based on essential oil components are marketed with claims that they enhance growth performance and health. Under practical conditions dietary essential oil components would improve digestion and stimulate feed intake, and consequently raise growth performance. The present studies support that dietary essential oil components can improve performance of broiler chickens. However, in female broiler chickens fed a corn-soybean meal based diet, essential oil components in the diet did not stimulate weight gain, but in some instances feed:gain was improved and water intake lowered without a reduction in weight gain and feed intake. On the other hand, when either CMC was added to the cornsoybean meal based diet or when rye was substituted isoenergetically and isonitrogenously for corn, the essential oil components counteracted the anti- 
nutritional effects by stimulating feed intake, thus leading to extra weight gain. It is generally concluded that dietary essential oil components have potential to improve performance of broiler chickens. In contrast, the consistently reported hypocholesterolemic effects of dietary essential oil components were not observed. Based on the present work, future studies with dietary essential oil components should focus on identifying synergistic effects between essential oil components as to their application in animal production. In vivo metabolism of essential oil components should be monitored. Finally, in order to screen and test the effective components of essential oils, an experimental model should be developed that is not laborious and yields reproducible results that can be translated to practice.

\section{References}

Jamroz, D., and C. Kamel, 2002. Plant extracts enhance broiler performance. Journal of Animal Science (Suppl. 1): 41(Abstr.).

Williams, P., and R. Losa, 2001. The use of essential oils and their compounds in poultry nutrition. World Poultry 17 (No. 4): 14-15. 


\section{Summary}

Dietary antibiotics at low, subtherapeutic levels have been shown to improve growth performance in farm animals. However, there is a trend to look for alternatives to dietary antibiotics, due to occurrence of antibiotic-resistance bacteria.

The present thesis explored the essential oils as the possible alternative to dietary antibiotics. An essential oil is a mixture of fragrant, volatile compounds derived from the aromatic plant. Dietary feed additives based on essential oil components are marketed to enhance growth performance and health. It is claimed that under practical conditions dietary essential oil components improve digestion and stimulate feed intake, and consequently raise growth performance. However, the effect of essential oils on animal performance has not been proved in a controlled study.

The aim of this study was to evaluate the role of essential oils as the possible alternatives to antibiotics in poultry nutrition. Female broiler chickens were used as an animal model to study the effect of essential oils on growth performance, activities of digestive enzymes, macronutrient digestion and lipid metabolism. Furthermore, experiments were carried out to test whether dietary essential oil components could either counteract anti-nutrient effect of carboxymethylcellulose (CMC) or rye. Finally, the possible synergistic effects of individual essential oil components were tested in relation to growth performance when chickens were fed on a diet containing CMC.

The literature review describes the general biological activities of essential oils. Dietary essential oils can have several useful biological properties, e.g., acting as antimicrobial substance and antioxidants, and being hypocholesterolemic, affecting flavor, and stimulating the digestion process. Their metabolic pathways have been well elucidated, and based on that observation, it was suggested that their side effects are unlikely. Due to a limited number of controlled studies on the effect of essential oil components on growth performance in broiler chickens, an experiment was conducted to describe the effect of thymol, cinnamaldehyde and a commercial preparation of essential oil components (CRINA ${ }^{\circledR}$ Poultry) on growth performance, digestive enzyme activities and macronutrient digestibilities. Cornsoybean meal based diet was used to prepare the experimental diets and chicks were housed in wire-bottomed cages. It was shown that no effect of essential oil components on any of parameters monitored in female broiler chickens was observed, but it can not be excluded that positive effects would have been observed 
under less hygienic environmental conditions or when using a less digestible diet. However, in this study dietary cinnamaldehyde significantly lowered water intake without affecting growth performance. Consequently, dry matter contents of excreta were higher in birds fed diet containing cinnamaldehyde. The observed cinnamaldehyde-induced reduction of spontaneous water intake could be commercially interesting.

In subsequent studies, we further screened dietary carvacrol, and $\beta$-ionone as potential feed additives in female broiler chickens. Furthermore, we tested the alleged hypocholesterolemic effect of dietary essential oil components when the chickens were fed either cholesterol-free or cholesterol-rich diets. It was found that dietary carvacrol lowered feed intake and weight gain, but also lowered the feed:gain ratio. The carvacrol effect on feed:gain ratio could relate to increased efficiency of feed utilization and/or altered carcass composition. Unfortunately, carcass composition of the chickens was not analyzed. Carvacrol lowered plasma triglyceride concentrations, but did not affect plasma cholesterol. Dietary $\beta$-ionone failed to affect growth performance and the plasma lipid profile, irrespective of whether the diet was cholesterol free or rich in cholesterol.

The question then addressed was whether dietary essential oils (thymol, cinnamaldehyde, CRINA ${ }^{\circledR}$ Poultry) could antagonize the negative effect of CMC on growth performance in broilers. Intestinal viscosity was increased by CMC inclusion, but was not lowered by dietary essential oils. However, addition of cinnamaldehyde and CRINA ${ }^{\circledR}$ Poultry to the CMC diet tended to counteract the negative effect on growth performance. Fat digestibility was reduced by $\mathrm{CMC}$, but cinnamaldehyde and CRINA ${ }^{\circledR}$ Poultry partially relieved the CMC-induced inhibition of fat digestion. This study indicates that cinnamaldehyde and CRINA ${ }^{\circledR}$ Poultry, but not thymol, may antagonize the negative effect of $\mathrm{CMC}$ on growth performance which may relate to improving fat digestibility.

In following study, we observed whether dietary essential oil components, i.e., thymol, cinnamaldehyde and CRINA ${ }^{\circledR}$ Poultry could have effects on growth performance, fat digestibility, and intestinal viscosity in female broiler chickens fed on rye. Feeding rye to chicken lowered weight gain, elevated intestinal viscosity and reduced fat digestibility. Addition of dietary cinnamaldehyde to rye diet partially counteracted rye-suppressed weight gain in female broiler chickens. However, intestinal viscosity and fat digestion were not modified by dietary cinnamaldehyde. The partial counteraction of dietary cinnamaldehyde on rye-induced growth 
depression seemed to be mediated by concomitant increase in feed intake, however underlying mechanisms remain unknown.

It would expect that a mixture of essential oil components could act synergistically on growth performance. Carvacrol and cinnamaldehyde were selected based on earlier studies. In addition, CMC was included to enhance treatment contrasts. Individual components when supplemented to the CMC diet had no apparent effects on growth performance. On the other hand, a mixture of carvacrol and cinnamaldehyde added to CMC diet significantly impaired growth performance of the chickens. This latter study suggests that a certain combination of two or more essential oil components can impair growth performance of chickens when birds are fed a diet with the soluble fiber, CMC.

It is generally concluded that dietary essential oil components have potential to improve performance of broiler chickens. However, the consistently alleged hypocholesterolemic effects of dietary essential oil components were not observed. Based on the present work, future studies with dietary essential oil components should focus on identifying synergistic effects of different essential oil components and their application to animal production. 


\section{Samenvatting}

Het is bekend dat lage, subtherapeutische doseringen aan antibiotica in het voer de groeiprestaties van landbouwhuisdieren kunnen verbeteren. Echter, door toenemende bezorgdheid over de antibioticaresistentie van bacteriën, wordt er gezocht naar alternatieven voor deze antibiotica.

In dit proefschrift is nagegaan in hoeverre essentiële oliën gebruikt kunnen worden als mogelijke vervanger van antibiotica. Een essentiële olie is een mengsel van geurige en vluchtige stoffen uit aromatische planten. Momenteel zijn er al commerciële mengsels van essentiële oliën als veevoederadditief op de markt met als doel de groei en de gezondheid van de dieren te verbeteren. Deze preparaten zouden onder praktijk omstandigheden de vertering van het voedsel verbeteren, de voeropname stimuleren en als gevolg daarvan de groei verhogen. Echter, het effect van essentiële oliën op de prestaties van dieren is nog niet onderzocht onder gecontroleerde proefomstandigheden.

Het doel van dit onderzoek was om de rol van essentiële oliën als mogelijk alternatief voor antibiotica te toetsen bij pluimvee. Vrouwelijke slachtkuikens werden als diermodel gebruikt om het effect van essentiële oliën op de groeiprestatie, de activiteit van verteringsenzymen, de vertering van macronutriënten en het vetmetabolisme te bestuderen. Verder werd onderzocht of bestanddelen van essentiële oliën in het voer de anti-nutritionele effecten van carboxymethyl-cellulose (CMC) of rogge teniet konden doen. In een laatste proef werd het mogelijke synergistisch effect van verschillende bestanddelen van essentiële oliën op de groeiprestatie onderzocht bij slachtkuikens die gevoerd werden met een rantsoen met CMC.

Het literatuuroverzicht beschrijft de algemene biologische activiteit van essentiële oliën. Het toevoegen van essentiële oliën aan het voedsel kan meerdere bruikbare, biologische eigenschappen hebben. Hierbij kan gedacht worden aan antimicrobiële activiteit, antioxidantwerking, verlaging van de cholesterolspiegel, verbeteren van de smaak en het stimuleren van het verteringsproces. Omdat de metabole paden van essentiële oliën goed bekend zijn, is het onwaarschijnlijk dat er bij het gebruik van deze stoffen bijwerkingen zullen zijn. Omdat er nauwelijks gecontroleerde studies zijn over het effect van bestanddelen van essentiële oliën op de groei van slachtkuikens, werd in een proef het effect van thymol, cinnamaldehyde 
en een commercieel verkrijgbaar preparaat met bestanddelen van essentiële oliën (CRINA ${ }^{\circledR}$ Poultry) op groei, verteringsenzymactiviteiten en de verteerbaarheid van een aantal macronutriënten onderzocht. Het basisrantsoen bestond hoofdzakelijk uit maïs en sojaschroot en de kuikens waren gehuisvest in kooien met een gaasbodem. De uitkomst van deze proef met vrouwelijke vleeskuikens liet geen effect van de bestanddelen van de essentiële oliën op de onderzochte kenmerken zien. Het kan niet worden uitgesloten dat er misschien wel positieve effecten waargenomen zouden zijn, wanneer de kuikens waren bloot gesteld aan minder hygiënische omstandigheden of wanneer er een minder goed verteerbaar voer was gebruikt. Wel bleek in deze proef dat cinnamaldehyde de wateropname van de kuikens wezenlijk verlaagde zonder de groeiprestaties te beïnvloeden. Als gevolg hiervan was het droge-stofgehalte van de uitwerpselen hoger bij de kuikens die cinnamaldehyde via het voer kregen. Deze waarneming kan van belang zijn voor de praktische pluimveehouderij.

In vervolgonderzoek werden het gebruik van carvacrol en $\beta$-ionone in het voer als potentieel veevoederadditief onderzocht bij vrouwelijke vleeskuikens. Bovendien hebben we het vermeende cholesterol-verlagende effect van de bestanddelen van essentiële oliën getoetst bij kuikens die gevoerd werden met een cholesterol vrij of rijk voer. Carvacrol verlaagde de voeropname en de groei van de kuikens, maar verlaagde ook de voederconversie. Dit laatste zou kunnen wijzen op een verbeterde benutting van het voer of een verandering in de groeisamenstelling. Helaas is de samenstelling van de groei in deze proef niet bepaald. Carvacrol verlaagde het gehalte aan triglyceriden in het plasma, maar had geen effect op de plasma cholesterolspiegels. Het toevoegen van $\beta$-ionone aan het voer had geen effect op de groeiprestaties. Ook de parameters van de vetstofwisseling in het plasma lieten geen behandelingseffecten zien ongeacht het cholesterolniveau van het voer.

Hierna werd de vraag onderzocht of essentiële oliën (thymol, cinnamaldehyde, CRINA ${ }^{\circledR}$ Poultry) in staat waren de negatieve effecten van CMC op de groei van kuikens op te heffen. Het opnemen van $C M C$ in voer zorgde voor een verhoging van de viscositeit van de dunne darminhoud. De onderzochte essentiële oliën waren niet in staat om deze verhoging van viscositeit te verlagen. Echter, cinnamaldehyde en CRINA ${ }^{\circledR}$ Poultry leken in staat om de verminderde groei ten gevolge van het toevoegen van $\mathrm{CMC}$ aan de voeders grotendeels teniet te doen. Ook de vetvertering verminderde door het gebruik van CMC. Cinnamaldehyde en CRINA $^{\circledR}$ Poultry bleken in staat om een groot deel van dit negatieve effect van CMC op de vetvertering te compenseren. Dit onderzoek wijst er op dat zowel 
cinnamaldehyde als CRINA ${ }^{\circledR}$ Poultry het negatieve effect van CMC op de groeiprestatie kunnen tegen gaan. Dit effect zal waarschijnlijk verband houden met de verbeterde vetvertering ten gevolge van het gebruik van cinnamaldehyde en CRINA ${ }^{\circledR}$ Poultry. Thymol liet geen positieve effecten.

Het onderzoek werd voortgezet met het bestuderen van het effect van thymol, cinnamaldehyde en CRINA ${ }^{\circledR}$ Poultry op groei, vetvertering en viscositeit van de dunne darminhoud bij vrouwelijke vleeskuikens die gevoerd werden met rogge. Het voeren van rogge verlaagde de groei van kuikens, verhoogde de viscositeit van de dunne darminhoud en verlaagde de vetverteerbaarheid. Door het gebruik van cinnamaldehyde werd wel het negatieve effect van rogge op de groei deels opgeheven, maar werd er geen effect op de viscositeit van de dunne darminhoud en op de vetvertering waargenomen. Het positieve effect van cinnamaldehyde op de groei in deze proefopzet kan deels verklaard worden door de waargenomen hogere voeropname, maar het onderliggende mechanisme blijt onopgehelderd.

Het is te verwachten dat het gebruik van een mengsel van verschillende bestanddelen van essentiële oliën kan leiden tot een synergistisch effect op de groeiprestatie. Op basis van eerdere studies werd er gekozen voor carvacrol en cinnamaldehyde. Om de contrasten te vergroten werd er CMC aan de voeders toegevoegd. Het gebruik van de afzonderlijke bestanddelen had geen effect op de groei, maar het mengsel van carvacrol en cinnemaldehyde had een statistisch significant negatief effect op de groei van de kuikens. Deze proef liet zien dat bepaalde combinaties van twee of meer bestanddelen van essentiële oliën de groei van kuikens sterk kon verminderen wanneer de kuikens gevoerd werden met een rantsoen met oplosbare vezels zoals CMC.

De conclusie van al deze onderzoekingen is dat bestanddelen van essentiële oliën in het voer de prestaties van vleeskuikens mogelijk kunnen verbeteren. Echter, de vermeende cholesterolverlagende effecten van de bestanddelen van essentiële oliën konden niet worden aangetoond. Op basis van het nu gepresenteerde onderzoek, zouden toekomstige onderzoeken met bestanddelen van essentiële oliën zich moeten richten op het vinden van synergistisch effecten van verschillende bestanddelen van de essentiële oliën en op de toepassing ervan in de dierlijke productie. 


\section{Acknowledgements}

I would like to express profound gratitude to my supervisor, Prof. Dr. Ir. Anton Beynen, for his invaluable support, encouragement, supervision and useful suggestions throughout this research work. His continuous guidance enabled me to complete my work successfully.

I am also highly thankful to Dr. Henk Everts and Dr. Thomas Schonewille for their readiness to read this text and supervision of data analysis. Many thanks should be given to Henk Kappert whose work and ideas were useful to this thesis. I would like to thank Hugo Wouterse, Jan Van der Kuilen, Inez Lemmens, Giet Lankhorst, Xandra Fielmich, and Robert Hovenier for their technical assistance. I thank Dr. Marco Frehner and Jelle de Haas for reading manuscripts and for helping to measure viscosity. I also thank my colleagues Nguyen Quang Linh, Surasak Jittakhot, Chalermpon Yuangklang, Marjan Javadi, David van Doorn and Anneke Schellingerhout for their warmth and kindness.

I acknowledge the financial support from CRINA S. A., Akzo Nobel, Switzerland and the National Institute for International Education Development, Ministry of Education, South Korea which made my work and thesis possible.

I would like to thank Prof. Dr. Bong-Duk Lee who introduced me to Animal Nutrition and who has strengthened this thesis by his advice. I also want to thank Prof. Dr. Chang-Keun Sung for his encouragement and advice. Many thanks to Prof. Dr. Seung-Wook Han, Prof, Dr. Kyu-Seung Lee, Prof, Dr. Chang-Sik Park, Prof. Dr. Hong-Rock, Oh, and Prof. Dr. Soo-Kee Lee of Chungnam National University for taking care of me.

I am very indebted to my parents for their love throughout my life. I also wish to thank my brothers, Chan-Woo Lee and Hyun-Woo Lee for their support and understanding during my study. Finally, I would like to thank my wife Keum-Hee Yeom whose love and confidence completed this thesis. 


\section{Curriculum vitae}

Kyung-Woo Lee is born on September 251970 in Dangjin, Chungnam, South Korea. He had his B.Sc. at Department of Animal Science, Chungnam National University, Korea in 1997. He continued his study in the field of poultry nutrition and obtained his M.Sc. in 1999. After the competitive selection examination in the field of Animal Science, the National Institute for International Education Development (Ministry of Education) awarded him a scholarship. Since 1999, he started his Ph.D. program under the guidance of Prof. Dr. Ir. Anton C. Beynen at Department of Nutrition, Faculty of Veterinary Medicine, Utrecht University, The Netherlands. 